\author{
UNIVERSIDADE DE SÃO PAULO \\ FACULDADE DE ECONOMIA, ADMINISTRAÇÃO E CONTABILIDADE \\ DEPARTAMENTO DE ECONOMIA \\ PROGRAMA DE PÓS-GRADUAÇÃO EM ECONOMIA
}

\title{
Long-Term Effects of Conditional Cash \\ Transfers on Children: The Brazilian Case
}

Efeitos de Longo Prazo de Programas de Transferência Condicionada de Renda sobre as Crianças: O Caso Brasileiro

Gabriel Lyrio de Oliveira

Orientador: Prof. Dr. André Luis Squarize Chagas

São Paulo - Brasil

2020 
Prof. Dr. Vahan Agopyan

Reitor da Universidade de São Paulo

Prof. Dr. Fabio Frezatti

Diretor da Faculdade de Economia, Administração e Contabilidade

Prof. Dr. José Carlos de Souza Santos

Chefe do Departamento de Economia

Prof. Dr. Ariaster Baumgratz Chimeli

Coordenador do Programa de Pós-Graduação em Economia 


\section{GABRIEL LYRIO DE OLIVEIRA}

\section{Long-Term Effects of Conditional Cash}

\section{Transfers on Children: The Brazilian Case}

\section{Efeitos de Longo Prazo de Programas de Transferência Condicionada}

de Renda sobre as Crianças: O Caso Brasileiro

Tese apresentada ao Programa de PósGraduação em Economia do Departamento de Economia da Faculdade de Economia, Administração e Contabilidade da Universidade de São Paulo como requisito parcial para a obtenção do título de Doutor em Ciências.

Área de Concentração: Teoria Econômica Orientador: Prof. Dr. André Luis Squarize Chagas

Versão Corrigida

São Paulo - Brasil 2020 



\section{Catalogação na Publicação (CIP)}

Ficha Catalográfica com dados inseridos pelo autor

Oliveira, Gabriel Lyrio de.

Long-term Effects of Conditional Cash Transfers on Children: The Brazilian Case / Gabriel Lyrio de Oliveira. - São Paulo, 2020. $109 \mathrm{p}$.

Tese (Doutorado) - Universidade de São Paulo, 2020.

Orientador: Prof. Dr. André Luis Squarize Chagas

1. Conditional Cash Transfers. 2. Long-term Effects. 3. Human Capital. 4. Labor Market. 5. Bolsa Família. I. Universidade de São Paulo. Faculdade de Economia, Administração e Contabilidade. II. Título. 



\section{Agradecimentos}

Agradeço aos meus pais Paulino e Sheila, e irmãos, Lucas e Nathan, pela formação e apoio desde as primeiras lembranças que tenho. À minha esposa, Marcela, por mais de uma década de muita paciência e incentivo nos momentos mais difíceis. A todos os privilégios que tive na vida, sem os quais a conclusão desta etapa seria muito improvável.

Agradeço a todos os amigos e colegas que dividiram a caminhada, alguns desde a preparação para o exame Anpec, outros desde 2014, com início do Mestrado em Economia na Universidade de São Paulo. Em especial, Alexander Chow, Bruno Cordeiro, Bruno Palialol, Denise Li, Elias Cavalcante Filho e Gustavo Serra.

Ao Professor André Chagas, por inúmeras discussões, orientação e incentivo desde o meu mestrado. Aos membros do Núcleo de Economia Regional e Urbana (NEREUS-USP), em especial, aos Professores Carlos Azzoni e Eduardo Haddad. Também aos Professores Danilo Iggliori, Naercio Menezes Filho, e Paula Pereda, por aceitarem participar de avaliações preliminares. Ao Prof. Ariaster, pela disponibilidade em nos ouvir e ajudar sempre que foi necessário enquanto coordenador da Pós-Graduação em Economia.

Ao Pinho e à Leka, sempre disponíveis para resolver nossas questões burocráticas. À amiga Keyi Ussami, por realizar adaptações no fornecimento de dados fundamentais a esse trabalho. Ao amigo Rodrigo Beiro, da FIPE, pelo processo de extração de outros dados fundamentais. À todos os funcionários que mantém a estrutura física da Pós-Graduação da FEA-USP, imprescindíveis ao bom funcionamento acadêmico.

Aos Professores Sandy Dall'Erba e Geoffrey Hewings, por me receberem e contribuírem com meu desenvolvimento durante meu período no Regional Economics and Applications Laboratory da University of Illinois at Urbana-Champaign.

Por fim, agradeço à FIPE e à Capes pelo apoio financeiro. 



\section{Resumo}

Esta tese avalia efeitos de longo-prazo do maior programa de Transferência Condicionada de Renda, o Bolsa Família (PBF). A avaliação se concentra em efeitos sobre escolaridade, empregabilidade e salário dos indivíduos expostos a esse programa durante a infância e adolescência, e foi viabilizada através do cruzamento de dados identificados do Cadastro Único, da folha de pagamentos do PBF, e do mercado de trabalho formal.

A análise se concentra nos efeitos diferenciais entre os períodos de exposição ao PBF. Neste Experimento Natural, a estratégia de identificação principal se apoia em um rico conjunto de variáveis de controle, e no fato de a liberação do benefício ocorrer de forma automatizada e baseada em parâmetros de pobreza estimados para o município de cada família. Além de variáveis dos indivíduos, são consideradas características familiares referentes ao período de sua infância, como a escolaridade e os resultados de seus pais no mercado de trabalho. Em uma estratégia de identificação alternativa, considera-se uma variável instrumental que representa o esforço municipal em incluir famílias no Cadastro Único, condição necessária para receber o benefício. As estratégias reduzem o viés de seleção das famílias. Ainda assim, uma vez que o programa seleciona as famílias mais vulneráveis, eventuais ameaças a identificação sugerem que as estimativas podem ser limites inferiores dos efeitos do PBF. Os resultados revelam efeitos positivos do tempo de exposição ao PBF sobre o nível de escolaridade observado no início da vida adulta, e efeitos positivos sobre a probabilidade de participar do mercado de trabalho formal. Os efeitos para salários se mostram inconclusivos. Além disso, testes de heterogeneidade demonstram efeitos mais fortes para homens, para individuos de cidades menores, e para indivíduos cujos pais não tiveram empregos formais.

Palavras-chaves: Transferência Condicionada de Renda; Efeitos de Longo Prazo; Capital Humano; Mercado de Trabalho; Bolsa Família 



\section{Abstract}

In this dissertation, I present some long-term effects of the largest Conditional Cash Transfers program in the world, and one of the pioneers, the Bolsa Família Program (BFP). I focus on the effects on Schooling attained in early adulthood and Labor Market outcomes of individuals more or less exposed during their childhood. The estimates were enabled by linking identified data from Formal Labor Market, BFP Payment Records, and the Single Registry (SR).

I focus the analyses on the differential effects of different durations of exposure divided into levels. In this Natural Experiment, the main identification strategy relies on a rich set of control variables, and on the fact that the release of BFP resources for registered families is automatized and based on municipality poverty parameters estimated by the government. Beyond the individual's demographics, I consider observable family characteristics related to their childhood, like the schooling and labor market outcomes of their parents. In an alternative identification strategy, I consider an instrumental variable, the observed proxy for the municipality effort to register vulnerable families. These strategies help to solve the potential selection bias of families to the SR, and consequently to the treatment. Nonetheless, since the program selects the most vulnerable families, the threats to the identification suggest that the estimates are lower bounds.

The main results show positive long-term effects of the BFP exposure on Schooling, and on the Formal Labor Market participation, while mixed results are observed for Earnings. Heterogeneity tests suggest that the effects are stronger for boys, for smaller cities, and for families with never formally employed parents.

Key-words: Conditional Cash Transfers, Long-term effects; Human Capital; Labor Market; Bolsa Família 



\section{Contents}

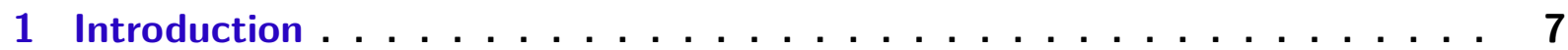

2 Background ...................... 15

2.1 CCT Programs . . . . . . . . . . . . . . . . . . . . . 15

2.1.1 Known Effects of the CCT Programs . . . . . . . . . . . . . 15

$2.1 .2 \quad$ BFP Design . . . . . . . . . . . . . . . . . . 24

2.2 Human Capital and Education in Brazil . . . . . . . . . . . . . . 30

3 Methodology ....................... 35

3.1 Schooling . . . . . . . . . . . . . . . . . . 36

3.2 Formal Labor Market Participation . . . . . . . . . . . . . . . . . . . 40

3.3 Earnings in the Formal Labor Market . . . . . . . . . . . . . . . . . . 42

3.4 Data . . . . . . . . . . . . . . . . . . . . . 45

4 Results . . . . . . . . . . . . . . . . . 51

4.1 Descriptive Statistics . . . . . . . . . . . . . . . . . 51

4.2 Results on early adults Schooling and Labor Outcomes . . . . . . . . . . 61

4.2 .1 Schooling . . . . . . . . . . . . . . . . . . . . . 61

4.2 .2 Formal Labor Market Participation . . . . . . . . . . . . . . 72

4.2 .3 Earnings in the Formal Labor Market . . . . . . . . . . . . . 80

5 Final Remarks . . . . . . . . . . . . . . . . . . . . . 87

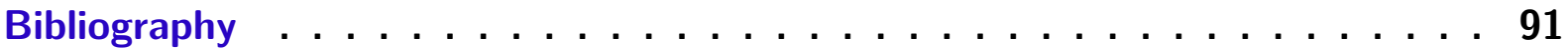

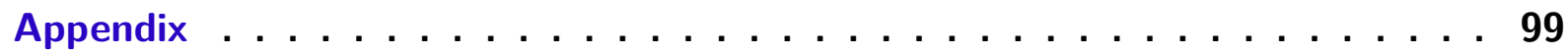





\section{Introduction}

Brazil is a developing country that still presents many social problems. The share of extreme poverty ${ }^{1}$ of $4.4 \%$ of the population (The World Bank), is relatively high, and the level of education relatively low, with only $51.3 \%$ of Brazilian adults between 25 and 64 years old attaining secondary education in 2017 (OECD). Although the scenario has been changing in the last decades, considering, for example, that the share of extreme poverty was $21.4 \%$ in 1981, and the literacy rate increased from $74.59 \%$ in 1980 to $93.08 \%$ in 2017, it is still far from observable indicators of the developed world. For instance, the average of extreme poverty rate for the countries of the G7, the group of the seven largest advanced economies, was $0.56 \%$ in 2013. Moreover, for this countries an average of $81.46 \%$ of the adults attained the secondary education ${ }^{2}$ in 2017.

About twenty years ago, some of the Latin American developing countries implemented important social policies that later were revealed to be very powerful tools in alleviating misery and poverty. They are named Conditional Cash Transfers Programs (CCTs). Each program usually has its own rules, but there are some common elements shared by most of them.

In general, to receive the benefit the family must meet some requirements on income, education, and health. The requirements for education and health have the aim of improving the future of these families through the Human Capital formation of their children. So far, the results on immediate poverty and inequality reduction are established consensus in the literature, but the second aim of these programs began to be studied recently. Since these programs are relatively new from a historical perspective, only now their long-term effects are getting attention from the literature, with many open questions to be addressed in the next years.

The success of the Latin American programs to reduce poverty, mainly Progresa (Mexican) and Bolsa Família (Brazilian), were determinant to the spread of the CCTs

1 The World Bank definition for extreme poverty is given by the income limit of USD 1.90 per day per capita, considering the 2011 Purchase Power Parity rate.

2 This indicator was not available for Japan. 
around the world. Currently, many other countries in different continents like Africa and Asia developed their versions of CCTs.

The Bolsa Família Program (BFP) is the largest CCT in the world. Currently, it covers about one-quarter of the Brazilian population ${ }^{3}$. The program began to operate in 2001 with the name Bolsa Escola. A few years later it was unified with other smaller programs and strongly expanded from 2004 to 2006, with its new name, Bolsa Família Program (BFP). Since its beginning, the program focuses on the poor and extremely poor people, and demands from the benefited families to present a minimum school attendance of their schooling-age children and health monitoring of the children and pregnant women.

Among the well-known effects of the BFP I mention, not exhaustively: the poverty and inequality reduction found by Soares et al. (2010), and Soares et al. (2009); shortterm regional inequality reduction (Azzoni et al., 2009); the short-term increase of school attendance (Silveira-Neto and Duarte, 2010); and retention of migrants on their home municipality (De Oliveira and Chagas, 2020). Nonetheless, there is a complete lack of evidence about the long-term effects of this program.

The BFP will complete 20 years of existence in 2021, and the children of some cohorts of the beginning of the program are not in schooling age anymore. Moreover, they are now in the initial years of their working age, which provides a good opportunity to explore the long-term impacts of the program. The school attendance and health monitoring conditionalities of the program constitute a way to improve the human capital formation of the next generation individuals of the currently poor families. Therefore, this research provides a new contribution to the literature, exploring the long-term effects of the BFP conditionalities and financial resources on education and labor market outcomes of these children.

In this work, I focus on three outcomes: the Schooling attained by individuals in their early adulthood; their Formal Labor Market (FLM) Participation; and the Earnings (nominal wages) they get in those employments. The relevance of schooling for economic

3 Approximately 50 million people of the 210 million country residents are currently benefited by the program. 
development is supported by Human Capital theory, dating back at least to Schultz (1961) and Becker (1962). Moreover, although early childhood investments in human capital have been shown as relatively more important to individual development (Cunha and Heckman, 2007), in the data, I only observe the program exposure from later stages of childhood onward, and investments in these other stages are still relevant ${ }^{4}$.

To make the work possible, I linked three different identified datasets: the Single Registry for Social Programs (SR); the BFP Payment Records; and the Formal Labor Market administrative data (RAIS-MTE). The resulting merged data enables future research concerning the poor families of the country.

The SR was implemented in 2001 to get a better knowledge of the vulnerable families of the country and to be used by all federal social programs ${ }^{5}$. Since the beginning of the BFP, a necessary condition for the family to get the benefit was to be registered in the SR. The SR collects information like age, gender, schooling, and income of all the family members.

The definition of a vulnerable family (target of the SR) is given by that with a per capita income of less than half of the minimum wage (BRL 522.50) ${ }^{6}$. This limit was always higher than the income criteria ${ }^{7}$ to get the BFP benefit (BRL 178.00). This enabled us to observe families in the SR that, at least at some point in time from 2001 to 2017, were vulnerable but not necessarily eligible to the BFP.

In the initial years, the SR went through a strong expansion all over the country. The cumbersome task of registering millions of vulnerable families in a narrow time window, certainly responds for an important random part of the observed variation in the timing that each family is incorporated on the records, and then potentially start receiving the BFP benefits. The SR registration process can happen in two ways. Either the social

4 In the coming years, it will be possible to focus on the younger cohorts of the BFP in the Labor Market and explore the effects of exposure during early childhood. Currently, the younger adults observed in the data were 6 years old at the beginning of the BFP Payment Records (2004).

5 At that time, each federal social program had its system and data management, which resulted in many inefficiencies.

6 The national minimum wage was set in BRL 1,045.00 on January 30, 2020. Considering the OECD estimates for the Purchase Power Parity rate for 2018 (2.03), this amount corresponds to USD 515.

7 Currently, families with per capita income lower than BRL 178.00. 
assistance team visits the potentially-vulnerable family and collects its information, or the family presents itself in the social assistance office and requires its registration.

SR data are annually based and cover the period from 2012 to 2017. An important remark is that, although the first year observed is 2012, the data contain a variable that indicates the year that the family was registered. This enabled us to restrict the sample to families registered in the stronger SR expansion period.

The BFP Payment Records cover the lack of information for the years before 2012, absent in the SR. In this data, I observe the head of each family, usually the mother, name and identification document ${ }^{8}$, and the amount of BFP benefits transferred for the family each year from 2004 to 2017. This data was fundamental to this research since it enabled us to build the interest variable, i.e., the individuals' exposure to the program during their childhood.

The Formal Labor Market identified data comes from the administrative records of the Ministry of Labor ${ }^{9}$, the Relatório Anual de Informações Sociais (RAIS). It contains compatible information of all firms and formal employees from 2002 to 2017. The most important variables for this work are the individual's document number, which I use to generate a yearly indicator variable of participation in the formal labor market, and the respective year-average of the nominal earnings. With a long period observed, I was able to incorporate in the analysis the labor outcomes of individuals' parents, restricted to the time of their childhood.

I consider in the sample only the cohorts of individuals that were born between 1996 and 1998. These individuals are old enough to have been beneficiaries of the BFP during their childhood in 2004, the first year of BFP Payment Records. They are also teenagers in the first year of SR data (2012), which makes it possible to collect their family information before they eventually build their own family. Moreover, these individuals are old enough to have finished high school and participate in the FLM in the most recent

\footnotetext{
8 Número de Identificação Social (NIS) is the common identification document that is observed in the three identified databases.

9 In 2019 the Ministry of Labor was reformulated and renamed to Secretary of Employment. Currently, it is under the Ministry of the Economy.
} 
year of the data, i.e., more than 18 years old in 2017.

My methodology relies on traditional impact evaluation techniques. It took into account the continuous or discrete nature of each outcome variable I am interested in. This led me to a probabilistic approach for the Schooling level and FLM participation. I applied an ordered outcome model for the former and a binary outcome model for the latter. On the other hand, for the Earnings outcome, I followed the huge literature on empirical earnings regressions and applied the traditional log-linear model.

I rely on two alternative identification strategies. The first one takes advantage of the rich identified data I built. The final database comprises individual socio-demographic characteristics, some family background variables including the schooling and labor market outcomes of the parents during individuals' childhood, and municipality socioeconomic indicators, also related to the individual's childhood period.

Even if I could accurately observe the BFP eligibility criteria and incorporate it in the analysis, I would still observe a variation in the individuals' exposure to the program. The variation not related to the family eligibility rules emerges from three different sources.

The first source of variation can be seen as a measurement error. It comes from the difference between the average real income of the family during the individuals' childhood, and the income that the family declares ${ }^{10}$ to the social assistant at the moment of SR registration, or the moment of information update ${ }^{11}$. Beyond being a reasonable argument, it is supported by the evidence from the data. I observe individuals from families with the same parents' average formal income, but different BFP Exposure levels. Moreover, once the family turns its status to BFP beneficiary, the condition to cancel or suspend the benefit is the existence of strong evidence pointing to the family income being above the eligibility. However, it seems unreasonable to expect that small income differences would be easily identified by the local BFP managers.

The second source of variability is also related to the family. It is related to the

10 I do not observe the family declared income in the SR previous to 2012.

11 It is expected that the program local manager keeps the vulnerable families' information always updated in less than two years. 
timing that the family gets registered in the SR. To put it simply, eligible families that are reached by the SR earlier tend to become beneficiaries of the BFP before the families reached later.

Finally, the government centralized procedure of release of BFP benefits tries to balance the estimated coverage of the program between municipalities. The program coverage is computed by the current benefited families divided by the estimated number of poor families. Then, the third source of variation occurs between municipalities. For instance, families from municipalities that included many people in the registry and currently have higher BFP coverage could be assigned to a waiting list. This would occur if the annual budget of the Federal Government destined to the BFP was not enough to release the benefit for all eligible families at that moment.

The alternative identification strategy considers the same control variables, but I introduce an instrumental variable approach ${ }^{12}$. I consider this strategy as a robustness check to the main results. I assume exogeneity, from the family perspective, of the municipality effort to include vulnerable families in the program registry. Once being registered is a condition to be benefited, this effort is strongly related to the children's exposure to the BFP. The major drawback of this approach is that I throw away the first two sources of variation in the individuals' $\mathrm{BFP}$ exposure not related to the program eligibility criteria. In other words, I keep only the exogenous variation that occurs between municipalities.

The long-term effects of CCTs are summarized in Millán et al. (2019). Results on Schooling are mostly positive, whereas results for Labor Market Participation and Earnings are uncertain. In the present research, I also find positive results for Schooling Level attainment and Labor Market participation. These effects are stronger boys, for smaller cities, and for individuals whose parents were never formally employed. On the other hand, the effects on Earnings are uncertain.

I have some reasons to believe that the estimated effects in this work are lower

\footnotetext{
12 I applied this approach only for FLM Participation and Earnings outcomes. The Schooling outcome is analyzed through an ordered probability model, the Ordered Logit, in which the instrumental variable estimator faced convergence problems.
} 
bounds. There is a potential negative relation between family exposure time and improvement in economic conditions. Once the family improved economically, it can voluntarily advise the municipality manager or can be caught by it, and have the benefit suspended. Moreover, the families with zero exposure are also expected to have had better economic conditions during the childhood period of their children, and maybe, it is not completely controlled by the observable covariates. For instance, I do not observe the informal income of the family.

Although probably small, a remaining endogeneity can not be completely discarded. Selection bias from families' unobservable-characteristics is possible if, for instance, the well-informed families get registered first, or tend to differently under-report their income in order to become a beneficiary of the program. Unfortunately, there was not much that could be done with respect to this source of bias, beyond including the covariates related to the socio-economic background of the families.

In what follows, I present the literature review on the known effects of CCTs, the BFP design and evolution, the Human Capital literature and current education scenario in Brazil, the data and empirical methodology for each outcome of interest, and finally my results. In the last section, I summarize the dissertation and point to valuable future research questions related to this topic. 



\section{Background}

\subsection{CCT Programs}

Conditional Cash Transfers programs are important tools available to governments to reduce poverty and inequality. They are applied in Latin America for two decades and are currently spread to other countries around the world.

Considering the Brazilian program, the size and relevance of BFP are expressive to the country's social policy. In 2019, the social assistance spent BRL 92.85 billion, of which BRL 33 billion were destined to the BFP (Transparência, 2020). In September of that year, the program attended approximately 13.5 million families, which is equivalent to about one-quarter of the 210 million residents of the country (IBGE, 2020).

With the high importance of these programs, many of them were the focus of economic research. In the next subsection, I make a non-exhaustive review of the studies about the effects of the CCTs and, especially, the BFP. Some of their findings, like shortterm poverty reduction and increase school attendance, are strongly related to the potential long-term effects on the second generation. Other findings may have, at a first glance, unclear connections, like the program's spatial effects.

After the literature review, in section 2.1.2 I present the BFP characteristics concerning the period of the program implementation, and the evolution of the program design over the years, which comprise important elements that support my identification strategy.

\subsubsection{Known Effects of the CCT Programs}

This literature review is divided by themes. For each of them, I present the studies and results for other programs in the world, followed by the BFP. I begin with povertyrelated effects on the adults, like poverty alleviation, employment, and consumption, followed by the effects more related to the children, like health, nutrition, and education. Then, I cover some macroeconomic effects, like inequality and aggregate economic activity. 
After that, I review some of the spatial effects, like regional inequality and migration changes influenced by the CCTs. Finally, I introduce the known long-term effects of these programs, which are strongly related to their goal of breaking the intergenerational poverty cycle.

The literature review provided by Bastagli et al. (2016) covers many studies that approached the relation of cash transfer programs with employment, investment, savings, production, and consumption. Among them, only eight approached Latin America, but none considered Brazil. From the studies considered by the authors, some aimed the effects on labor market participation, of which less than half found that the programs increased it among the active age adults.

In general, the same is true for the studies that cover the Brazilian case, i.e., effects on employment range from zero to positive. Baird et al. (2018) review the mechanisms that could explain effects different than reductions in the labor market participation when individuals receive cash transfers, which should be expected if one considers the simple economic models for labor supply and leisure.

Beyond employment, an important result of the CCTs related to the mechanisms reviewed by Baird et al. (2018), is that the credit constraints of the poor population seem to be relieved directly by the cash transfers and indirectly through informal credit arrangements. This can be a mechanism to enable increases in food consumption, entrepreneurship, or even to finance subsistence costs while the individual is searching for a job.

Considering one of the pioneers of CCTs, Parker and Skoufias (2000) and Skoufias and Di Maro (2006) found no effects on the labor market participation for the beneficiary adults of the Mexican program, Progresa. Covarrubias et al. (2012) approached the program of Malawi and evaluated the productive impacts with experimental data. They found that the program induced agricultural assets investments, reduction of the share of lowskill employments, and reduction of child-labor outside the household. Moreover, they argued that the reduction in the involvement in casual jobs can represent a departure from exploratory subsistence activities. Also in Africa, Daidone et al. (2015) applied 
experimental data from Lesotho's program and found no effects on the labor market participation. Besides, they found a strengthening of risk-sharing arrangements.

Concerning the Brazilian case, Oliveira (2009) applied data of a special survey of BFP for 2005, the Impact Evaluation of Bolsa Família $\left(\mathrm{AIBF}^{13}\right)$, but not many significant results were found for the formalization of employment, participation in the labor market, worked hours, and labor supply. Foguel and Barros (2010) and De Brauw et al. (2015a) also found no influences of the program on participation in the labor market. Moreover, in Barbosa and Corseuil (2014) no effects on formal-informal employment composition were found when applying a fuzzy Regression Discontinuity Design method to the National Household Sample Survey $\left(\mathrm{PNAD}^{14}\right)$ data.

On the other hand, Chitolina et al. (2016) applied a differences-in-differences approach to PNAD data and found positive effects on the choice of the youths to study and work at the same time, while their parents' labor supply decisions were not affected. Assessing the employment duration, Santos et al. (2017) applied a Cox-proportional hazard model to microdata and found that the beneficiaries have a smaller chance of leaving their formal employments.

Ribas (2019) applied PNAD panel data and estimated a municipality fixed-effects model. The author found that the number of less-educated men entrepreneurs increased by $10 \%$ with the BFP, as a result of indirect effects. It constitutes evidence in favor of credit mechanisms, as the author also found an increase in private transfers between households. In contrast with the last studies presented, the author estimates show a decrease of the informal sector's share followed by an increase in entrepreneurship, which are explained as a result of financial opportunities given by the BFP. The positive effects on entrepreneurship occurred only in small towns.

Another important aspect of the behavior of the beneficiary adults that could affect the children's development is the consumption level and composition. The cash transfers

\footnotetext{
13 Avaliação de Impacto do Programa Bolsa Família was a survey with vulnerable families, beneficiaries and non-beneficiaries, in 2005. It had a second round in 2009 with $74 \%$ of the same families.

14 Pesquisa Nacional por Amostra de Domicílios.
} 
can enable the consumption of more and better food, which can be related to healthier growing stages of the children.

Angelucci and De Giorgi (2009) applied experimental data and found an increase in food consumption and a reduction on precaution saving of non-beneficiaries of Mexican program Progresa in the rural areas. They concluded that the indirect effects are relevant, and if neglected, considerably underestimate the local treatment effect.

Angelucci et al. (2012) also found an increase of beneficiary families' consumption and changes in its composition in the urban areas, which were include included in the program after the rural villages. They found an increase in food consumption, durable and non-durable goods, and a difference in the destination of the transfers, while in the rural areas they are used in the agriculture production, in the urban areas they are more destined to pay-off debts.

Considering the Brazilian program, Oliveira (2009) applied a Propensity Score Matching to data of the AIBF of 2005 but did not find significant results for consumption. On the other hand, Costa et al. (2017) applied the Consumer Expenditure Survey from IBGE and found evidence of an increase in the beneficiary family's consumption of calories and nutrients related to individual health.

Attanasio and Mesnard (2006) evaluated the Colombian program. Like the previous two studies for the Mexican program, they also found an increase in children's consumption, mainly in food, education, and clothing expenses, while no significant result was found for adults. This last study brings an interesting insight, suggesting that the adults gave priority to their children's consumption and education. These specific results may constitute another mechanism of action of the BFP program on the Human Capital formation, and thereafter on the labor market returns of these children.

There is an important debate considering the effects of the conditionalities of a cash transfer program. Banerjee et al. (2011) mention two studies that do not find conditionalities effects. They argue that the reason behind it could be that the parents need the resources, and it is enough to send the children to school. In the same direction, 
Barrera-Osorio et al. (2019) pose some doubts about its functionality when comparing three different program designs.

On the other hand, in the review of Bastagli et al. (2016), the collected evidence shows that 6 of 8 studies that compare CCT with Unconditional Cash Transfers (UCT), point to the former having a stronger effect than the latter. In the Brazilian case, the conditionalities and the enforcement, as shown by Brollo et al. (2020), had an important role. Furthermore, the authors found that the enforcement of school attendance rules through penalties had effects not only in the school attendance of the student of the punished family, but on its classmates as well.

An effect that seems to be consensus in the cash transfers literature is the schooling attendance increase, whether through conditionalities or not. Some examples of this effect are presented bellow. Although the effects of the BFP on school attendance were already studied, as far as I am concerned, no study estimates the long-term schooling level of the grown children of the BFP. Beyond the scope of the present work, a necessary step to the Human Capital and cash transfer discussion is to add evidence to the scarce literature about the learning responses to these programs (Bardasi and Garcia, 2014; Bastagli et al., 2016), because the quality of the education available for the poor children may be considerably lower.

De Brauw et al. (2015b) investigated the effects of BFP on schooling, with sample survey data and the Propensity Score Matching method. They argued that the weak results may hide heterogeneous effects. Nonetheless, they found that the BFP induced an increase in school attendance of girls, but had no effect on boys. This last finding contrasts with other studies' results, and with the present work, which shows stronger effects for the males. Without gender differentiation, positive effects on school enrolment were also found in Chitolina et al. (2016). However, the effects seem to be absent in urban areas.

A related topic probably affected by the increase of school attendance and enrollment is the quality of the schools and public expenditure on education. Camargo and Pazello (2014) focused on school quality after the entry of BFP beneficiaries. They evaluated 
the effect of an increase in the share of beneficiaries on the average performance of the schools in the National Exam (Prova Brasil) of 2009. Their results showed that there was a decrease in drop out rates, while no significant effects were found for proficiency exam approvals.

Also focusing on education spillovers, Menezes-Filho et al. (2014) investigated if the entry of many beneficiaries on public schools increased the supply of private ones. Applying a municipality panel data to a fixed effect model they concluded that it happened. They also found that the distribution of students' skills in public schools was widened with the BFP expansion.

A theoretical approach considering the children's schooling decision was presented by Del Rey and Estevan (2013). The authors constructed a theoretical two-period model that predicts that under sufficiently accurate targeting, the CCT is more successful in enhancing the efficiency of the household decisions related to children's education than the Unconditional Cash Transfer. In contrast, improving the quality of education has unclear effects on the household decision concerning its children's schooling.

Estevan (2013) presented a theoretical structure in which introducing a CCT program can change the preference of the households, and through political economy mechanisms increases the public education expenditures per student. The model brings an interesting prediction, in which increasing enrollment through school attendance conditionality can also lead to improvements in the quality of public education. However, currently, there is a need for empirical research on the relation of the CCTs and school quality with the programs' long-term effects.

The aggregate effects of the CCTs can be relevant depending on the poverty and development level of the local economy. Although they affect both, the exposed and nonexposed individuals, it is important to present them to contextualize the local economic changes in which the children grew up.

Soares et al. (2009) results for CCTs' effects on inequality point to a participation of $21 \%$ of the fall observed in Gini Index in Mexico and Brazil, and $15 \%$ in Chile, while 
the CCTs' share on the income responded for less than $1 \%$ in each of the three countries.

Considering aggregate economic activity, Daidone et al. (2015) showed that the Lesotho program contributed to an increase in the household's production and harvests, with each monetary unit transferred generating 2.23 in the local economy. They also estimated that in the case of land and capital restrictions, when discounting the price pressures the real multiplier would be around 1.36 .

Aggregate effects of the Brazilian program were approached by Neri et al. (2013), which estimated in 1.78 the BFP multiplier on the GDP. Considering a lower level of aggregation, Denes et al. (2016) applied Brazilian municipality panel data and found a multiplier of 4 for the BFP transfers on the municipalities' GDP, although heterogeneously distributed between economic sectors.

Beyond aggregate effects, the BFP induced some changes in spatial patterns in the country. Historically, the Brazilian internal migration tended to be from the poorest regions, typically Northeast, to the richest, typically the Southeast. Even though the BFP is not a spatially oriented program, the initial distribution of poverty had a spatial concentration in the program resources distribution. In other words, the regions with higher share of poverty naturally had a higher proportion of BFP beneficiaries among its population.

The previous logic led to changes in regional inequality and internal migration in Brazil. The short-term regional inequality was shown to be decreased by the program (Silveira Neto and Azzoni, 2011), and intended migrations seem to be discouraged toward municipalities where the differential of BFP coverage is negative (De Oliveira and Chagas, 2020). Considering that migration could balance wage differentials, the medium and long term effects of these changes are still open questions in the literature.

As some of the pioneer CCT programs are 15 to 20 years old, I turn to the hot spot in the cash transfers literature, its long-term effects. I make a brief review of some of the studies that approach this theme based on the literature presented in Millán et al. (2019). In general, effects on schooling are mostly positive, while impacts on employment of the 
young adults are mixed, depending on the length of time observed after the individuals became adults. These mixed results for labor market may be expected if it is considered that individuals may be postponing their entrance in the labor market to study more. Therefore, effects on participation and earnings may appear only some years later.

Behrman et al. (2011) applied experimental and non-experimental data of the Mexican program, Progresa. The results suggest a long-term increase in the schooling attainment of the young aged 15 to 21 years. Considering work, they found a movement from agricultural to non-agricultural employment, and a reduction of labor supply of the younger youth, which they explain by the individuals postponing their entry in the labor force. For the older youth, they found an increase in the specific group of older girls.

Considering the program of Nicaragua, Barham et al. (2013) showed that the boys exposed to the program while still in their mothers' uterus presented better cognitive outcomes 10 years later than those exposed at the age of 2 or more. However, no anthropometric differences were found.

For the same program, Barham et al. (2017) evaluated the effects for boys aged 9 to 12 years at the beginning of the program. The authors found that the short-term gain of schooling attainment was sustained after the end of the program. Moreover, scores in math and language tests also presented one-quarter of deviation gains for the treated young men.

Barham et al. (2018) focused on the long-term effects on the girls of the Nicaraguan CCT. Although they did not find effects for schooling attainment or learning, they found that the early exposed girls had a higher chance of being economically active, with a higher income than those exposed three years later. Besides, the authors approached important outcomes of the reproductive health of these individuals. The early treated girls started sexual activity later than the girls treated later, resulting in lower fertility rates as well.

Barrera-Osorio et al. (2019) approached a Colombian experiment, where the random assignment cash transfers had three different program designs. They found that forcing the families to save induced tertiary education attainment. Encouraging the tertiary education 
enrollment had similar results, although in this case, the enrollment tended to be in low-quality colleges.

Parker and Vogl (2018) considered the Mexican program and exploited the variation of the municipal level rollout combined with cohort variation to estimate the individuals' intensity of exposure. The authors' estimates show improvements in the educational attainment for both sexes and in geographic mobility. The labor market participation and earnings are also higher, but more pronounced among women.

Millán et al. (2020) take advantage of municipality level coverage of Honduras' CCT program, PRAF-II ${ }^{15}$, combined with individual characteristics to assess the long-term effects of exposure. They found that 13 years later, the grade attained was higher for the more exposed individuals. Considering labor outcomes, the authors relied on municipality level survey data and estimated that more exposed women presented lower earnings and labor market participation, while no results were found for men.

In contrast with these last two studies, in the present work, I do not need to estimate the exposure of the families and children to the CCT. Thanks to administrative data of the Single Registry, the BFP Payment Records, and administrative data of the Formal Labor Market, I observe each individuals' exposure and formal labor market outcomes.

Most of these mentioned studies take advantage of the random assignment of each program, either at the individual (Barrera-Osorio et al., 2019) or at a more aggregate level (Parker and Vogl, 2018). For the BFP, no random assignment was implemented, so that I had to build my Natural Experiment with a careful econometric identification strategy. Maybe, this explains why, to the best of my knowledge, there is no evidence for the long-term effects of the largest CCT in the world. The present research intends to fill this vacuum, and will hopefully be followed by others.

15 Programa de Asignación Familiar 


\subsubsection{BFP Design}

The Bolsa Família Program is a conditional cash transfer (CCT) that targets poor families with per capita income ${ }^{16}$ currently bellow BRL 178,00, and extremely poor families, with income bellow BRL 89,00 (MC). The BFP emerged as a unification of four previous programs (Bolsa Escola, Cartão Alimenteção, Bolsa Alimentação, and Auxílio Gás) and went through a strong expansion since its creation in October 2003.

The selection process is implemented through the Single Registry (SR), a unified registry for federal social programs. For the family be listed in the SR, preferably the municipality social assistance team must visit it. Another way is the head of the family to go to the social assistance office and require registration. Then, after having the information collected, the family can be classified as eligible to the BFP or not.

To be benefited by the program the poor families must have a child, a teenager, or a pregnant woman on its composition, while for the extremely poor families only the income criteria are considered. According to the program regulation ${ }^{17}$, beyond income and family composition criteria, the respective municipality must have an official estimate of poverty incidence and the amount of new benefits must fit in the given federal budget established by the Budget Annual Law.

The rules give the ministry the right of assigning the families to some priority groups considering the social vulnerability, such as indigenous, quilombolas ${ }^{18}$, children in a working situation, people released from slavery conditions, and families benefited by the BFP precursor programs. They also allow the ministry to identify if the municipality is in agreement with collaboration terms that promise its engagement in providing complimentary social policies.

After ordering by priority the vulnerable groups and families from municipalities with lower BFP coverage ${ }^{19}$, if there are more eligible families than the assigned budget,

\footnotetext{
16 The family income is computed disregarding the amounts of all official programs of cash transfers but the BPC, which is paid to the poor elderly or disabled individuals.

17 Portaria 341 from October 7, Senarc - Ministry of Citizenship (2008).

18 Residents of settlements established by escaped slaves.

19 Defined by the current number of beneficiaries divided by the estimated number o poor people in the
} 
the system selects the families with the lowest income and more children and teenagers on their composition.

All these rules are applied through an automatic and centralized system that classifies the family as beneficiary. The eligible families not selected to receive the benefit enter in a waiting line. The waiting line rolls with the federal budget assigned for the program in the next year or with other families getting out of the program.

Once selected to the benefits, the families can get out of the program either by voluntarily requiring it for the social assistance office or by the office requiring it, if some irregularity is discovered. Both are relatively rare events ${ }^{20}$. Moreover, the major part of them remains in the $\mathrm{SR}^{21}$.

The family can be excluded from the SR under some conditions: all family members die; the family is not found for more than two years; the family denies to provide, omits, or lies in the SR information; the family requires its information to be excluded ${ }^{22}$.

The types of benefits the families can receive varies with their income and composition: Basic Benefit of BRL 89.00 is given to extremely poor families; Variable Benefit of BRL 41.00 is given for each pregnant or breastfeeding woman, child and teenager of the family up to the limit of five per family; Variable Benefit for Young is given for each teenager of 16 an 17 years old. The amount is BRL 48.00 and each family can receive at maximum two; Benefit to Overcome Extreme Poverty is given for the extremely poor families in the amount to set the family per capita income in the extreme poverty limit, i.e., BRL 89.00; The most recent one, established in 2019 is the Christmas Bonus, which is constituted by the same amount of the installment paid for the family in December.

Beyond income, important education and health conditionalities to receive all of these benefits are: keep at least $85 \%$ of school attendance for children and teenagers

municipality.

20 Between 2003 and 2015, 3.1 million families got out of the program by its own will, and 3.0 million had the benefit canceled due to SR data inconsistencies (MC).

21 Of all the heads of family benefited by the BFP in 2004, $82 \%$ appear in the SR data at least in one year after 2012 .

22 Major actions of exclusion of outdated registers happened at the end of 2013 and the beginning of 2015. Therefore, in the SR data of 2012, most of the families excluded are still observed. 
from 0 to 15 years old and $75 \%$ for 16 and 17 years old; keep children 0 to 7 years old vaccination card updated; pregnant women must attend the schedule of monitoring exams; breastfeeding women must participate in educational activities; women aged 14 to 44 must regularly check their health conditions.

On education conditions, the public schools, municipalities, states, and the Ministry of Education work together to register the children's attendance in the official systems. Considering health, the Ministry of Health and the municipalities' Health Secretary are in charge of ensuring that the families are matching the requirements, and must provide information about it.

The procedures of checking and reporting if the families were matching the education and health conditionalities were effectively established by the end of 2006 (Soares and Sátyro, 2010), and sharply increased the number of families investigated until 2008. Once some irregularity is found, the consequent actions are divided into five steps. In the first incident, the family receives a warning, and after two months, if the family is still not attending the requirements, the benefit is blocked for one month, although the respective value can be withdrawn in the following month. If the family continues not meeting the conditions, the benefit is suspended for one month but at this time the amount will not be available in the next period. In the fourth round, the benefit is suspended for two months. In the last round, the family has the benefit canceled and is removed of the program ${ }^{23}$.

Considering the income criteria, some rounds of matching data from the formal labor market with the SR were done by the government to find the non-eligible families that were receiving the benefit. As a result, the Ministry classified the families' information in a range from probably inconsistent to strongly inconsistent. In the latter, the benefit is immediately blocked, but for both cases, the Ministry sends the list of theses families for further investigation by the local BFP manager.

The BFP and its precursor programs went through some important changes across their history. In what follows I make a timeline of them, comprising the most relevant

23 From 2003 to 2009 all of the families received warnings, 36.6\% got the benefit blocked, and only $4.5 \%$ got the benefit canceled. 
facts to the purposes of this research.

Lavinas (1998) makes a review of the first CCTs in Brazil, like Bolsa Escola and other local and small cash transfer programs during the second half of this decade. One of the pioneers ${ }^{24}$, Bolsa Escola - DF, was created in 1995 in the state of Distrito Federal. The program distributed the equivalent of one minimum wage for low-income families that had on their composition children from 7 to 14 years old enrolled in public schools. Other important requirements were the monthly per capita family income, that should not exceed half of a minimum wage, and children's school attendance, that should be at least 90\%. In December 1997 this program covered 22,151 families, with a monthly nominal expenditure of BRL 2.7 million, equivalent to $0.77 \%$ of the state expenditure budget.

In 1996, the first federal CCT was created, the Child Labor Eradication Program (PETI), which focused on children from 7 to 15 years old that were working or about to get involved in harmful working activities to generate income for their families. By the year 2000, PETI covered 140 thousand children and teenagers. In 2002 this number increased to 810,769 spread across 2,590 municipalities (Carvalho, 2004).

Between 1995 and 2001 other Brazilian municipalities implemented local cash transfer programs, but they were kept on a relatively small scale until the creation of the Bolsa Escola at the federal level in 2001 (Soares and Sátyro, 2010). Currently, the local programs act mostly like complementary income transfers, taking into account the federal benefits. Unfortunately, it is important to mention that many difficulties arise in assessing these programs, or incorporating them in the present analysis since the respective data and program management are, in general, customized.

On March 14, 2001, it was created the program Bolsa Escola, inspired by the local program Bolsa Escola-DF, but now at the federal level, covering the whole country. This is the first and most important from the four programs that later were merged in the BFP. In the same year, it was also created a very important tool for the CCT programs, the

\footnotetext{
24 The first was the Programa de Garantia de Renda Familiar Minima created in March 1995 in Campinas municipality, but the Bolsa Escola played a more important role in the CCTs' history, becoming the largest federal program in 2003.
} 
Single Registry (SR). For the first time, there was a unified registry of all of the poor families with their social and demographic characteristics. This registry gradually became mandatory for all of the federal social programs. Recently, even the BPC, paid to poor elderly and people with disabilities, turned the registration in the SR a requirement to maintain the benefit.

The second merged program to be created was the Bolsa Alimentação. It was established by the end of 2001 but was kept on a relatively small size. The amount defined was BRL 15.00 per child in the range of 0 to 6 years old, with a maximum of BRL 45. The third one was the Auxilio Gás, created in 2002. Since its beginning, the beneficiary families should be registered in the SR. This was a non-conditional transfer to poor families and although it reached a high number of covered families by 2004, the amount of the benefit was less relevant, adding BRL 7.50 per month for each family. Finally, the last program merged in the BFP was created in June 2003, the Cartão Alimentação. It was constituted by a transfer of BRL 50.00 that should be exclusively spent on the purchase of food.

With many different rules, systems, and stakeholders, the situation of the cash transfer programs in the country was very inefficient. Finally, in October 2003, through the Provisory Act 132, it was created the unified program, the Programa Bolsa Família (BFP). It was decided that the previous programs would be maintained, but no new beneficiaries would be included and the existent ones would gradually be transferred to the new program.

The original law defined the extreme poverty line as BRL 50.00 monthly per family, and the poverty line as BRL 100.00. It established the Variable Benefit in BRL 15.00 per child/teenager aged 0 to 14 years, and the Basic Benefit in BRL 50.00 for the extremely poor families.

In January 2004, the federal CCT programs benefited the following number of families: Bolsa Escola 3,601,217; Bolsa Alimentação 327,321; Cartão Alimentação 346,300; Auxílio Gás 6.7 million$^{25}$; Bolsa Família 3,615,861; PETI around 1 million. An important

\footnotetext{
$\overline{25}$ Although many families were covered, the benefit amount was low, composed by BRL 7.50 per family
} 
feature of these programs is that all of these families were registered in the SR, and after the unification, any new family was included in the previous programs.

In 2005, another important federal CCT program, PETI, was merged with the BFP. A characteristic of this last unification is that the families above the poverty limit, theoretically, could be included in the PETI but not in the BFP. Observing the shrinkage on the resources destined to this program (MDS), this almost did not happen. This is a reasonable argument since the non-poor families have fewer bad-incentives to send their children to work. Therefore, almost all new families benefited by PETI after the BFP creation are also included in the BFP.

In July 2007, the extreme poverty line was changed to BRL 60.00, and the poverty line to BRL 120.00. The Variable Benefit was adjusted from BRL 15.00 to BRL 18.00 for children and teenagers of the range 0-14 years old, and the Basic Benefit was increased from BRL 50.00 to BRL 58.00.

In 2008 the Variable Benefit was redefined to BRL 20.00 and the age range to 0-15 years old. It was also created the Variable Benefit for the Young of BRL 30.00 per teenager in the range of 16-17 years old. Each family could receive a maximum of two of this new benefit.

In May 2012 it was established the Benefit to Overcome Extreme Poverty. The amount was computed in a way to set the family per capita income, considering the other benefits, exactly in the extreme poverty limit (BRL 70.00). Initially, the families eligible for this benefit should have children from 0 to 6 years old. Some months later, in October of the same year, the law changed this age range to $0-15$. In the following year, the need to have children in the composition to be eligible was removed.

In 2016 there was another round of matching income information from SR with the formal labor market data. As a result, 469 thousand families had the benefit canceled and 654 thousand were blocked. At that time, the total number of beneficiary families were 13.9 million.

In 2019, it was established the thirteenth installment of the BFP. However, with the 
ongoing government expenditures adjustment and high unemployment level, the program presents a growing waiting line. Moreover, there are uncertainties about the availability of resources to pay this thirteenth installment.

After this historical review, it is clear that the program analyzed in this work did not begin exactly in 2004, and the families could have been treated by other programs. Moreover, the BFP law also guarantees that the local CCTs can complement the benefits of the federal program. The local programs can, for instance, adjust for differences in the living costs between municipalities. However, as described later, by properly selecting the sample focusing on specific children's cohorts, and years of registration in the SR, I avoid major biases concerns.

In the next section, I review a part of the literature of Human Capital, that comprises the underlying mechanisms through which the CCT programs affect the future of the children. I also present some numbers of the education sector in Brazil.

\subsection{Human Capital and Education in Brazil}

This section reviews the literature on Human Capital. It is the main mechanism and likely is underlying the effects I estimate in this work. The early adulthood schooling level, the first outcome of interest, although imperfect is a straight measure of one of the dimensions of Human Capital, while the last two outcomes, Formal Labor Market Participation and Earnings, are likely influenced by the first one.

After reviewing the literature of Human Capital, I close the section contextualizing the Brazilian current situation, presenting some education data in comparison to some developed countries. With this exercise, I argue that there is still space for improvement in Brazilian education.

The influences of the Human Capital on economics are considered by scholars at least since the classical economists. However, it gained much attention more recently (Schultz, 1961; Becker, 1962; Mincer, 1974), and continues to be an important field for 
researches on its causes and effects (Cunha and Heckman, 2007; Heckman et al., 2018).

The modern approach to the Human Capital theory began with the studies of Schultz (1961) and Becker (1962). The former analyzed concepts embedded in the term Human Capital and defined five important activities to be considered as Human Capital investments: health facilities and services; on-the-job training organized by firms; formal education; study programs for adults not organized by firms; and migrations aiming job opportunities. In the present work, I focus on the easier-to-measure dimension, the formal education attained by the young adults who had a poor childhood.

A formal framework for economic analysis of these investment decisions was provided in the following year, in the work of Becker (1962). Two years later, Becker (1964) added an empirical approach to the previous concepts and theoretical works.

In the famous work of Mincer (1974), a simple empirical functional form considering the schooling, experience, and their non-linear effects on earnings was presented. Since then, it has been widely applied in the empirical studies of schooling returns. However, some criticisms of the Mincer model were also elaborated. Heckman et al. (2006) argue that uncertainty and psychic costs on the schooling decision are important for the schooling returns determination. The authors also presented the conditions under which the Mincer model estimates the ex-post internal rate of return of schooling.

In the present work, when analyzing the BFP long-term effects on Earnings I am not constrained to this kind of biases. I analyze the part of the earnings associated with the family background, the individual fixed characteristics, and the BFP exposure, and not to the individual choices. Therefore, I do not introduce experience or schooling as control variables, since they may be also outcomes of the treatment. Nonetheless, a formal theoretical structure to investigate the outcomes' relations and the mechanisms driving the effects would be very welcome in future research.

Considering the stages of childhood that the investments are done, Cunha and Heckman (2007) review the evidence showing that actions during the early periods have more power on generating sustained gains of cognitive skills, while the non-cognitive have 
more substitutability between early and late childhood investments. Besides, the continuity of the investments during later stages keeps the returns of the early investments higher. The authors provide a technology function of skills formation that can explain the evidence.

Indeed, Barham et al. (2013) showed that the Nicaraguan CCT program contributed to generate more cognitive skills on boys exposed since the uterus relative to boys exposed in later stages, from 2 to 5 years old. Considering the age of the program, the BFP long-term effects of exposure during early childhood will certainly be approached in the years to come.

Some recent researches account for a variety of individual personality traits and characteristics. For example, Todd and Zhang (2020) apply Australian data to a Dynamic Discrete Choice Model and show that the "big five" traits ${ }^{26}$ explain roughly the same amount of ex-ante lifetime utility variation than the cognitive ability. Although important, it is difficult to have data with detailed measurements of the different Human Capital dimensions. In the present work, I analyze the Schooling level, which is one of the possible investments in Human Capital. Unfortunately, with this data I can not estimate what dimension of Human Capital the investment in schooling affects more or less.

In contrast with the previous literature, it is important to have in mind that other mechanisms can also explain the higher average earnings to the high schooling individuals. Spence (1974) showed that the fact that education costs are lower to high-skilled individuals can induce those individuals to obtain more education, to send the signal to the labor market that they are the high-skill type. In this context, it appears to be a smaller problem, since I am considering the basic education of poor families, which is mandatory if the family want to receive the BFP benefit, regardless of the children type.

Considering the Human Capital positive returns, it is important to have an explanation for the low observed level of average education attained by Brazilian population shown ahead. As a developing country, not all families have the choice of sending their children to school. In the presence of subsistence costs and costs to attend the school,

$\overline{26}$ Openness to experience, conscientiousness, extraversion, agreeableness, and neuroticism. 
families' decisions of preventing their children to go to school and sending them to work, inside or outside the household, can be optimal under credit constraints. I.e., if the family can not borrow resources to finance its subsistence and the school costs while its children are studying, eventual high long-term returns of the studies do not matter.

The credit constraints preventing the Human Capital investments are considered at least since Becker (1960). Keane and Wolpin (2001) showed that for college education in the United States, borrowing constraints seem to be less important. However, for basic education in a developing country like Brazil, it seems to matter much more, as shown by Chein and Pinto (2018). The authors found strong effects of credit constraints on basic education, while no effects for college and graduate studies. Considering this mechanism, a CCT in a developing country, like the BFP, alleviate the immediate poverty and can turn optimal the decision of sending the children to school.

The education scenario in Brazil, from primary to tertiary, is far from ideal. In most OECD and partner countries, less than $5 \%$ of the adults did not complete primary education, but Brazil is one of the notable exceptions, with $17 \%$ of its adults. Data collected in primary sources by The World Bank shows some changes ${ }^{27}$ in the country. However, the levels are still low compared to developed countries, and the quality of the obtained education is very low ${ }^{28}$.

Reis (2020) shows an interesting fact about the Brazilian education system. Considering a measure of over-education ${ }^{29}$, the author found that for individuals that come from public basic education it is higher than for those that came from private basic education schools. The opposite occurs for tertiary education, which matches a well-known fact, i.e., the public colleges tend to have higher quality in Brazil than the private ones.

The size of tertiary education in Brazil is also relatively small compared to high-

27 The share of the population 15-19 years old with 4 years of study passed from $67.2 \%$ in 1981 to $0.95 .6 \%$ in 2012, while the population with 9 years of study, equivalent to complete stages before high-school, passed from $13 \%$ to $49.7 \%$ in the same years.

28 Only $26 \%$ of children and young at the end of secondary education reaching a minimum of proficiency (Level 2 in PISA) in mathematics and reading OECD (2017).

29 The term means that the individual has more years of schooling than the expected for its employment occupation kind. 
income countries. In 2016, only $14 \%$ of the population aged between 25 and 64 years had completed higher education, while for the OECD countries this rate was around $35 \%$ OECD (2017).

Despite being relatively low, it seems to exist a modest positive trend. The group of adults aged 25 to 34 years with tertiary education in Brazil increased from $12 \%$ in 2010 to $17 \%$ in 2015. Probably, scholarship participation may increase in the next years as well. In Australia, England, and the United States, $75 \%$ or more of students are benefited by public loans or scholarships/grants. In contrast with Brazil, in the high-income countries the public sector provides $91 \%$ of the funds at primary, secondary, and post-secondary non-tertiary levels, and $70 \%$ of total expenditure at tertiary.

The literature and data presented in this section had the aim of supporting the following arguments. Human Capital is very important for economic development. However, the families from developing countries may not be able to invest in it, due to mechanisms like credit constraints and subsistence costs. This underinvestment can explain the descriptive statistics presented for Brazilian basic education. A CCT like the BFP can enhance this investment.

The causes and effects of Human Capital still constitute an important field of study, and is on the core of the present work. The first long-term outcome of interest in this work, the Schooling attained at 18 years old, is a measure of one of the possible Human Capital investments, and the other two outcomes, Formal Labor Market Participation and Earnings can be seeing as consequences of the first. 


\section{Methodology}

To estimate the long-term effects of the BFP on young adults' outcomes I apply traditional impact evaluation techniques, choosing the econometric specifications according to the nature of each outcome variable. I apply probabilistic models, binary choice in the case of the Formal Labor Market Participation and ordered choice in the case of Schooling. Concerning the outcome of Earnings, represented by the nominal hourly wage, I apply log-linear models as usual in the literature.

Considering the impact evaluation literature terms, I have a Natural Experiment where there is a correlation of many factors with the treatment and the outcomes' measures, but likely the most of these factors are observable. In other words, by conditioning on the observable characteristics of family, individual, and municipality, and relying on the identification hypothesis that no other important factor is omitted, I estimate here the Average Treatment Effect of each level of BFP Exposure on the long-term outcomes.

The treatment measure is divided into five levels comprising intervals of years of exposure to the program. The level zero means that the head of the family did not receive the BFP in any year from 2004 until the child becomes an adult (turns 18 years old). The next levels are defined respectively by the intervals 1 to 3,4 to 6,7 to 9 and 10 to $12^{30}$ years of benefit receiving. Each level is represented by a dummy variable included in the model and is associated with an estimated parameter.

In the robustness tests and the alternative identification strategy, the instrumental variable approach, I consider a continuous treatment variable represented by the years of exposure itself, without splitting it into levels. I also add the squared years of exposure to capture non-linear effects, which was proved to be an important component in the results section. It is important to have in mind that, in this alternative approach, an important part of the random variation of the families' BFP Exposure, which occurs within the municipality and between families, goes away.

I restrict the sample to individuals of families registered during a strong expansion

30 Considering the cohorts of interest, the maximum possible exposure during childhood is 10 years. 
period of the Single Registry, 2004 to 2006, when it is reasonable to assume that there was a lot of randomness in the order of inclusion of the vulnerable families, regardless of their income or social characteristics. For instance, the social assistance teams may have visited some regions of the municipality before others. Likewise, the families that by chance lived closer to the social assistance office may have known before about the registering process, and presented themselves earlier. As was argued before, to be registered first in the SR increases the chances of the family having the benefit released earlier, which tends to increase the duration of the exposure to the program.

Although I believe that both identification strategies address the major part of the endogeneity problems, it is possible that a minor part is not solved by them. A bias from the selection on family unobservables may have occurred, and thus may be affecting my estimates. If, for example, the better-informed families tended to get registered before the others, this would lead the coefficients to an over-estimation if the former families have a better socio-economic background than the latter. The same kind of argument can be done for a bias from the selection on unobservables of the municipalities, that would be affecting my estimates of the instrumental variables identification strategy.

The sources of endogeneity discussed above are almost always present in studies where the data does not come from a randomized experiment. Even being common and very hard to address, it is important to be aware of them, and interpret the results and derived conclusions of these studies as conditioned on these problems being small enough.

In what follows, I present in separate subsections the measures of each of the long-term outcomes of interest, the respective regression equations, and comment on each estimation procedure. Then, in the last subsection I present the different data sources applied in this work and the procedures adopted to clean and merge them.

\subsection{Schooling}

The variable chosen to represent the education attained by the child when it turns into an adult is the schooling level when the the individual is exactly 18 years old. There 
are two reasons for this age choice. First, individuals are already legally responsible for themselves, and in regular conditions would have just completed the secondary education ${ }^{31}$. This education level is considered mandatory for any citizen and the government, at least in theory ${ }^{32}$, is obliged to provide it free of additional costs for the entire population. The second reason is related to the program rule. The education follow-up of these early adults was important for the family to get the BFP benefits until one year ago, therefore the education variables observed are expected to contain more reliable and updated information than for individuals of later ages.

Through the information of literacy and grades attendance, it was possible to transform all the variables of education in the Single Registry into one variable of Schooling, divided into six levels with a natural increasing order. It starts at level 0 , that corresponds to individuals that never went to school and do not know how to read or write, and stops at level 5, which comprises the individuals that finished tertiary education ${ }^{33}$. The Schooling level 1 represents individuals that finished pre-school or learned how to read and write. The level 2 comprises people that concluded elementary education ${ }^{34}$. Level 3 is defined by individuals that concluded the equivalent to middle school ${ }^{35}$. Finally, Schooling level 4 represents individuals that finished high-school, that in regular conditions is expected to happen at the age of 17 years old.

Considering the natural ordered characteristic of this outcome variable, I apply an Ordered Discrete Choice model, the Ordered Logit ${ }^{36}$, a particular case of Ordinal Regression models that were first considered by McCullagh (1980). This model allows us to retrieve how the probability of reaching some level of education varies along with the program exposure levels. Besides the estimated probability, the sign of the parameters also gives the direction of the effects of the program exposure on schooling. Following the

\footnotetext{
31 In Brazil, a regular student completes secondary education (high-school) when it is 17 years old.

32 Act. n. 9394 from December 20, 1996

33 As was shown in the data description section, there are relatively few individuals with Schooling level 5 , which is expected if the assumed age of reference (18 years old) is considered.

${ }^{34}$ In the Brazilian system, for a regular student, this is expected to happen at the age of 10 years old, in the conclusion of the fourth grade, currently renamed to fifth year

35 In Brazil, this is expected to happen at the age of 14, with the conclusion of the $8^{\text {th }}$ grade, currently renamed to $9^{\text {th }}$ year.

36 The error distribution assumptions, usually Normal or Logistic, pointed to the same results.
} 
textbook of Wooldridge (2010), the model can be derived from a latent variable equation represented in Equation 3.1.

$$
\text { Schooling }_{i}^{*}=\text { Exposure }_{i} \beta_{1}+X_{i} \beta_{x}+\epsilon_{i}
$$

The $\epsilon_{i} \mid$ Exposure $_{i}, X_{i}$ is assumed to follow a Logistic distribution, Exposure ${ }_{i}$ is the vector with the four interest dummy variables representing each level exposure to the BFP during childhood, from 1 to 4 , and $\beta_{1}$ is the vector with the respective parameters of interest. The level of BFP Exposure 0 is omitted, which means that all results reported using these measures of program exposure must be interpreted in differential to the non-exposed group. The $X_{i}$ comprises the vector with all the individual, family, and municipality control variables, without the constant term. $\beta_{x}$ is the vector with the respective parameters to be estimated.

Let $\alpha_{1}<\alpha_{2}<\alpha_{3}<\alpha_{4}<\alpha_{5}$ be different unknown intercepts for each Schooling level and define the following variable that I observe, I have Equation 3.2.

$$
\text { Schooling }_{i}=\left\{\begin{array}{l}
0, \text { if Schooling }{ }_{i}^{*} \leq \alpha_{1} \\
1, \text { if } \alpha_{1}<\text { Schooling } g_{i}^{*} \leq \alpha_{2} \\
2, \text { if } \alpha_{2}<\text { Schooling }{ }_{i}^{*} \leq \alpha_{3} \\
3, \text { if } \alpha_{3}<\text { Schooling } g_{i}^{*} \leq \alpha_{4} \\
4, \text { if } \alpha_{4}<\text { Schooling } g_{i}^{*} \leq \alpha_{5} \\
5, \text { if } \alpha_{5}<\text { Schooling } g_{i}^{*}
\end{array}\right.
$$

Given the distribution assumed for $\epsilon_{i}$, I retrieve the set of parameters finding the ones that maximize the likelihood of observing the data I have, i.e., I apply the method of Maximum Likelihood ${ }^{37}$. The $\log$-likelihood function of the individual $i$ is given by Equation

$\overline{37}$ This model is estimated through the open-source software, $\mathrm{R}$, with the function polr of the library $M A S S$. 
3.3.

$$
\begin{gathered}
l_{i}\left(\alpha, \beta_{1}, \beta_{x}\right)= \\
1\left[\text { Schooling }_{i}=0\right] \log \left[F\left(\alpha_{1}-\text { Exposure }_{i} \beta_{1}-X_{i} \beta_{x}\right)\right]+ \\
1\left[\text { Schooling }_{i}=1\right] \log \left[F\left(\alpha_{2}-\beta_{1} \text { Exposure }_{i}-X_{i} \beta_{x}\right)-F\left(\alpha_{1}-\text { Exposure }_{i} \beta_{1}-X_{i} \beta_{x}\right)\right]+ \\
\ldots+ \\
1\left[\text { Schooling }_{i}=5\right] \log \left[1-F\left(\alpha_{5}-\text { Exposure }_{i} \beta_{1}-X_{i} \beta_{x}\right)\right]
\end{gathered}
$$

Where $F($.$) is the logit function { }^{38}$, the terms $1\left[\right.$ Schooling $\left._{i}=x\right]$ represent indicator variables equal to one, if the schooling level of the individual $i$ is equal to $x$, and zero otherwise. In other words, for each individual, only one of the terms is different from zero. Then, the function to be maximized is the sum of the log-likelihood functions of all individuals in the sample.

$$
L L=\sum_{i=1}^{N} l_{i}\left(\alpha, \beta_{1}, \beta_{x}\right)
$$

Maximizing the function given by Equation 3.4 gives us the parameters of interest $\left(\hat{\alpha}, \hat{\beta}_{1}, \hat{\beta}_{x}\right)$. Then, it is possible to estimate the probability of an individual to exhibit each of the Schooling levels conditioned on the level Exposure to BFP during its childhood, and also conditioned on the other observed characteristics $X_{i}$. In the results section, I report the estimated probabilities over the BFP Exposure levels, keeping the control variables fixed on their means ${ }^{39}$.

The predicted probability of an individual with a BFP exposure of Exposure Ex $_{i}$ and a set of characteristics $X_{i}$, to present the level of Schooling $j$, is then given by Equation 3.5, and the standard errors of this predicted probability can be obtained through Delta

$38 F(x)=e^{x} /\left(1+e^{x}\right)$

39 For the discrete control variables, I mention explicitly the assumed values. 
Method.

$$
\begin{aligned}
& P\left(\text { Schooling }_{i}=j \mid \text { Exposure }_{i}, X_{i} ; \hat{\alpha}, \hat{\beta}_{1}, \hat{\beta}_{x}\right)= \\
& \quad F\left(\hat{\alpha}_{j}-\text { Exposure }_{i} \hat{\beta}_{1}-X_{i} \hat{\beta}_{x}\right)-F\left(\alpha_{j-1}-\text { Exposure }_{i} \hat{\beta}_{1}-X_{i} \hat{\beta}_{x}\right)
\end{aligned}
$$

\subsection{Formal Labor Market Participation}

To represent the Formal Labor Market participation and analyze how it varies with the BFP exposure, I define a binary variable, $F L M_{i}$, that indicates if the individual $i$ appears at least one time in the formal labor market data until the most recent available year, 2017.

Following the textbook of Wooldridge (2010), I apply one of the most common probability model, the Logit. As is the case for the ordered Logit, presented in the previous section, the logit can also be derived from a latent variable model.

$$
F_{L} M_{i}^{*}=\beta_{0}+\text { Exposure }_{i} \beta_{1}+X_{i} \beta_{x}+\epsilon_{i}
$$

This means that the probability of being observed in the formal labor market $\left(F L M_{i}=1\right)$ is given by Equation 3.7

$$
\begin{gathered}
P\left[\text { FLM }_{i}=1 \mid \text { Exposure }_{i}, X_{i}\right]=P\left[\text { FLM }_{i}^{*}>0 \mid \text { Exposure }_{i}, X_{i}\right]= \\
\mathrm{P}\left[\epsilon_{i}>-\beta_{0}-\text { Exposure }_{i} \beta_{1}-X_{i} \beta_{x}\right]= \\
\mathrm{F}\left(\beta_{0}+\text { Exposure }_{i} \beta_{1}+X_{i} \beta_{x}\right)
\end{gathered}
$$

The last equality holds because the distribution of $\epsilon_{i}$ is symmetric around zero. 
The log-likelihood function for each individual is then given by Equation 3.8.

$$
\begin{gathered}
l_{i}\left(\beta_{0}, \beta_{1}, \beta_{x}\right)= \\
\mathrm{FLM}_{i} \log \left[F\left(\beta_{0}+\text { Exposure }_{i} \beta_{1}+X_{i} \beta_{x}\right)\right]+ \\
\left(1-\mathrm{FLM}_{i}\right) \log \left[1-F\left(\beta_{0}+\text { Exposure }_{i} \beta_{1}+X_{i} \beta_{x}\right)\right]
\end{gathered}
$$

The $F($.$) function is the accumulated density function evaluated on a set of$ parameters $\left(\beta_{0}, \beta_{1}, \beta_{x}\right)$ and the values observed for the BFP Exposure and the control variables $X_{i}$. Of course, only one of these terms will be different from zero for each individual. The function to be maximized by the solution set of parameters is the sum of the individuals log-likelihood functions:

$$
L L=\sum_{i=1}^{N} l_{i}\left(\beta_{0}, \beta_{1}, \beta_{x}\right)
$$

As was done for the Schooling, for the FLM outcome I also report the predicted probability, given the solution set of parameters $\left(\hat{\beta}_{0}, \hat{\beta}_{1}, \hat{\beta}_{x}\right)$, of an individual with an observed level of Exposure Ex $_{i}$ and observed characteristics $X_{i}$ to appear in the Formal Labor Market. This is computed through Equation 3.10. The standard errors of this predicted probability are computed through the Delta Method.

$$
P\left[F L M_{i}=1 \mid \text { Exposure }_{i}, X_{i} ; \hat{\beta}_{0}, \hat{\beta}_{1}, \hat{\beta}_{x}\right]=F\left(\hat{\beta}_{0}+\text { Exposure }_{i} \hat{\beta}_{1}+X_{i} \hat{\beta}_{x}\right)
$$

The alternative identification strategy relies on the exogeneity of the municipality effort to include vulnerable families in the Single Registry. I measure the effort as the number of registered families in 2006 divided by the number of poor families in $2000^{40}$.

On the implementation of this strategy for the FLM outcome, I apply the Instru-

${ }^{40}$ In 2006, this was the most recent year for which there was comparable poverty survey data for all municipalities. The Demographic Census of 2000 was also an official source of poverty measures considered by the government 
mental Variable Probit ${ }^{41}$, and changed the interest variable from Levels of Exposure (0 to 4) to the Years of Exposure (0 to 10) and its squared term, to capture the non-linearity observed in the estimates of other specifications.

Equations of this approach are stated in 3.11, 3.12, and 3.13.

$$
\begin{gathered}
\text { FLM }_{i}^{*}=\beta_{0}+\text { Exposure }_{i} \beta_{1}+\text { Exposure }_{i}^{2} \beta_{2}+X_{i} \beta_{x}+\epsilon_{i} \\
\text { Exposure }_{i}=\gamma_{0}++S R \_ \text {Coverage }_{i} \gamma_{1}+S R \_ \text {Coverage }_{i}^{2} \gamma_{2}+X_{i} \gamma_{x}+u_{i} \\
\text { Exposure }_{i}^{2}=\delta_{0}+S R \_ \text {Coverage }_{i} \delta_{1}+S R \_ \text {Coverage }_{i}^{2} \delta_{2}+X_{i} \delta_{x}+v_{i}
\end{gathered}
$$

Equation 3.11 is known as the structural equation of this system, and Equations 3.12 and 3.13 are known as the first stage regressions, that work as exogenous source of variation to the interest variables, the Exposure and its squared term. Because I am interested in the probability of participation in the formal labor market and want to respect the nature of the observed binary variable $F L M_{i}$, I follow the structural approach (Cameron and Trivedi, 2009) and assume that the error terms of the three equations $\left(\epsilon_{i}, u_{i}, v_{i}\right) \sim N(\mathbf{0}, \Sigma)$. The estimation procedure is the Maximum Likelihood.

\subsection{Earnings in the Formal Labor Market}

To estimate the long-term effects of the BFP on the early adults' earnings, I chose to apply the dependent variable defined by the nominal hourly wages in the logarithmic scale. This is the most used specification of empirical earnings equations in the economic literature (Heckman et al., 2006), but here I do not control for schooling or experience as is usually the case. I had to keep schooling and experience out, because these may be also

$\overline{41}$ The Multivariate Normal Distribution of the errors makes the Maximum Likelihood estimates more straightforward in this case than a Multivariate Logistic assumption. 
outcomes of the treatment exposure, and as potential mechanisms driving the earnings, can take us to misleading interpretations. In other words, schooling and experience may act as bad controls that spoil the estimation of the effect of interest: the differential effect of BFP exposure on Earnings conditional on having at least one formal employment.

The wage regressions of the first identification strategy are estimated through the Ordinary Least Squares method. The model specification is given by equation 3.14.

$$
\text { Wage }_{i t}=\beta_{0}+\text { Exposure }_{i} \beta_{1}+X_{i} \beta_{2}+\phi_{t}+\epsilon_{i t}
$$

The Wage $_{i t}$ is measured as the logarithmic of the hourly average nominal wage of individual $i$ reported by its firm at the year $t$. The $k$ control variables are represented by vector $X_{i}$. Therefore, parameter $\beta_{2}$ belongs to the vector space of dimension $k$. The term $\phi_{t}$ represents the dummy variable for the year $t$, and $\epsilon_{i t}$ represents the non-observed random shock component of the wage.

I chose to apply the panel data for the Earnings outcome instead of the crosssection for one reason. In the panel, I do not need to create another measure of Earnings making more assumptions to consider, for example, inflation. Moreover, I can incorporate dummy variables of year and individuals' cohort. These variables are expected to capture macroeconomic cycles and eventual correlations between these cycles with the BFP Exposure that emerge from the relative presence in the labor market of each cohort in each year.

For the Earnings outcome, I also apply the alternative identification strategy considering the Instrumental Variable approach. I take advantage of the observation of the municipality effort to include families in the Single Registry in the period of great expansion of the BFP. From the family point of view, it is reasonable to argue that, conditioned on variables like pre-program municipality poverty, density, population size, the effort of the social assistance team is not correlated to the long-term outcome variable by other channels than the BFP participation. 
The drawback of this approach is that the variation of the instrument is at the aggregate level, while the endogenous variable, BFP exposure, is at the individual level. Moreover, the interest variable in this specification is the number of years that the individual was exposed to the program during childhood, and not the 5 levels measure as in the other models. This change was necessary because of the existence of only one instrument, and the previous measure would demand one instrument for each level of treatment exposure.

To tackle the eventual remaining endogeneity concerning the family exposure, I apply the Two-Stage Least Squares approach to retrieve the parameters of Equation 3.15.

$$
\text { Wage }_{i t}=\beta_{0}+\text { Exposure }_{i} \beta_{1}+\text { Exposure }_{i}^{2} \beta_{2}+X_{i} \beta_{3}+\phi_{t}+\epsilon_{i t}
$$

The first stage regressions that allow us to keep the variation on the exposure variables not related to the family unobservables are represented by equations 3.16 and 3.17 .

$$
\begin{aligned}
& \text { Exposure }_{i}=\gamma_{0}+S R \_ \text {Coverage } \gamma_{1}+S R \_ \text {Coverage }{ }_{i}^{2} \gamma_{2}+X_{i} \gamma_{3}+\phi_{t}+u_{i t} \\
& \text { Exposure }_{i}^{2}=\delta_{0}+S R \_ \text {Coverage } \delta_{1}+S R \_ \text {Coverage }{ }_{i}^{2} \delta_{2}+X_{i} \delta_{3}+\phi_{t}+v_{i t}
\end{aligned}
$$

The data structure in this instrumental variable approach remains the same. In other words, although the BFP exposure does not vary along the time dimension for a given individual, it is repeated for every wage observation that it has. This explains the error terms $u_{i t}$ and $v_{i t}$ dimensions, and the year dummy variable $\phi_{t}$ on both first-stage equations.

With the predicted Exposure and Exposure ${ }^{2}$ replacing the original variables, the 
second stage regression is stated in Equation 3.18.

$$
\text { Wage }_{i t}=\beta_{0}+\text { Exposure }_{i} \beta_{1}++ \text { Exposure }_{i}^{2} \beta_{2}+X_{i} \beta_{3}+\phi_{t}+\epsilon_{i t}
$$

This approach could be very limited if the country had only a few municipalities. Fortunately, this is not the case of this work. Brazil has more than 5.5 thousand municipalities, which provides data variation that enables the identification of the desired parameters. However, this strategy has the cost of throwing away two important parts of the BFP exposure variation: the one related to the timing that each family got registered in the SR; and the one related to the difference between the family income at the moment of SR registration/update and the average income.

\subsection{Data}

In this research, I combined three main data sources to obtain the characteristics of the individuals and their families. They are:

Single Registry for Social Programs ${ }^{42}$ (SR) from the Ministry of Social Development $^{43}$ (MDS): This data comprises the individual and its family identification and characteristics. I also observe the family BFP condition, beneficiary, or not. Moreover, it contains the date of the family registration, and information like zip code, income per member and the family's expenses. The available years are 2012 to 2017.

BFP Payment Records - Ministry of Social Development: This data is used to estimate the treatment of BFP on children from 2004 to 2011 since the SR is not available for this period. It has the identification document number of the family responsible (head), and the total value of BFP received per year. Knowing the family of the benefited individual in the SR allows us to build the variable of program exposure for the selected cohorts,

42 Cadastro Único para Programas Sociais. This identified data was obtained under special authorization linked to the SAGI/MDS Process number 71000.018838/2018-35.

43 Ministério do Desenvolvimento Social e Agrário, currently restructured and renamed to Ministério da Cidadania (Ministry of Citizenship). 
composed of individuals born between 1996 and 1998.

Annual Report of Social Information ${ }^{44}$ (RAIS) from the Ministry of Labor and Employment $^{45}$ (MTE): This dataset comes from a form that every firm in the country may fill every year about their employees. It contains the nominal wage, dates of admission and lay-off, in addition to other personal and firm characteristics. It is available from 2002 to 2017 .

Combining these three sources with municipalities indicators from the Demographic Census of 2000, the Ministry of Education, and Ministry of Social Development, produced two final datasets. The first is a panel where I observe the wages and employment characteristics of individuals of the selected cohorts. The first year is 2012, which is the first year when the older cohort (1996) could be formally employed, and the last is 2017.

Even though I observe in this data the wages over the adulthood years, I only observe one fixed BFP exposure measure for each individual during its childhood. This fact is related to the nature of the problem and prevented the consideration of individual-fixedeffects models. However, considering the set of control variables observed, disregarding individual fixed-effect seem to pose limited damage to the estimates.

I chose to consider this panel data in the baseline for the Earnings outcomes because it allows to control for cohort and year fixed effects. The fixed effects clean the estimates from macroeconomic effects, and individual experience and maturity effects on the wages. An alternative approach to the Earnings outcome models would be to apply a national inflation index and take the average wage, transforming the panel in a cross-section. However, I believe that this procedure could introduce additional noise in the estimates ${ }^{46}$.

Considering the wages of the individuals' parents during their childhood, I had to apply the inflation index. The years in which I observe the interest cohorts in the labor

44 Relatório Anual de Informações Sociais.

45 Ministério do Trabalho e Emprego. This Ministry was dissolved in 2019, and its activities are currently shared between the Ministry of Economy and the Ministry of Citizenship.

46 Estimates considering the cross-section data and the averaged real wages as dependent variable also presented mixed results for the Earnings outcome. In this specification, the nominal wages were corrected with one of the official inflation indexes, the INPC (IBGE), before I computed the averages. 
market are not the same as the years of their parents during their childhood. The same is true for the parents schooling, for which I took averages for the values observed in the years of SR before the individual become an adult (18 y.o.).

The second dataset is a cross-section derived from the panel. In this data, are observed the Schooling attained when individuals are 18 years old and their Formal Labor Market Participation. The data also include information on the individuals' parents restricted to their childhood period, like the average schooling attained, Formal Labor Market participation, and average Earnings. All variables are time-fixed, which justifies why I keep only one observation per individual.

Before linking the three identified datasets, I adopted some criteria to keep only reliable observation from the raw data. Nonetheless, the quality of the three is remarkable, and the number of observations lost due to cleaning rules is reasonable if compared to other empirical microeconometrics studies. Considering the size of each of the three primary data, I had to sample only a portion of individuals and keep all of their family members.

The first data I approach is the Single Registry. To reduce computational time and memory requirements, I sampled 10\% of individuals of the selected cohorts $(1996,1997$ and 1998).

For those that changed of family within a year, I maintained only the first family code. These individuals end up appearing in the next year of the SR with the new family code and respective characteristics, which makes this procedure of limited damage.

From the first family that each individual under 18 years old appears as a member, I extract the code of the family. This allows to find the head of the individual's family, usually its mother, and the partner of the head, usually the father ${ }^{47}$, that I name here as the Co-head.

The schooling variable comes in a complex set of indicator variables. The division of basic education stages has changed in Brazil over the years. I applied procedures to

$\overline{47}$ Same-sex couples are practically absent in the SR data. Although I believe this is a fact for further investigation, it is out of scope here. 
turn it comparable and set the levels of Schooling from 0 to 5. The highest level represents undergraduate or technical degree after high school.

Considering the second identified data, the BFP Payment Records, I pooled the years from 2004 to 2017 and kept only one observation by individual and year applying two rules. I throw away the duplicated observations, and for some individuals that appeared in more than one municipality in a given year, I kept the municipality of the first appearance. After that, I kept in the data only the individuals with the document number sampled in the SR.

In the Formal Labor Market data (RAIS-MTE), I select only the same individuals and respective family members sampled in the SR. Then, I keep only one employment by year. The adopted rule is to prioritize the most recent employment, indicated by a variable of the status of each occupation in December. If the individual is not employed in December and had more than one occupation in that year, the criterion is to keep the higher-wage occupation.

After applying these procedures to each dataset, I combine them as follows. In the first place, I create the panel structure (it) that later allows to compute the averages of the childhood characteristics of each individual. I begin building the dataset with two columns containing in the lines all combinations of the document number of the sampled individuals (i) from the interest cohorts, and years (t) from 2000 through 2017.

Then, I joined to these columns the SR information of each individual of the cohorts of interest. For each individual, I have the Head and Co-head document numbers, which allow to perform the next step. I join the individuals' Head and Co-head SR characteristics, always merging by id and year. Finally, I keep in the SR only individuals that in its first appearance are not the Head of its own family $(86.3 \%)^{48}$.

Next, I complete the family Head and Co-head document codes for the period before 2012, the first year of SR. Supposing that family Head and Co-head were members

\footnotetext{
48 These observations do not seem problematic to the estimates if it is considered that the identification strategy focuses the analyses on the families registered from 2004 to 2006. Besides, individuals that in their first appearance are the head of the family tend to appear in the later years of SR.
} 
of the family since 2000, I can link possible BFP benefits from the BFP Payment Records, year by year. Moreover, this enables to link the parents' wages and other characteristics since 2002, which is the first year of available data of the Formal Labor Market.

The last merging procedure is between the resulting SR-BFP Payment Records and the labor market data, the RAIS. The first rule adopted is to keep in the RAIS only the same individuals and respective family members sampled in the SR. This reduces considerably the computational requirements. Then, I merge both databases by the individuals' document numbers, first for the selected cohorts, second for the Head of the family, and last for the Co-head.

The quality of the merge is directly observed when other variables that are present in both primary databases are compared. For instance, I have the municipality's code in the SR, the BFP Payment Records, and the RAIS. I have the individuals' names in the SR and the BFP Payment Records. I also have individuals' birth-date in the SR and the RAIS.

The last and least memory-demanding procedure is to connect the individual municipality information. For that purpose, in the resulting dataset, I fill the SR municipality code for the years before 2012. Supposing that the family was in the same municipality of its first appearance in SR, I can bring its municipality characteristics since 2000. The proportion of individuals residing out of their birth-municipality is around $64 \%{ }^{49}$. Although I have the municipality of birth, I do not know when the family moved.

After all the cleaning and merging stages, I remove from the sample the individuals with more than one birth-date, gender, or race, which is equivalent to around $0.5 \%$ of the sample. Moreover, I remove individuals that appear in the labor market when under 16 years old, i.e., under the legal permission to get a formal job.

The resulting data comprises $7.83 \%$ of the individuals in the SR that were born between 1996 and 1998 and are members of families registered in the SR from 2004 to 2006. Considering the random sampling of $10 \%$ adopted to reduce the computational burden, in

49 The potential damages for the estimates were tested selecting only individuals that in 2012 resided in the same municipality they were born. However, the results did not change. 
the complete sample one would observe $78.3 \%$. 


\section{Results}

\subsection{Descriptive Statistics}

In this section, I describe the primary data, approaching the total number of individuals observed in the SR, the BFP Payment Records, and the Formal Labor Market (RAIS) over the years. Then, I turn to the merging statistics, showing the number of individuals from each dataset found in the other ones. I also generate the same information selecting specific periods of each dataset. This procedure allows me to show that the problem of attrition in this sample seems to be very small.

The strong expansion in the first years of the Single Registry and the BFP benefits constitute the most important feature of the program for the purpose of this work. I take advantage of the timing of this expansion to identify the program's effects. These characteristics are observable in the next two tables.

Table 1 shows the number of members of families registered in the Single Registry from 2001 to 2017. The second column reports the total of individuals that, in their first year of appearance in the SR data, belonged to a family registered in the corresponding year of the table. With the data of this column, I computed the share of individuals whose first family were registered between 2004 and 2006. This group corresponds to $17.8 \%$ of all registered individuals, and $24.85 \%$ of the individuals from the SR that were born between 1996 and 1998. I focus the analysis on this last group, composed of 1,895,925 individuals.

Table 1 - Registered Individuals in the SR

\begin{tabular}{ccccccc}
\hline Year & $\begin{array}{c}\text { Total } \\
\text { (Accumul.) }\end{array}$ & $\begin{array}{c}\text { Current } \\
\text { Year }\end{array}$ & $\begin{array}{c}\text { \% of } \\
\text { Total }\end{array}$ & $\begin{array}{c}\text { Cohorts 96-98 } \\
\text { (Accumul.) }\end{array}$ & $\begin{array}{c}\text { Current } \\
\text { Year }\end{array}$ & $\begin{array}{c}\text { \% of } \\
\text { Total }\end{array}$ \\
\hline 2001 & 732,834 & 732,834 & 0.64 & 58,970 & 58,970 & 0.77 \\
2002 & $16,620,703$ & $15,887,869$ & 13.83 & $1,523,592$ & $1,464,622$ & 19.20 \\
2003 & $31,212,495$ & $14,591,792$ & 12.70 & $2,770,157$ & $1,246,565$ & 16.34 \\
2004 & $38,017,285$ & $6,804,790$ & 5.92 & $3,452,296$ & 682,139 & 8.94 \\
2005 & $41,535,749$ & $3,518,464$ & 3.06 & $3,786,641$ & 334,345 & 4.38 \\
2006 & $51,665,672$ & $10,129,923$ & 8.82 & $4,666,082$ & 879,441 & 11.53 \\
2007 & $58,350,552$ & $6,684,880$ & 5.82 & $5,160,863$ & 494,781 & 6.49 \\
2008 & $63,764,198$ & $5,413,646$ & 4.71 & $5,518,378$ & 357,515 & 4.69 \\
2009 & $69,963,859$ & $6,199,661$ & 5.40 & $5,894,279$ & 375,901 & 4.93 \\
2010 & $77,031,813$ & $7,067,954$ & 6.15 & $6,258,651$ & 364,372 & 4.78 \\
2011 & $82,526,440$ & $5,494,627$ & 4.78 & $6,471,542$ & 212,891 & 2.79 \\
2012 & $91,317,252$ & $8,790,812$ & 7.65 & $6,762,387$ & 290,845 & 3.81
\end{tabular}


Table 1 - Registered Individuals in the SR

\begin{tabular}{ccccccc}
\hline Year & $\begin{array}{c}\text { Total } \\
\text { (Accumul.) }\end{array}$ & $\begin{array}{c}\text { Current } \\
\text { Year }\end{array}$ & $\begin{array}{c}\text { \% of } \\
\text { Total }\end{array}$ & $\begin{array}{c}\text { Cohorts 96-98 } \\
\text { (Accumul.) }\end{array}$ & $\begin{array}{c}\text { Current } \\
\text { Year }\end{array}$ & $\begin{array}{c}\% \text { of } \\
\text { Total }\end{array}$ \\
\hline 2013 & $97,004,927$ & $5,687,675$ & 4.95 & $6,949,148$ & 186,761 & 2.45 \\
2014 & $102,458,254$ & $5,453,327$ & 4.75 & $7,137,037$ & 187,889 & 2.46 \\
2015 & $106,259,807$ & $3,801,553$ & 3.31 & $7,273,476$ & 136,439 & 1.79 \\
2016 & $110,159,950$ & $3,900,143$ & 3.39 & $7,436,330$ & 162,854 & 2.13 \\
2017 & $114,906,578$ & $4,746,628$ & 4.13 & $7,628,572$ & 192,242 & 2.52 \\
\hline
\end{tabular}

Note: This table reports the yearly evolution of the SR. The second column presents the accumulated number of registered individuals until that given year. The third column reports the total of individuals registered on each year. The fourth computes the value of the second column divided by the final number of registered individuals, in 2017. The following three columns report the same measures as the previous three but considering only individuals that were born between 1996 and 1998. Source: Author's calculations with the data from MDS.

With the data from the National Demographic Census of 2010 of the Brazilian Institute of Geography and Statistics ${ }^{50}$ (IBGE), I estimate the Brazilian population born between 1996 and 1998 in a total of 10,258,680. This means that around three-quarters of the individuals born in these years entered in the Single Registry at some point of their lives. In other words, they were members of an economically vulnerable family. Moreover, this emphasizes that the sample represents a big part of the country population within these birth years.

Table 2 shows the granting of BFP benefits from 2004 to 2017. The second column reports the total of different families benefited by BFP accumulated until each year. For instance, as of 2017, 31 million families were benefited by the program at least one month from 2004 until 2017. In the third column, I present the number of families that received the benefit at least in one month of each year. These columns show that the program reached its peak around 2013, which contrasts with the increasing official indexes of poverty in Brazil after this year.

I do not observe the total of families that were benefited by BFP previous to 2004, but with the total of benefited families in January of 2004, it is reasonable to assume that the BFP expansion was strong in this year.

50 Instituto Brasileiro de Geografia e Estatísica.. 
Table 2 - BFP Benefited Families over the years

\begin{tabular}{cccc}
\hline Year & $\begin{array}{c}\text { Families } \\
\text { Accumulated }\end{array}$ & $\begin{array}{c}\text { Currently } \\
\text { Benefited }\end{array}$ & $\begin{array}{c}\text { \% of } \\
\text { Total }\end{array}$ \\
\hline January 2004 & $3,598,484$ & & \\
2004 & $6,681,581$ & $6,681,581$ & 21.53 \\
2005 & $8,989,951$ & $8,969,428$ & 7.44 \\
2006 & $12,634,727$ & $12,285,626$ & 11.74 \\
2007 & $13,851,885$ & $12,326,107$ & 3.92 \\
2008 & $14,816,545$ & $12,280,090$ & 3.11 \\
2009 & $17,448,327$ & $13,914,796$ & 8.48 \\
2010 & $19,238,621$ & $14,327,731$ & 5.77 \\
2011 & $20,984,811$ & $14,592,121$ & 5.63 \\
2012 & $22,274,294$ & $14,891,010$ & 4.15 \\
2013 & $24,478,012$ & $16,347,545$ & 7.10 \\
2014 & $25,956,655$ & $15,680,465$ & 4.76 \\
2015 & $27,379,479$ & $16,075,319$ & 4.58 \\
2016 & $29,096,630$ & $15,931,219$ & 5.53 \\
2017 & $31,038,939$ & $16,020,743$ & 6.26 \\
\hline
\end{tabular}

Note: The table reports the BFP number of benefited families over the years. The second column presents the accumulated number of families at least once benefited by BFP in previous years. The third column presents the number of current benefited families each year. The last column divides the current number by the final (2017) accumulated number of benefited families. As the beneficiary families previous to 2004 are not observed, I report the number of January of that year as a proxy for the families benefited in 2003. Source: Author's calculations with the data from MDS.

Table 3 concerns the third data source of this work, where I report the numbers of the Formal Labor Market from 2002 to 2017. I observe a total of 107,251,994 distinct individuals from 2002 until 2017. Two economic phenomenons that happened in Brazil during these years come to attention. The economic growth and the formalization of the labor market are represented in this table by the sharp increase in the number of formally-employed individuals from 2002 until 2014. Afterward, the effects of the economic crisis that began in that year are also represented in this table by the decrease in the number of formally-employed individuals.

From all of the formal employees, the share that appears in the Single Registry ranges from $22 \%$ to $33 \%$ over the years. Concerning the cohorts of interest of this work, there is an underestimate of 4,839,089 ${ }^{51}$ distinct individuals that were born between 1996

51 This is an underestimate because I do not observe the individuals' birth-year in the RAIS data for the years of 2011, 2012, and 2013 . 
and 1998. It corresponds to approximately half of the 10 million residents of Brazil that were born in the same years, participating in the formal labor market at least once in this time range. Interestingly, also around half of these young individuals formally employed appear at some point in families registered from 2001 to 2017 in the Single Registry.

Furthermore, in the columns corresponding to the selected cohorts this table shows a sharp increase from 2012 to 2017. This is expected if it is considered that the cohorts of 1996, 1997, and 1998 just turned 16 years old, the legal age to be formally employed, respectively in the years of 2012, 2013, and 2014 .

Table 3 - Total of Individuals observed in the Formal Labor Market (RAIS)

\begin{tabular}{|c|c|c|c|c|}
\hline Year & $\mathrm{N}$ & $\begin{array}{c}\mathrm{N} \\
\text { in the } \mathrm{SR}\end{array}$ & $\begin{array}{l}\text { N Cohorts } \\
1996 \text { to } 1998\end{array}$ & $\begin{array}{c}\text { N Cohorts } 1996 \text { to } \\
1998 \text { in the SR }\end{array}$ \\
\hline 2002 & $34,950,398$ & $7,796,335$ & 0 & 0 \\
\hline 2003 & $35,925,326$ & $8,008,151$ & 0 & 0 \\
\hline 2004 & $37,856,735$ & $8,631,268$ & 0 & 0 \\
\hline 2005 & $40,179,150$ & $9,201,687$ & 0 & 0 \\
\hline 2006 & $42,486,868$ & $10,123,408$ & 0 & 0 \\
\hline 2007 & $45,227,446$ & $10,967,784$ & 0 & 0 \\
\hline 2008 & $48,573,811$ & $12,282,379$ & 0 & 0 \\
\hline 2009 & $50,219,948$ & $12,947,561$ & 0 & 0 \\
\hline 2010 & $53,771,613$ & $14,397,004$ & 0 & 0 \\
\hline 2011 & $56,641,168$ & $16,418,381$ & $\mathrm{~N} / \mathrm{A}$ & 0 \\
\hline 2012 & $58,738,850$ & $17,586,211$ & $\mathrm{~N} / \mathrm{A}$ & 137,712 \\
\hline 2013 & $60,450,823$ & $19,091,211$ & $\mathrm{~N} / \mathrm{A}$ & 382,494 \\
\hline 2014 & $61,492,767$ & $20,014,778$ & $1,662,430$ & 821,619 \\
\hline 2015 & $59,856,891$ & $19,567,103$ & $2,437,596$ & $1,228,197$ \\
\hline 2016 & $56,906,493$ & $18,590,272$ & $2,980,462$ & $1,492,256$ \\
\hline 2017 & $55,561,692$ & $18,713,269$ & $3,498,993$ & $1,822,894$ \\
\hline
\end{tabular}

\begin{abstract}
Note: The table presents the evolution of the number of observed individuals in the Formal Labor Market. The second column presents the total distinct individuals observed each year. The third column presents the number of individuals from the second column that are observed at least one year in the Single Registry. The following two columns present the same numbers considering only individuals that were born between 1996 and 1998. Source: Author's calculations with the data from MDS and MTE
\end{abstract}

In the previous paragraphs and descriptive statistics, it was demonstrated the evolution over time of the aggregate numbers concerning the three identified data, the Formal Labor Market, the Single Registry, and the BFP benefits payment. I believe that it is clear that the expansions of the $\mathrm{SR}$ and the BFP in the initial years were very strong, which enables us to assume that a phenomenon like this is certainly charged with a lot of randomnesses. Moreover, it should be clear that the data comprises a large part of the 
Brazilian population.

The last descriptive statistics about aggregate numbers are reported in Table 4. I put apart the interest cohorts for a moment to present some aggregate numbers of the linking procedure applied to the three datasets. I concentrate on individuals' identification documents and the specific time ranges that they appear on each data source.

Table 4 - Aggregate Statistics of the Data Linking Process

\begin{tabular}{cccccc}
\hline & SR & BFP & BFP & FLM & FLM \\
& $2012-2017$ & $2004-2017$ & 2004 & $2002-2017$ & $2012-2017$ \\
\hline SR 2012-2017 & $\mathbf{1 1 4 , 9 0 6 , 5 7 8}$ & & & & \\
BFP 2004-2017 & $28,194,877$ & $\mathbf{3 1 , 0 3 8 , 9 3 9}$ & & & \\
BFP 2004 & $5,444,694$ & $6,681,581$ & $\mathbf{6 , 6 8 1 , 5 8 1}$ & & \\
FLM 2002-2017 & $35,537,005$ & $11,285,157$ & $1,705,291$ & $\mathbf{1 0 7 , 2 5 1 , 9 9 4}$ & \\
FLM 2012-2017 & $30,313,216$ & $9,131,623$ & $1,341,976$ & $86,010,351$ & $\mathbf{8 6 , 0 1 0 , 3 5 1}$ \\
\hline
\end{tabular}

Note: This table presents statistics of the linking process of the Single Registry (SR) Formal Labor Market (FLM) and BFP Payment Records (BFP). It presents the number of individuals observed in both data sets represented in the names of the lines, and names of the columns. Each unit of the BFP data represents a family since only the head of the family appears in the payment records. For the SR and FLM, the unit is the individual. Source: Author's calculations with the data from MDS, and MTE.

In Table 4 the Single Registry (SR) numbers consider each individual of each family registered. The BFP records only comprise the head of each family, which is the person that receives directly the benefits. The Formal Labor Market data consider each different individual that appears in the labor market during the indicated periods.

From the 6.68 million heads of family that appear in BFP Payment Records of 2004, 1.24 million (18.51\%) do not appear in the SR data. Of this 1.24 million, only 80.4 thousand individuals appeared in the formal labor market after 2012. I can use this number to get an estimate of the attrition problem in this sample.

Assume for these missing heads-of-family the formal employment rate of $30 \%$, which is a magnitude close to the observed for the heads-of-family that are not missing in the SR. Then, the estimate of total missing individuals is 268 thousand (equivalent to 80.4 divided by $30 \%$ ). This represents only $4 \%$ of the individuals that received at least once the BFP benefit from 2004 to 2017. 
If I extrapolate the heads-of-family's SR disappearance rate to all family members, only $4 \%$ of the individuals that were registered before 2012 would have been excluded from the SR data. This is a relatively small attrition rate. Moreover, although I have no means to state what happened to these missing individuals, the most probable reason is that they improved a lot their economic condition so that they became non-eligible to the BFP and non-eligible to the SR, which means they were not vulnerable anymore. Under this condition, they may have been excluded by ordering it, or by getting caught by the local manager of the program. Both reasons pose a small threat to the identification of the effects of BFP exposure, but the biases in these cases are toward the underestimation of positive effects.

From the 7,628,572 individuals from selected cohorts in the SR, 1,895,925 were from families registered from 2004 to 2006 . After sampling $10 \%$ of them and applying the cleaning procedures to keep only reliable information, 149,023 individuals remain. This illustrates the quality of the three identified data. The amount of individuals lost because they were not children of the head of the family in the first SR appearance, or because of inconsistencies in the document number or other fixed characteristic, responds for only $21.4 \%$.

Table 5 shows descriptive statistics for all of the explanatory and outcome variables for the older selected cohort, formed by those that were born in the year 1996. The respective tables ${ }^{52}$ for the cohorts of 1997 and 1998 have equivalent results and could replace this one without any damage to the interpretations and arguments provided.

Table 5 - Descriptive statistics across BFP Exposure - Cohort 1996

\begin{tabular}{lccccc}
\hline & & \multicolumn{4}{c}{ BFP Exposure Level } \\
\cline { 3 - 6 } Variable & Measure & 0 & 1 & 2 & 3 \\
\hline Individuals & $\mathrm{N}$ & 3,062 & 9,416 & 20,421 & 15,584 \\
\hline Schooling & Mean & 1.96 & 2.25 & 2.36 & 2.47 \\
attained at 18 y.o. & Std. Dev. & 0.94 & 0.87 & 0.81 & 0.77 \\
& Min & 0.00 & 0.00 & 0.00 & 0.00 \\
& Max & 5.00 & 5.00 & 5.00 & 5.00 \\
\hline Formal Employed & Mean & 0.45 & 0.47 & 0.42 & 0.42
\end{tabular}

$\overline{52}$ The tables with descriptive statistics for the other cohorts are reported in the Appendix. 
Table 5 - Descriptive statistics across BFP Exposure - Cohort 1996

\begin{tabular}{|c|c|c|c|c|c|}
\hline \multirow[b]{2}{*}{ Variable } & \multirow[b]{2}{*}{ Measure } & \multicolumn{4}{|c|}{ BFP Exposure Level } \\
\hline & & 0 & 1 & 2 & 3 \\
\hline & Std. Dev. & 0.50 & 0.50 & 0.49 & 0.49 \\
\hline & Min & 0.00 & 0.00 & 0.00 & 0.00 \\
\hline & Max & 1.00 & 1.00 & 1.00 & 1.00 \\
\hline Avg. Real & Mean & 7.41 & 7.37 & 7.30 & 7.32 \\
\hline \multirow[t]{3}{*}{ Hourly Wage } & Std. Dev. & 2.16 & 2.79 & 2.47 & 2.53 \\
\hline & Min & 2.03 & 1.55 & 1.94 & 1.97 \\
\hline & Max & 30.68 & 50.33 & 47.44 & 48.71 \\
\hline \multirow[t]{4}{*}{ Years BFP Exp. } & Mean & 0.00 & 2.37 & 5.48 & 7.58 \\
\hline & Std. Dev. & 0.00 & 0.76 & 0.74 & 0.49 \\
\hline & Min & 0.00 & 1.00 & 4.00 & 7.00 \\
\hline & Max & 0.00 & 3.00 & 6.00 & 8.00 \\
\hline Age at First & Mean & 18.32 & 18.32 & 18.55 & 18.62 \\
\hline \multirow[t]{3}{*}{ Employment } & Std. Dev. & 1.47 & 1.50 & 1.46 & 1.43 \\
\hline & Min & 16.00 & 16.00 & 16.00 & 16.00 \\
\hline & Max & 21.00 & 21.00 & 21.00 & 21.00 \\
\hline \multirow{4}{*}{ Female } & Mean & 0.48 & 0.49 & 0.48 & 0.48 \\
\hline & Std. Dev. & 0.50 & 0.50 & 0.50 & 0.50 \\
\hline & Min & 0.00 & 0.00 & 0.00 & 0.00 \\
\hline & Max & 1.00 & 1.00 & 1.00 & 1.00 \\
\hline \multirow[t]{4}{*}{ White } & Mean & 0.38 & 0.36 & 0.29 & 0.29 \\
\hline & Std. Dev. & 0.49 & 0.48 & 0.45 & 0.45 \\
\hline & Min & 0.00 & 0.00 & 0.00 & 0.00 \\
\hline & Max & 1.00 & 1.00 & 1.00 & 1.00 \\
\hline \multirow[t]{4}{*}{ Migrant } & Mean & 0.43 & 0.44 & 0.41 & 0.38 \\
\hline & Std. Dev. & 0.50 & 0.50 & 0.49 & 0.49 \\
\hline & Min & 0.00 & 0.00 & 0.00 & 0.00 \\
\hline & Max & 1.00 & 1.00 & 1.00 & 1.00 \\
\hline \multirow[t]{4}{*}{ Formal Head } & Mean & 0.40 & 0.41 & 0.30 & 0.25 \\
\hline & Std. Dev. & 0.49 & 0.49 & 0.46 & 0.43 \\
\hline & Min & 0.00 & 0.00 & 0.00 & 0.00 \\
\hline & Max & 1.00 & 1.00 & 1.00 & 1.00 \\
\hline \multirow[t]{4}{*}{ Co-head } & Mean & 0.58 & 0.54 & 0.54 & 0.53 \\
\hline & Std. Dev. & 0.49 & 0.50 & 0.50 & 0.50 \\
\hline & Min & 0.00 & 0.00 & 0.00 & 0.00 \\
\hline & Max & 1.00 & 1.00 & 1.00 & 1.00 \\
\hline \multirow[t]{4}{*}{ Formal Co-head } & Mean & 0.33 & 0.31 & 0.26 & 0.24 \\
\hline & Std. Dev. & 0.47 & 0.46 & 0.44 & 0.43 \\
\hline & Min & 0.00 & 0.00 & 0.00 & 0.00 \\
\hline & Max & 1.00 & 1.00 & 1.00 & 1.00 \\
\hline \multirow{4}{*}{$\begin{array}{l}\text { Co-head Avg Real } \\
\text { Hourly Wage }\end{array}$} & Mean & 8.40 & 7.88 & 7.46 & 6.96 \\
\hline & Std. Dev. & 4.82 & 4.04 & 4.24 & 3.77 \\
\hline & Min & 2.08 & 1.50 & 1.49 & 1.84 \\
\hline & Max & 55.83 & 54.91 & 56.15 & 54.82 \\
\hline Head Avg Real & Mean & 6.37 & 6.04 & 5.91 & 5.74 \\
\hline
\end{tabular}


Table 5 - Descriptive statistics across BFP Exposure - Cohort 1996

\begin{tabular}{|c|c|c|c|c|c|}
\hline \multirow[b]{2}{*}{ Variable } & \multirow[b]{2}{*}{ Measure } & \multicolumn{4}{|c|}{ BFP Exposure Level } \\
\hline & & 0 & 1 & 2 & 3 \\
\hline \multirow{3}{*}{ Hourly Wage } & Std. Dev. & 3.50 & 2.89 & 2.99 & 3.13 \\
\hline & Min & 1.85 & 1.54 & 1.45 & 1.43 \\
\hline & Max & 43.59 & 48.66 & 51.08 & 56.66 \\
\hline \multirow[t]{4}{*}{ Head Schooling } & Mean & 2.20 & 2.12 & 1.90 & 1.88 \\
\hline & Std. Dev. & 1.20 & 1.14 & 1.13 & 1.08 \\
\hline & Min & 0.00 & 0.00 & 0.00 & 0.00 \\
\hline & Max & 5.00 & 5.00 & 5.00 & 5.00 \\
\hline \multirow[t]{4}{*}{ Co-head Schooling } & Mean & 1.96 & 1.86 & 1.65 & 1.60 \\
\hline & Std. Dev. & 1.13 & 1.11 & 1.12 & 1.09 \\
\hline & Min & 0.00 & 0.00 & 0.00 & 0.00 \\
\hline & Max & 5.00 & 5.00 & 5.00 & 5.00 \\
\hline \multirow[t]{4}{*}{ Family Size } & Mean & 3.94 & 4.12 & 4.42 & 4.53 \\
\hline & Std. Dev. & 1.35 & 1.41 & 1.58 & 1.58 \\
\hline & Min & 1.00 & 1.00 & 1.00 & 1.00 \\
\hline & Max & 13.00 & 14.00 & 16.00 & 14.00 \\
\hline \multirow[t]{4}{*}{ Munic. Density 2000} & Mean & 951.58 & 919.94 & $1,042.92$ & $1,187.86$ \\
\hline & Std. Dev. & $2,046.99$ & $1,943.48$ & $2,148.06$ & $2,199.27$ \\
\hline & Min & 0.22 & 0.19 & 0.13 & 0.16 \\
\hline & Max & $11,924.99$ & $11,924.99$ & $11,924.99$ & $11,924.99$ \\
\hline \multirow[t]{4}{*}{ Munic. Families 2000} & Mean & 229.07 & 188.43 & 204.68 & 249.94 \\
\hline & Std. Dev. & 652.93 & 505.20 & 606.92 & 637.36 \\
\hline & Min & 0.53 & 0.35 & 0.30 & 0.27 \\
\hline & Max & $3,173.50$ & $3,173.50$ & $3,173.50$ & $3,173.50$ \\
\hline \multirow{4}{*}{ Munic. Poor Fam 2000} & Mean & 0.47 & 0.46 & 0.52 & 0.52 \\
\hline & Std. Dev. & 0.20 & 0.19 & 0.21 & 0.21 \\
\hline & Min & 0.11 & 0.10 & 0.07 & 0.10 \\
\hline & Max & 0.96 & 0.93 & 0.96 & 0.93 \\
\hline Munic. Education & Mean & 4.13 & 4.13 & 3.87 & 3.87 \\
\hline \multirow{3}{*}{ Quality 2007} & Std. Dev. & 0.74 & 0.76 & 0.80 & 0.74 \\
\hline & Min & 1.80 & 1.80 & 0.90 & 1.80 \\
\hline & $\operatorname{Max}$ & 6.90 & 7.60 & 7.70 & 7.50 \\
\hline Munic. SR & Mean & 0.79 & 0.77 & 0.71 & 0.71 \\
\hline \multirow[t]{3}{*}{ Coverage 2006} & Std. Dev. & 0.25 & 0.22 & 0.23 & 0.24 \\
\hline & Min & 0.20 & 0.20 & 0.20 & 0.10 \\
\hline & Max & 3.50 & 3.50 & 3.50 & 3.50 \\
\hline
\end{tabular}

Note: This table reports descriptive statistics for each variable of the linked data for the individuals that were born in 1996, whose family was registered in the SR between 2004 and 2006. The mean of the dummy variables (Female, Migrant, Formal Head, Co-Head, and Formal Co-Head) must be interpreted as the proportion of that category in the data. The number of municipality resident families are measured in thousands. Source: Author's calculation with data from IBGE, INEP, MDS, and MTE.

Table 5 shows some interesting features of the BFP. Considering the poverty 
alleviation focus of the program, many of these statistics should be expected. Even so, this table brings many new information for the public. The most important message of this table is that the BFP seems to have been focused on the most disadvantaged families. As a consequence, the program also focused on the less developed municipalities, which tend to have a higher concentration of these families.

The average individual Schooling at the age of 18 shows a substantial and monotonic increase from the non-exposed group (1.96) to the more exposed one (2.47). Considering the poverty focus of the program and that these are unconditional averages, this is a very surprising result.

On the other hand, the table shows that the higher the level of exposure to the BFP the lower the rate of formally employed and the lower the average real hourly wage on these employments.

Since the years of BFP Exposure are divided into levels, it can be seeing in the variable Years of BFP Exposure the range and average of time of program exposure within each of the defined levels. As a consequence of the years observed in the data, the maximum possible exposure during childhood for the cohort of 1996 is Level 3, which ranges from 7 to 8 years of benefits.

The variable Female indicates that there are no substantial differences across exposure groups. The average indicates an expected result since it assumes value 1 if the individual is a female and 0 otherwise. The dummy variable that indicates white individuals shows a consistent decreasing pattern as the exposure level increases, which is consistent with the country's history of slavery and discrimination.

The last variable concerning the individual shows a non-expected result, with a slight increase in the proportion of migrants from the exposure level zero to one, but afterward it decreases until the maximum exposure level, which is consistent with the known positive selection of migrants.

The average family characteristics of the more exposed individuals show remarkable differences to the non-exposed group. The formal labor market participation of the Head 
and the Co-Head decreases from the non-exposed group to the most exposed. Another expected result is the decrease in the parents' average wages in the formal sector as the BFP exposure level increases. The same is true for the parents' schooling level. The fact that the family income considered to the BFP eligibility is per capita may explain an important part of the higher average family size for the more exposed groups.

Considering variables of the environment in which these individuals probably grew up, the municipality characteristics across the exposure groups also show interesting patterns. The more exposed individuals tend to live in municipalities that in the year 2000 had a higher incidence of poverty, and higher demographic density. Moreover, the average municipality of residence of the more exposed also presented worse education quality in 2007.

The SR Coverage ${ }^{53}$ in 2006 tend to be lower in the more exposed groups (2 and 3) than in the less exposed ones (0 and 1$)$. Considering that in this sample there is only individuals that were registered in 2006, this may represent a potential competition for the benefits since the yearly budget maybe were not sufficient for all eligible families. In other words, given that an individual is registered, its chance to get the BFP benefit is higher if its municipality registered less eligible individuals.

To summarize the most important results of these descriptive statistics, I can state that the BFP program was strongly focused on the poor families, and maybe as a consequence, focused on less developed municipalities.

Fortunately, for this work, the most important potential source of endogeneity pushes the results to being considered as lower bounds. The total income of the families at the moment of SR registration is not observed, but the Formal Labor Market income of the parents during the individuals' childhood suggests a negative relation between real income and program exposure. The same is true for the observed Schooling Level attained by the parents.

53 Defined by the ratio between the number of registered individuals in 2006 and an estimate of poor individuals with the Demographic Census of 2000. 


\subsection{Results on early adults Schooling and Labor Outcomes}

In this chapter, I report in separate sections the results obtained for the effects of BFP Exposure on the Schooling, the FLM participation, and on the Earnings outcomes. For the former two outcomes, the data applied is the cross-section derived from the panel data from 2002 to 2017. For the last outcome, the applied data comprises the years 2012 to 2017. It covers the first year in which each of the selected cohorts has their formal wages observed.

Although the treatment is a fixed childhood characteristic of these young adults, it is worth to take advantage of several years of labor market data, to avoid to introduce errors in the earnings measure. Since the composition of the cohorts by BFP exposure groups may not be proportionally represented over the years ${ }^{54}$, macroeconomic fluctuations could be correlated to this unbalance, which justifies the inclusion of year and cohort fixed effects. Differences in the cost of living in different places are assumed to be controlled by the municipalities' initial conditions.

Each subsection begins reporting the table with the main results. Then, I report the estimates of heterogeneous effects for specific groups selected from the complete sample. Finally, I present the robustness checks, changing the rule of sample selection, and changing the identification strategy to the instrumental variable approach, in the cases of the outcomes of FLM participation and Earnings.

\subsubsection{Schooling}

In this section, I report the results for the effects of BFP Exposure during childhood on the Schooling Level, obtained through the Maximum Likelihood estimation of the Ordered Logit model.

The dependent variable of the model is given by the Schooling observed when the individual is 18 years old. I computed the Schooling Level from 0 to 5, following the

\footnotetext{
${ }_{54}$ For instance, the more exposed may postpone their labor market participation if they choose to stay
} more years studying. 
procedures described in the previous section. The results of the estimates of equation 3.1 are presented in Table 6.

Table 6 - BFP Exposure effects on the Schooling Level

\begin{tabular}{|c|c|c|c|}
\hline & \multicolumn{3}{|c|}{ Regression } \\
\hline & $(1)$ & $(2)$ & $(3)$ \\
\hline BFP Exp 1 & $\begin{array}{c}0.664^{* * *} \\
(0.034)\end{array}$ & $\begin{array}{c}0.642^{* * *} \\
(0.034)\end{array}$ & $\begin{array}{c}0.698^{* * *} \\
(0.035)\end{array}$ \\
\hline BFP Exp 2 & $\begin{array}{c}0.836^{* * *} \\
(0.032)\end{array}$ & $\begin{array}{c}0.829^{* * *} \\
(0.032)\end{array}$ & $\begin{array}{c}0.913^{* * *} \\
(0.033)\end{array}$ \\
\hline BFP Exp 3 & $\begin{array}{c}1.094^{* * *} \\
(0.031)\end{array}$ & $\begin{array}{c}0.975^{* * *} \\
(0.032)\end{array}$ & $\begin{array}{c}1.075^{* * *} \\
(0.033)\end{array}$ \\
\hline BFP Exp 4 & $\begin{array}{c}1.182^{* * *} \\
(0.038)\end{array}$ & $\begin{array}{c}0.868^{* * *} \\
(0.039)\end{array}$ & $\begin{array}{c}0.997^{* * *} \\
(0.040)\end{array}$ \\
\hline Cohort 1997 & & $\begin{array}{c}0.370^{* * *} \\
(0.014)\end{array}$ & $\begin{array}{c}0.330^{* * *} \\
(0.014)\end{array}$ \\
\hline Cohort 1998 & & $\begin{array}{c}0.522^{* * *} \\
(0.015)\end{array}$ & $\begin{array}{c}0.469^{* * *} \\
(0.015)\end{array}$ \\
\hline Female & & $\begin{array}{c}0.525^{* * *} \\
(0.011)\end{array}$ & $\begin{array}{c}0.535^{* * *} \\
(0.011)\end{array}$ \\
\hline White & & $\begin{array}{c}0.085^{* * *} \\
(0.012)\end{array}$ & $\begin{array}{c}0.004 \\
(0.014)\end{array}$ \\
\hline Migrant & & $\begin{array}{c}0.086^{* * *} \\
(0.011)\end{array}$ & $\begin{array}{c}0.036^{* * *} \\
(0.012)\end{array}$ \\
\hline Co-Head & & & $\begin{array}{c}0.118^{* * *} \\
(0.019)\end{array}$ \\
\hline Formal Co-Head & & & $\begin{array}{c}0.213^{* * *} \\
(0.054)\end{array}$ \\
\hline Formal Head & & & $\begin{array}{c}0.202^{* * *} \\
(0.055)\end{array}$ \\
\hline Head Avg Wage & & & $\begin{array}{c}-0.203^{* * *} \\
(0.031)\end{array}$ \\
\hline Co-head Avg Wage & & & $\begin{array}{c}-0.112^{* * *} \\
(0.028)\end{array}$ \\
\hline Head Schooling & & & $\begin{array}{c}0.230^{* * *} \\
(0.005)\end{array}$ \\
\hline Co-head Schooling & & & $\begin{array}{c}0.067^{* * *} \\
(0.007)\end{array}$ \\
\hline Family Size & & & $0.051^{* * *}$ \\
\hline
\end{tabular}


Table 6 - BFP Exposure effects on the Schooling Level

\begin{tabular}{|c|c|c|c|}
\hline & \multicolumn{3}{|c|}{ Regression } \\
\hline & $(1)$ & $(2)$ & $(3)$ \\
\hline & & & $(0.015)$ \\
\hline Sq. Family Size & & & $\begin{array}{c}-0.009^{* * *} \\
(0.001)\end{array}$ \\
\hline Mun. Density 2000 & & & $\begin{array}{c}0.016^{* * *} \\
(0.004)\end{array}$ \\
\hline Mun. Families 2000 & & & $\begin{array}{c}-0.033^{* * *} \\
(0.006)\end{array}$ \\
\hline Mun. \% Poor Fam. 2000 & & & $\begin{array}{c}0.497^{* * *} \\
(0.026)\end{array}$ \\
\hline Mun. Educ. Quality 2007 & & & $\begin{array}{c}1.273^{* * *} \\
(0.042)\end{array}$ \\
\hline Alpha 1 & $\begin{array}{c}-4.0842^{* * *} \\
(0.0451)\end{array}$ & $\begin{array}{c}-3.6426^{* * *} \\
(0.0460)\end{array}$ & $\begin{array}{c}-2.1034^{* * *} \\
(0.0901)\end{array}$ \\
\hline Alpha 2 & $\begin{array}{c}-1.3513^{* * *} \\
(0.0306)\end{array}$ & $\begin{array}{c}-0.8983^{* * *} \\
(0.0320)\end{array}$ & $\begin{array}{c}0.6438^{* * *} \\
(0.0835)\end{array}$ \\
\hline Alpha 3 & $\begin{array}{c}0.8388^{* * *} \\
(0.0303)\end{array}$ & $\begin{array}{c}1.3367^{* * *} \\
(0.0319)\end{array}$ & $\begin{array}{c}2.9518^{* * *} \\
(0.0838)\end{array}$ \\
\hline Alpha 4 & $\begin{array}{c}3.5968^{* * *} \\
(0.0322)\end{array}$ & $\begin{array}{c}4.1457^{* * *} \\
(0.0341)\end{array}$ & $\begin{array}{c}5.8336 \\
(0.0852)\end{array}$ \\
\hline Alpha 5 & $\begin{array}{c}7.8442^{* * *} \\
(0.0962)\end{array}$ & $\begin{array}{c}8.40^{* * *} \\
(0.0968)\end{array}$ & $\begin{array}{c}10.1068^{* * *} \\
(0.1247)\end{array}$ \\
\hline Observations & 118,285 & 118,221 & 116,876 \\
\hline Log-likelihood & $-136,011.4$ & $-134,102.1$ & $-129,939.4$ \\
\hline
\end{tabular}

Statistical Significance: ${ }^{*} \mathrm{p}<0.1 ;{ }^{* *} \mathrm{p}<0.05 ;{ }^{* * *} \mathrm{p}<0.01$

Note: This table presents the Maximum Likelihood estimates of the coefficients of the Ordered Logit model for the Schooling level attained in early adulthood. The interest variables are the BFP Exposure level dummies. The BFP level of exposure zero is the reference category. From Column (1) to Column (2) the covariates of the individuals' characteristics are introduced. From Column (2) to Column (3) I add covariates with characteristics of family background, and characteristics of the residence municipality of the time of the individual's childhood. The Alpha coefficients represent the $\alpha$ 's presented in equations of the methodology section. Source: Author's calculations with the data from MDS, MTE, IBGE, and INEP.

Interestingly, the BFP Exposure coefficients do not change much from the regression without control variables (1) to the regression controlled for individual characteristics 
(2), and the regression with individual, family and municipality characteristics (3). The latter is the baseline model and shows that the coefficients of the BFP Exposure levels are positive, and increase from level of exposure 1 until level 3. The coefficient of the exposure level 4 is only smaller than level 3. This shows a potential maximum of the BFP effects on schooling occurring around 7 to 9 years of program exposure during childhood.

Regression (3) shows that things appear to be improving, as the younger cohorts have higher schooling levels than the older one, formed by those that were born in 1996 . Females appear with higher schooling levels than males. Furthermore, the migrant positive selection, famous in the literature, is also present with the positive coefficients estimated in regressions (2) and (3).

The family background variables show another interesting set of results. The individual schooling seem to be higher if the Co-head is present in its family composition. The Co-head and Head schooling level also appear as positive influences on the children, while the latter seems to matter less than the former. Finally, to be born in a bigger family seems to be good to increase schooling attainment, but when it gets too big, the effect may be negative, as is shown by the coefficient of the variable with the square of the individual's family size.

External effects, captured by the municipality variables, are also shown to be important. As expected, the municipality Index of Education Quality of 2007 has a positive influence on the individual schooling attained at the age of 18 years old. Moreover, to be a resident of a municipality with a higher population density and smaller population, has also positive effects. Surprisingly, individuals from municipalities that had higher proportion of poverty in 2000 have a higher probability of attaining higher schooling levels.

Considering the baseline model, Regression (3) with the full set of control variables, I predicted the probability density of BFP Exposure within each Schooling level, through Equation 3.5. I set the control variables to the values reported in Table 7. 
Table 7 - Conditional Probability Prediction

Values assumed for the Control Variables

\begin{tabular}{cc}
\hline Control Variable & Value \\
\hline Cohort & 1998 \\
Female & 0 \\
White & 0 \\
Migrant & 0 \\
Co-head & 1 \\
Formally Employed Head & 1 \\
Formally Employed Co-head & 1 \\
Avg. Hourly Wage Head & 6.14 \\
Avg. Hourly Wage Co-head & 7.65 \\
Schooling Level Head & 1.98 \\
Schooling Level Co-head & 1.70 \\
Family Size at 17 y.o. & 4.36 \\
Municipality Density 2000 & $1,022.61$ \\
Munic. Families 2000 & $204,273.30$ \\
Munic. \% Poor Families 2000 & 50.99 \\
Munic. Educ. Quality Index 2007 & 3.93 \\
\hline
\end{tabular}

Note: The table presents the values assumed for the covariates for the estimation of the Conditional Probability of attaining each level of Schooling within each BFP exposure level. Source: Author's calculations with the data from MDS, MTE, IBGE, and INEP.

The resulting probabilities are then reported in Table 8. The values chosen for the continuous variables were simply the sample means. For the discrete variables, I made arbitrary choices. However, the direction of the results presented remains unchanged whichever values one defines, and the magnitude changes only slightly in the neighborhood of them.

The predicted probabilities suggest, for example, that an average individual with the given characteristics would have a $28.2 \%$ chance of completing the middle-school (Schooling Level 3) if it was not exposed to the BFP during its childhood, while a $48.2 \%$ if exposed for 10 years (Exposure Level 4). 
Table 8 - Schooling Predicted Conditional Distributions

\begin{tabular}{|c|c|c|c|c|c|}
\hline $\begin{array}{l}\text { BFP Exp. } \\
\text { Level }\end{array}$ & $\begin{array}{c}\text { Schooling } \\
\text { Level }\end{array}$ & $\begin{array}{l}\text { Prob. within } \\
\operatorname{BFP}(\%)\end{array}$ & $\begin{array}{c}\text { Lower } 95 \% \\
\text { C.I. }\end{array}$ & $\begin{array}{c}\text { Upper } 95 \% \\
\text { C.I. }\end{array}$ & $\begin{array}{l}\text { Prob. within } \\
\text { Schooling (\%) }\end{array}$ \\
\hline 0 & 0 & 1.42 & 1.26 & 1.58 & 38.13 \\
\hline 0 & 1 & 16.95 & 15.73 & 18.18 & 35.46 \\
\hline 0 & 2 & 50.98 & 50.33 & 51.64 & 24.57 \\
\hline 0 & 3 & 28.22 & 26.54 & 29.91 & 13.13 \\
\hline 0 & 4 & 2.38 & 2.17 & 2.59 & 9.29 \\
\hline 0 & 5 & 0.03 & 0.03 & 0.04 & 8.98 \\
\hline 1 & 0 & 0.71 & 0.65 & 0.78 & 19.10 \\
\hline 1 & 1 & 9.36 & 8.89 & 9.83 & 19.58 \\
\hline 1 & 2 & 42.89 & 42.00 & 43.78 & 20.67 \\
\hline 1 & 3 & 42.30 & 41.18 & 43.41 & 19.68 \\
\hline 1 & 4 & 4.67 & 4.41 & 4.93 & 18.22 \\
\hline 1 & 5 & 0.07 & 0.06 & 0.08 & 18.04 \\
\hline 2 & 0 & 0.58 & 0.53 & 0.62 & 15.43 \\
\hline 2 & 1 & 7.71 & 7.35 & 8.07 & 16.13 \\
\hline 2 & 2 & 39.31 & 38.44 & 40.18 & 18.95 \\
\hline 2 & 3 & 46.59 & 45.63 & 47.56 & 21.67 \\
\hline 2 & 4 & 5.72 & 5.44 & 6.01 & 22.33 \\
\hline 2 & 5 & 0.09 & 0.07 & 0.10 & 22.36 \\
\hline 3 & 0 & 0.49 & 0.45 & 0.53 & 13.13 \\
\hline 3 & 1 & 6.64 & 6.35 & 6.94 & 13.90 \\
\hline 3 & 2 & 36.45 & 35.60 & 37.29 & 17.57 \\
\hline 3 & 3 & 49.66 & 48.80 & 50.51 & 23.10 \\
\hline 3 & 4 & 6.66 & 6.36 & 6.97 & 25.99 \\
\hline 3 & 5 & 0.10 & 0.08 & 0.12 & 26.30 \\
\hline 4 & 0 & 0.53 & 0.48 & 0.58 & 14.20 \\
\hline 4 & 1 & 7.14 & 6.75 & 7.53 & 14.94 \\
\hline 4 & 2 & 37.84 & 36.81 & 38.88 & 18.24 \\
\hline 4 & 3 & 48.20 & 47.10 & 49.30 & 22.42 \\
\hline 4 & 4 & 6.19 & 5.84 & 6.54 & 24.16 \\
\hline 4 & 5 & 0.09 & 0.08 & 0.11 & 24.32 \\
\hline
\end{tabular}

Note: The table presents the predicted probability of attaining a given Schooling level conditional on the control variables assuming the values reported in Table 7, and the BFP Exposure level. For the covariates considered in the logarithm scale in the models (parents' wages and municipality characteristics), I applied the log transformation on the values reported in Table 7. The 95\% Lower and Upper Confidence Intervals estimated through Delta Method are also reported. The last column reports the schooling conditional distribution over the BFP exposure, in the hypothetical scenario in which all BFP exposure levels have the same unconditional probability. Source: Author's calculations with the data from MDS, MTE, IBGE, and INEP.

The results of Table 8 can be seen in Figure 1, which presents the predicted 
distribution of the BFP Exposure for each Schooling level, and Figure 2, which represents the predicted distribution of Schooling for each BFP Exposure level. Both distributions are conditioned on the values defined for the covariates.

Figure 1 - Predicted Distribution of the BFP Exposure within Schooling Level

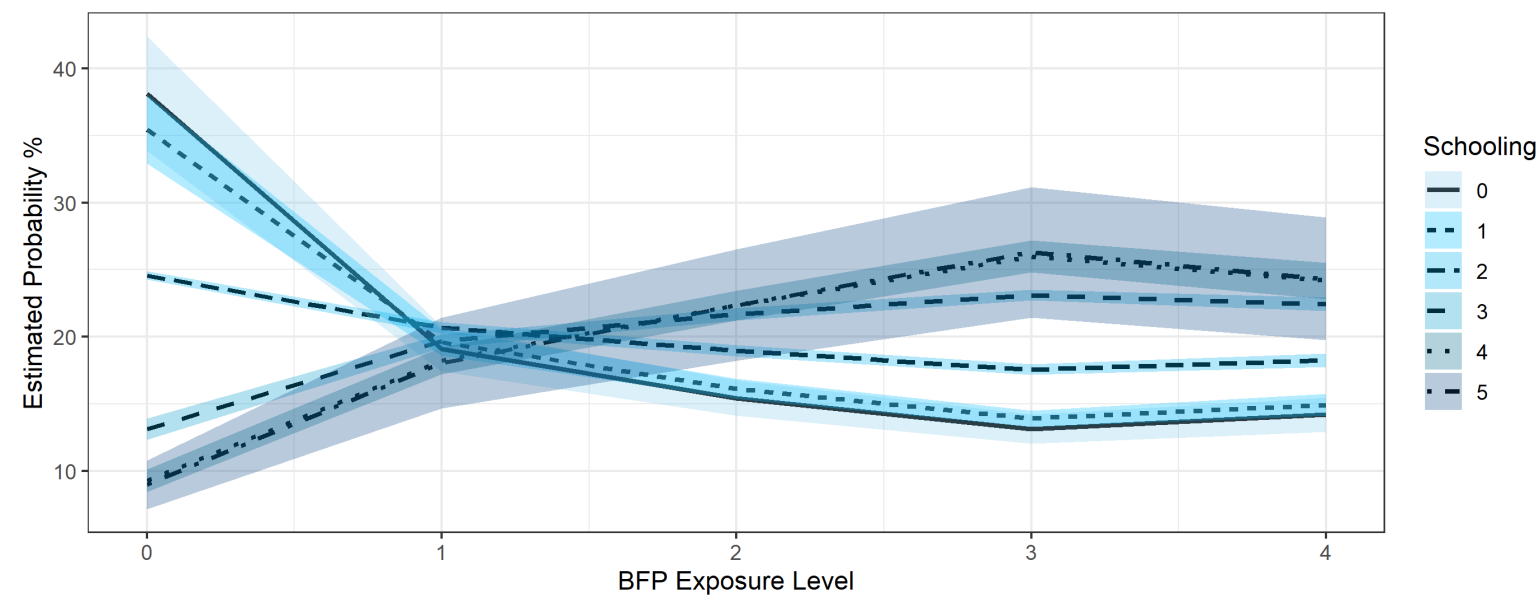

Note: The figure represents the distribution and 95\% Confidence Intervals of the BFP Exposure level within each Schooling Level, considering the hypothetical scenario where each exposure level has the same unconditional probability. Source: Author's calculations with the data from MDS, MTE, IBGE, and INEP.

The graph reported in Figure 1 uses the last column of the table of predicted probabilities, which was created with a hypothetical scenario where the groups of BFP Exposure have the same size with the covariates fixed in the values described. This normalization allows to analyze better the results reported in this table. The most important point here is that it becomes clear that the higher (lower) levels of Schooling concentrate probability mass on higher (lower) levels of BFP Exposure individuals, with the level 3 appearing as a potential maximum (minimum). The confidence intervals were obtained applying the same normalization factor on each BFP and Schooling combination value.

Figure 2 shows another point of view, i.e., the probability density of Schooling within each BFP Exposure level. This graph shows the right-shift in Schooling distribution for higher levels of exposure. Another important remark is that, although the Figure 1 graph shows strong results for tertiary education studies (level 5), this level is relatively rare for the low-income population, which concentrates probability on lower schooling levels (2 and 3). 
These figures represent another feature of the estimated coefficients, as I observe that the program exposure levels 2, 3 and 4, maybe are not so different among them, but are different than the non-exposed group, and the less exposed, level 1.

Figure 2 - Predicted Distribution of the Schooling within BFP Exposure Level

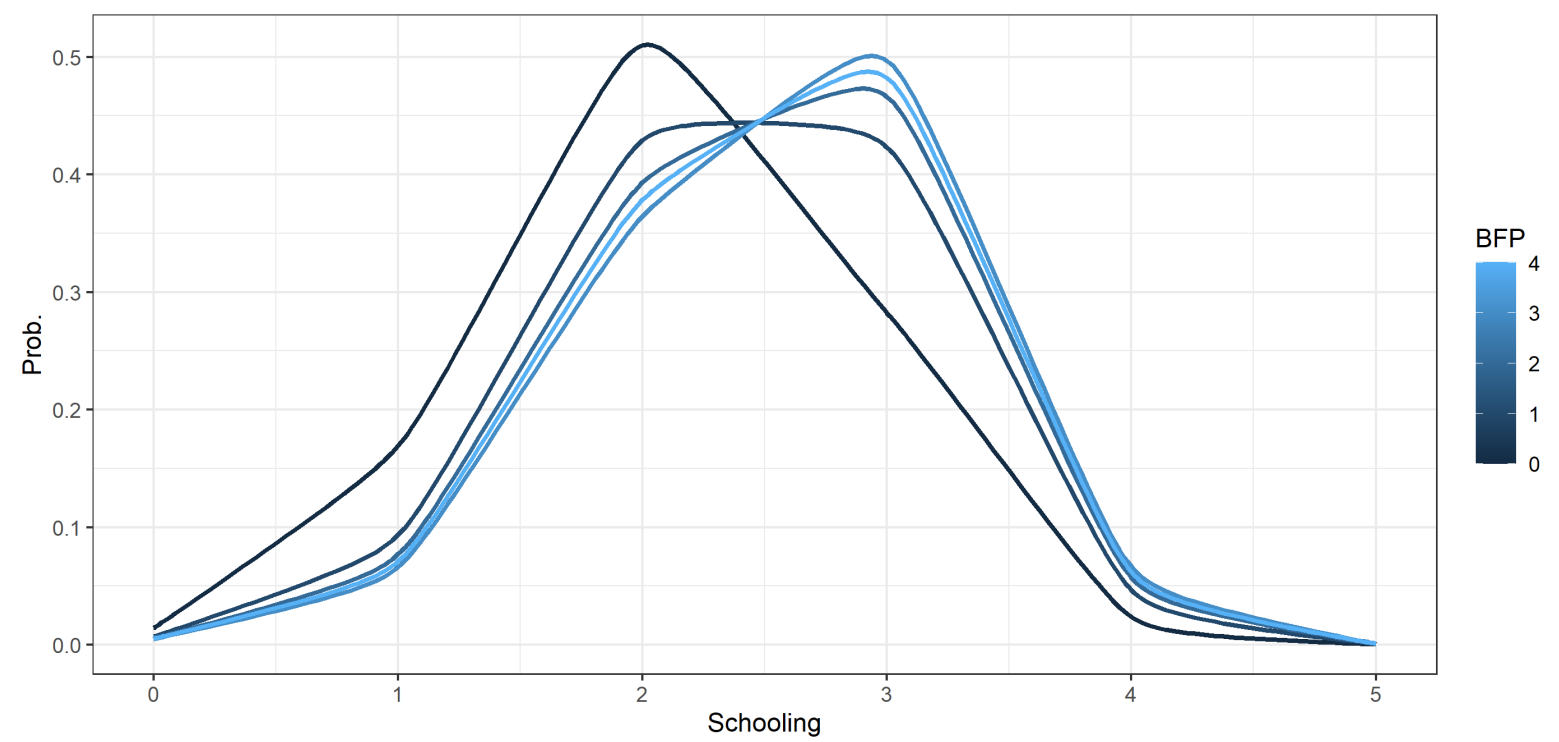

Note: The figure represents the distribution of the Schooling level within each BFP Exposure Level. Higher levels of exposure are represented in lighter shades. Although the Schooling levels are discrete, I chose to represent the results in continuous curves for easier visualization.

The next reported results concern some heterogeneous effects investigation and robustness tests, to compare with the baseline specification, the regression 3 of Table 6 . First, Table 9 reports the regressions for distinct samples, considering some specific groups of individuals by demographics, family background, or municipality characteristics ${ }^{55}$.

Regression (1) of Table 9 considers only the women of the sample. This sample allows to check if, for example, the fertility decision can produce different effects of the BFP on the Schooling. On the other hand, regression (2) considers only men. Comparing both samples' results, I can state that the effects of the program exposure on the long-term schooling level are stronger for males than females. Nonetheless, both present positive and increasing coefficients until the BFP exposure level 3.

55 The predicted probability considering a hypothetical average individual for each heterogeneous sample is presented in Tables 21, 22, 23, 24, 25, and 26 of the Appendix. 
Table 9 - Heterogeneous Effects on Schooling Level at 18 y.o.

\begin{tabular}{|c|c|c|c|c|c|}
\hline \multirow{3}{*}{ BFP Exp 1} & \multicolumn{5}{|c|}{ Regression } \\
\hline & $(1)$ & $(2)$ & (3) & $(4)$ & $(5)$ \\
\hline & $\begin{array}{c}0.594^{* * *} \\
(0.050)\end{array}$ & $\begin{array}{c}0.795^{* * *} \\
(0.048)\end{array}$ & $\begin{array}{c}0.544^{* * *} \\
(0.088)\end{array}$ & $\begin{array}{c}0.743^{* * *} \\
(0.043)\end{array}$ & $\begin{array}{c}0.288^{* * *} \\
(0.081)\end{array}$ \\
\hline BFP Exp 2 & $\begin{array}{c}0.823^{* * *} \\
(0.047)\end{array}$ & $\begin{array}{c}0.995^{* * *} \\
(0.046)\end{array}$ & $\begin{array}{c}0.685^{* * *} \\
(0.084)\end{array}$ & $\begin{array}{c}0.971^{* * *} \\
(0.040)\end{array}$ & $\begin{array}{c}0.480^{* * *} \\
(0.079)\end{array}$ \\
\hline BFP Exp 3 & $\begin{array}{c}0.970^{* * *} \\
(0.047)\end{array}$ & $\begin{array}{c}1.174^{* * *} \\
(0.046)\end{array}$ & $\begin{array}{c}0.891^{* * *} \\
(0.085)\end{array}$ & $\begin{array}{c}1.098^{* * *} \\
(0.040)\end{array}$ & $\begin{array}{c}0.734^{* * *} \\
(0.078)\end{array}$ \\
\hline BFP $\operatorname{Exp} 4$ & $\begin{array}{c}0.936^{* * *} \\
(0.059)\end{array}$ & $\begin{array}{c}1.057^{* * *} \\
(0.056)\end{array}$ & $\begin{array}{c}0.690^{* * *} \\
(0.118)\end{array}$ & $\begin{array}{c}1.070^{* * *} \\
(0.050)\end{array}$ & $\begin{array}{c}0.528^{* * *} \\
(0.095)\end{array}$ \\
\hline Observations & 55,649 & 61,227 & 10,662 & 78,238 & 20,358 \\
\hline \multicolumn{6}{|c|}{$\begin{array}{l}\text { Statistical Significance: }{ }^{*} \mathrm{p}<0.1 ;^{* *} \mathrm{p}<0.05 ;{ }^{* * *} \mathrm{p}<0.01 \\
\text { Note: This table presents the Maximum Likelihood estimates of the } \\
\text { Ordered Logit mode for the Schooling level attained by young adults, } \\
\text { with the interest dummy variables representing the levels of BFP Exposure, } \\
\text { for different samples. The sample of Column (1) considers only the girls, } \\
\text { and Column (2) only the boys. The sample of the regression of Column (3) } \\
\text { selects only the children of parents with at least one formal employment } \\
\text { during individuals childhood. Column (4) considers individuals from small } \\
\text { cities ( }<50,000 \text { families in } 2000) \text {, while Column (5) considers individuals } \\
\text { from large cities ( }>200,000 \text { families in } 2000) \text {. Source: Author's calculation } \\
\text { with data from IBGE, INEP, MDS, and MTE. }\end{array}$} \\
\hline
\end{tabular}

Regression (3) selects only individuals whose parents appeared at least once in the Formal Labor Market during their childhood. It is interesting to note that coefficients have a slightly smaller magnitude at all levels. This result makes sense if one thinks that the program may lose importance the better the family economic conditions are. Although many poor families of the country are excluded, with this sample I can control much better for income selection to the program because I observe the average wage of all parents during individuals childhood.

The regressions (4) and (5) consider samples of families that live, respectively, in small and large municipalities. This is an important heterogeneity supported by Urban and Regional Economics literature since the dynamics, quality of schools, and opportunities in the labor market may considerably vary with the city size. I defined small municipalities as those with less than 50,000 resident families in the Demographic Census of 2000. On the other hand, large municipalities are defined by those with more than 200,000 resident 
families.

From the sample with small to the sample with large municipalities I observe a sharp drop in the coefficients of all the BFP exposure levels. However, the positive and increasing effects (until level 3) remains unchanged. This result may suggest that larger cities, which on average are denser and richer, can potentially provide more public schools, with better quality and closer to the families, so that the BFP makes less difference on the school attendance opportunity costs.

In Table 10 I turn to robustness analyses and report the results of the estimates for alternative approaches. I consider a different rule to define the sample of interest and apply alternative measures of the interest variables of program exposure.

Table 10 - Robustness tests of the Effects on Schooling Level

\begin{tabular}{lccc}
\hline & \multicolumn{3}{c}{ Regression } \\
\cline { 2 - 4 } & $(1)$ & $(2)$ & $(3)$ \\
\hline Years of BFP & $0.209^{* * *}(0.009)$ & & \\
Sq. Years of BFP & $-0.012^{* * *}$ & & \\
& $(0.001)$ & & \\
BFP Exp 1 & & $0.642^{* * *}$ & $0.316^{* * *}$ \\
& & $(0.063)$ & $(0.064)$ \\
BFP Exp 2 & $0.665^{* * *}$ & $0.353^{* * *}$ \\
& & $(0.061)$ & $(0.061)$ \\
BFP Exp 3 & & $1.097^{* * *}$ & $0.416^{* * *}$ \\
& & $(0.058)$ & $(0.060)$ \\
BFP Exp 4 & & $0.930^{* * *}$ & $0.389^{* * *}$ \\
& & $(0.067)$ & $(0.067)$ \\
\hline Observations & & 41,477 & 66,924 \\
\hline
\end{tabular}

Statistical Significance: ${ }^{*} \mathrm{p}<0.1 ;{ }^{* *} \mathrm{p}<0.05 ;{ }^{* * *} \mathrm{p}<0.01$

Note: This table presents the coefficients of the robustness tests, estimating the Ordered Logit changing the interest variable definition to continuous, and introducing its squared term. In Column (2) I select the individuals from families registered in 2004. Column (3) estimates use only the individuals that still receive the BFP, whether from its initial family or on their own new family. Source: Author's calculation with data from IBGE, INEP, MDS, and MTE.

Regression (1) considers alternative measures of BFP Exposure, changing from the 
defined levels to the Years of Exposure and its squared term. In this alternative definition, both features of the baseline specification results are maintained. There is a positive effect and increasing until 8.7 years of exposure, when the parabola reaches its maximum. The effect would be positive until 17.4 years of exposure, which is completely out of the sample because the maximum possible exposure during childhood is 10 years.

The regression 2 throws away an important part of the BFP Exposure variation, by considering only individuals of families registered in 2004. This procedure guarantee that all families got registered in the SR of the municipality in the same year. Thus, the remaining variation conditioned on all control variables occurs from one municipality to the other. From those municipalities with the same poverty level, in the ones that more families were registered, the chance of each family to be granted with the BFP was lower. This argument is supported by the program rule that prioritizes municipalities with lower current benefit coverage. Even exploring less variation, the positive effect of the exposure remains.

Regression (3) of Table 10 considers a potential source of bias in the estimates of the baseline model, and select only the still treated individuals. If the more exposed families tend to update more the SR information, the schooling level of the more exposed would naturally tend to be higher because the schooling attained can not reduce over time. This bias can occur because updating the SR information each two years is a condition to keep the family receiving the benefits. On the other hand, disregarding the individuals that improved their livelihood and are not in the program anymore may induce even worst biases in the other direction. In any case, the positive and increasing effects of BFP exposure until level 3 remain, but the magnitude of the coefficients suffers a substantial reduction in this sub-sample.

The baseline, heterogeneity, and robustness results altogether lead us to the same conclusion. Some groups or specifications may point to stronger of softer results, but all point to positive effects of the BFP time of exposure during childhood on the observed early adulthood schooling level. 


\subsubsection{Formal Labor Market Participation}

This section presents the results for the first Labor Market outcome, the probability of participating in the Formal Labor Market. I present the baseline specification results and predict the variation in the probability over the program exposure measure for a representative individual. Then, I proceed to the investigation of heterogeneous effects and present some robustness checks, including the alternative identification strategy through an instrumental variable approach.

In Table 11 I report the estimated coefficients and standard errors of the Logit regressions given by equation 3.6 of the methodology section. Each column represents a different regression, with a different set of control variables.

Table 11 - Formal Labor Market Participation - Logit

\begin{tabular}{|c|c|c|c|}
\hline & \multicolumn{3}{|c|}{ Regression } \\
\hline & $(1)$ & $(2)$ & $(3)$ \\
\hline BFP Exp. 1 & $\begin{array}{c}0.053^{*} \\
(0.028)\end{array}$ & $\begin{array}{c}0.076^{* * *} \\
(0.029)\end{array}$ & $\begin{array}{l}0.078^{* *} \\
(0.031)\end{array}$ \\
\hline BFP Exp. 2 & $\begin{array}{c}-0.049^{*} \\
(0.026)\end{array}$ & $\begin{array}{l}-0.019 \\
(0.027)\end{array}$ & $\begin{array}{c}0.140^{* * *} \\
(0.029)\end{array}$ \\
\hline BFP Exp. 3 & $\begin{array}{c}-0.345^{* * *} \\
(0.026)\end{array}$ & $\begin{array}{c}-0.156^{* * *} \\
(0.027)\end{array}$ & $\begin{array}{c}0.175^{* * *} \\
(0.029)\end{array}$ \\
\hline BFP Exp 4 & $\begin{array}{c}-0.826^{* * *} \\
(0.037)\end{array}$ & $\begin{array}{c}-0.189^{* * *} \\
(0.039)\end{array}$ & $\begin{array}{c}0.183^{* * *} \\
(0.041)\end{array}$ \\
\hline Cohort 1997 & & $\begin{array}{c}-0.391^{* * *} \\
(0.014)\end{array}$ & $\begin{array}{c}-0.491^{* * *} \\
(0.014)\end{array}$ \\
\hline Cohort 1998 & & $\begin{array}{c}-0.913^{* * *} \\
(0.015)\end{array}$ & $\begin{array}{c}-1.084^{* * *} \\
(0.016)\end{array}$ \\
\hline Female & & $\begin{array}{c}-0.304^{* * *} \\
(0.011)\end{array}$ & $\begin{array}{c}-0.342^{* * *} \\
(0.012)\end{array}$ \\
\hline White & & $\begin{array}{c}0.593^{* * *} \\
(0.012)\end{array}$ & $\begin{array}{c}0.138^{* * *} \\
(0.014)\end{array}$ \\
\hline Migrant & & $\begin{array}{c}0.015 \\
(0.012)\end{array}$ & $\begin{array}{c}0.079^{* * *} \\
(0.013)\end{array}$ \\
\hline Co-head & & & $\begin{array}{c}-0.135^{* * *} \\
(0.022)\end{array}$ \\
\hline Formal Co-head & & & $\begin{array}{c}0.182^{* * *} \\
(0.055)\end{array}$ \\
\hline
\end{tabular}


Table 11 - Formal Labor Market Participation - Logit

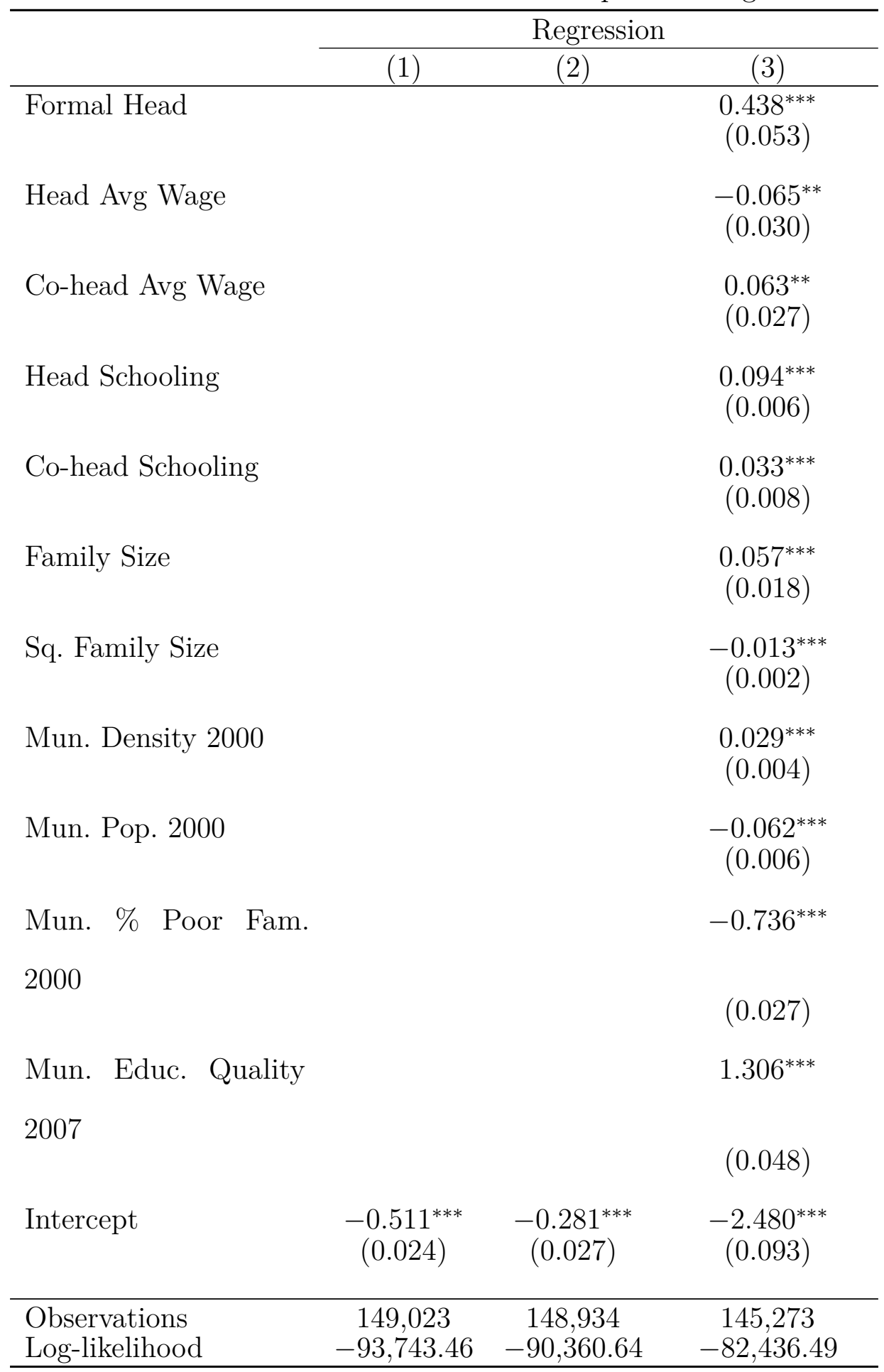

Statistical Significance: ${ }^{*} \mathrm{p}<0.1{ }^{* *} \mathrm{p}<0.05{ }^{* * *} \mathrm{p}<0.01$

Note: This table reports the Maximum Likelihood estimates of the Logit model for the Formal Labor Market Participation probability. The interest variables are the BFP Exposure level dummies. The BFP level of exposure zero is the reference category. From Column (1) to Column (2) the covariates with the individuals' characteristics are introduced. From Column (2) to Column (3) I add covariates with characteristics of family background, and characteristics of the residence municipality of the time of the individual's childhood. Source: Author's calculation with data from IBGE, INEP, MDS, and MTE. 
Contrasting with the results for the schooling outcome, controlling the regressions for the covariates seem to play an important role in the Formal Labor Market Participation. From regression (1) to regression (3) all the coefficients of the dummy variables for the program exposure levels increase. The baseline model, regression (3), shows the increase at decreasing rate effect of the program exposure on FLM Participation. Interestingly, this non-linearity was also present in the results for the Schooling outcome.

The individual characteristics show that the youngest tend to be less present in the formal labor market. The same is true considering female, non-white, and non-migrant individuals. Considering the family background variables, I observe a positive influence of having a Co-head in the family, as long as it participated in the formal labor market. The schooling of the Head and Co-head are also positive influences on the individual FLM participation. Moreover, the same effect present in the schooling results appears here, with the family size being a positive influence but at a decreasing rate.

Individuals that reside in municipalities with higher population density and a smaller population in the year 2000 have a higher probability of participating in the FLM. Municipalities with a smaller proportion of poor families in 2000 and higher Index of Education Quality in 2007 also affect positively the probability of its residents getting a formal job.

Assuming the coefficients of regression (3) reported in Table 11 I computed the conditional probability of an individual, with a given set of observed characteristics, to appear in the Formal Labor Market at least once until 2017. The formula of this probabilities is given by Equation 3.7.

For simplicity purposes, I applied the same values for the control variables when predicting the Formal Labor Market participation probability across the BFP Exposure levels that I used in the Schooling outcome section. These values are presented in Table 7 of section 4.2.1.

The Figure 3 shows that an individual with the given set of characteristics is expected to have a probability of $28.6 \%$ to get a formal job if it was exposed to the 
program during 10 years, i.e., 3.6 percentage points higher than if it was not exposed to the BFP during its childhood (25\%). The effect increases in a decreasing rate, as was also the case in the Schooling outcome.

Figure 3 - Predicted Probability of Participation in the Formal Labor Market by BFP Exposure

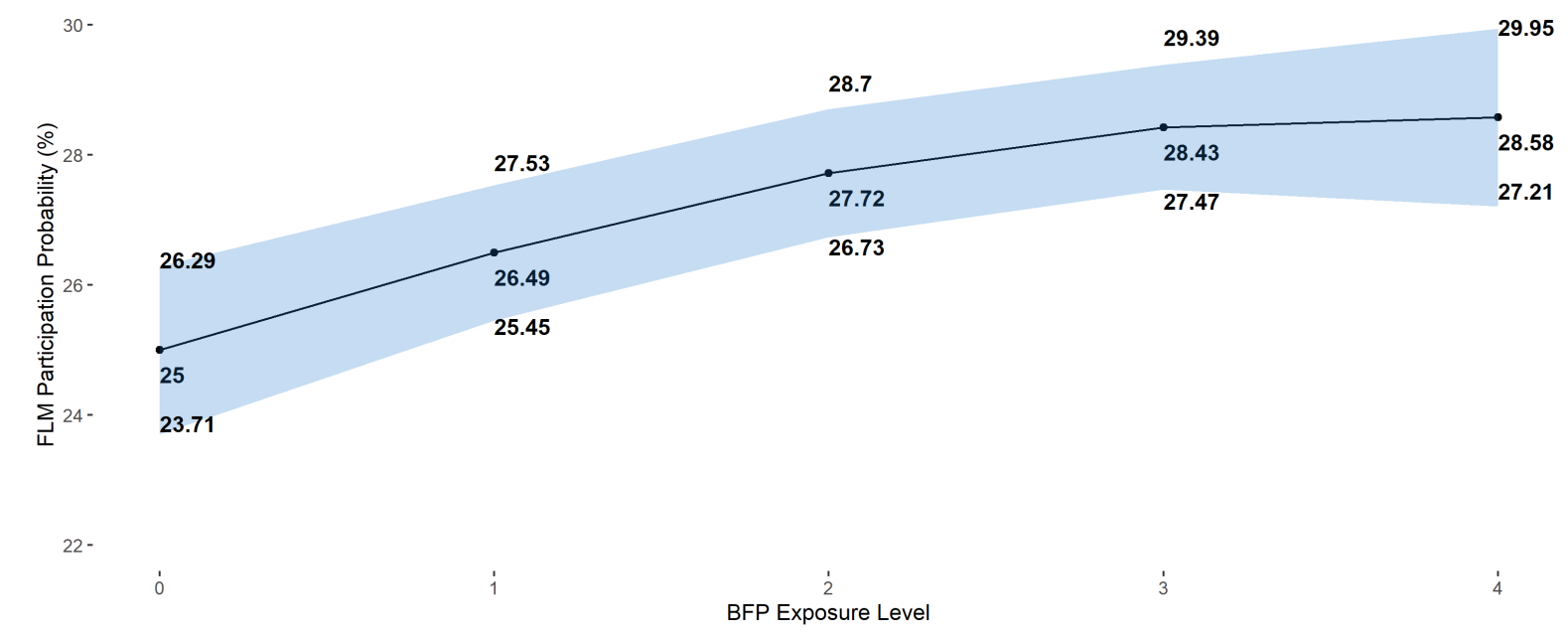

Note: The figure represents the probability and respective $95 \%$ Confidence Intervals of a representative individual to participate in the Formal Labor Market at least in one year from 2012 to 2017 for each level of BFP Exposure during its childhood. Source: Author's calculation with data from IBGE, INEP, MDS, and MTE.

This is a remarkable result and goes against many thoughts and comments made by the public common sense. With the formal sector being more productive than the informal one, this constitutes an important mechanism, in addition to the schooling increase, to foster productivity and development for the most disadvantaged groups of Brazilian society.

The next groups of results concentrate on possible heterogeneous effects ${ }^{56}$ concerning individual, family and municipality characteristics, and robustness analyses, changing the BFP exposure measure, the sample selection rule, and the econometric identification strategy.

$\overline{56}$ The predicted probability considering a hypothetical average individual for each heterogeneous sample of Table 12 is presented in Table 27 of the Appendix. 
Table 12 - BFP Exposure effects on Formal Labor Market Participation Heterogeneous Effects

\begin{tabular}{lccccc}
\hline & \multicolumn{5}{c}{ Regression } \\
\cline { 2 - 6 } & $(1)$ & $(2)$ & $(3)$ & $(4)$ & $(5)$ \\
\hline BFP Exp. 1 & 0.032 & $0.123^{* * *}$ & -0.017 & $0.109^{* * *}$ & -0.064 \\
& $(0.044)$ & $(0.042)$ & $(0.072)$ & $(0.039)$ & $(0.073)$ \\
BFP Exp. 2 & $0.080^{*}$ & $0.199^{* * *}$ & 0.075 & $0.174^{* * *}$ & 0.036 \\
& $(0.042)$ & $(0.040)$ & $(0.069)$ & $(0.037)$ & $(0.071)$ \\
BFP Exp. 3 & $0.116^{* * *}$ & $0.232^{* * *}$ & 0.050 & $0.204^{* * *}$ & -0.0003 \\
& $(0.042)$ & $(0.039)$ & $(0.070)$ & $(0.036)$ & $(0.070)$ \\
BFP Exp 4 & $0.122^{* *}$ & $0.242^{* * *}$ & 0.018 & $0.235^{* * *}$ & -0.031 \\
& $(0.061)$ & $(0.055)$ & $(0.111)$ & $(0.053)$ & $(0.092)$ \\
& & & & & \\
\hline Observations & 69,385 & 75,888 & 14,805 & 95,093 & 26,044 \\
\hline
\end{tabular}

Statistical Significance: ${ }^{*} \mathrm{p}<0.1 ;{ }^{* *} \mathrm{p}<0.05 ;{ }^{* * *} \mathrm{p}<0.01$

Note: This table presents the coefficients of the BFP Exposure levels for maximum likelihood estimates of Formal Labor Market participation probability, with the full set of control variables, selecting sub-samples. Regression (1) considers only the girls, Regression (2) only the boys. Regression (3) selects only the children of parents with at least one formal employment during individuals childhood. Regression (4) considers individuals from small cities $(<50,000$ families in 2000), while Regression (5) considers individuals from large cities ( $>200,000$ families in 2000). Source: Author's calculation with data from IBGE, INEP, MDS, and MTE.

Regression (1) selects only Females. This is justified to investigate potential differential effects of the fertility decision, and the potential effects of discrimination in the Labor Market. With the same justification, in regression (2) are reported the results considering only the males of the sample. Comparing both, the results for males are stronger than for females.

Regression (3) selects individuals whose parents (Head and Co-Head) appeared at least once in the formal labor market during their childhood. In this sample, I control much better the program selection since I observe the formal income of these parents. The drawback is that I select only the individuals with a better family background, for which the program is shown to have no effect.

The last two regressions of the heterogeneous effects concern the size of the residence municipality of each individual. The sample used in regression (4) selects only Small Municipalities, arbitrarily defined by those with less than 50,000 families 
in the Demographic Census of 2000. On the other hand, regression (5) selects only big municipalities, defined by those with more than 200,000 resident families in the Demographic Census of 2000.

These are important sources of heterogeneous effects and are supported by Urban and Regional Economics literature. Since the dynamics, quality of schools, and opportunities in the labor market may vary considerably with the city size, the effects of the BFP on the individual Formal Labor Market Participation may also vary over that.

In the next set of results of this section, I present the robustness analyses and concentrate in three additional regressions, which results are reported in Table 13.

Table 13 - BFP Exposure effects on Formal Labor Market Participation Robustness Tests

\begin{tabular}{|c|c|c|c|}
\hline & \multicolumn{3}{|c|}{ Regression } \\
\hline & (1) & $(2)$ & (3) \\
\hline Years of BFP & $\begin{array}{c}0.025^{* * *} \\
(0.009)\end{array}$ & $\begin{array}{c}0.7234^{* * *} \\
(0.008)\end{array}$ & \\
\hline Squared Years of BFP & $\begin{array}{l}-0.001 \\
(0.001)\end{array}$ & $\begin{array}{c}-0.0778^{* * *} \\
(0.008)\end{array}$ & \\
\hline BFP Exp. 1 & & & $\begin{array}{c}0.058 \\
(0.055)\end{array}$ \\
\hline BFP Exp. 2 & & & $\begin{array}{c}0.080 \\
(0.053)\end{array}$ \\
\hline BFP Exp. 3 & & & $\begin{array}{c}0.156^{* * *} \\
(0.050)\end{array}$ \\
\hline BFP Exp 4 & & & $\begin{array}{l}0.127^{* *} \\
(0.061)\end{array}$ \\
\hline Observations & 145,273 & 145,273 & 51,706 \\
\hline
\end{tabular}

Statistical Significance: ${ }^{*} \mathrm{p}<0.1 ;{ }^{* *} \mathrm{p}<0.05 ;{ }^{* * *} \mathrm{p}<0.01$

Note: This table presents the coefficients of robustness tests, always considering the full set of control variables. Column (1) reports the coefficients of the Logit model for the Formal Labor Market Participation probability, considering the Years of Exposure and its squared term as the interest variables. Column (2) presents the Instrumental Variable Probit estimates considering both interest variables as endogenous and instrumenting them by the logarithm of municipality SR Coverage in 2006, and its respective squared term. Column (3) presents the coefficients estimated considering the sample of individuals from families registered in the SR in 2004. Source: Author's calculation with data from IBGE, INEP, MDS, and MTE. 
In regression (1) are reported the coefficients of the Logit estimated with the interest variable measure redefined to the Years of Exposure instead of levels. To consider the apparent non-linear effects I also incorporate the quadratic term. The positive effect of the BFP exposure on the Formal Labor Market Participation probability remains. However, the quadratic term appears as non-significant in this specification.

Regression (2) reports the Instrumental Variable Probit coefficients, considering the municipality effort to get the families registered in the SR and the respective squared term as instruments for both the Years of BFP and Squared Years of BFP exposure. In this specification, the positive and decreasing effect of the program exposure remains. The coefficients suggest that the maximum occurs around 4.65 years of BFP Exposure, while the effect remains positive until the second root of the quadratic equation, which occurs when Years of Exposure is equal to 9.3. Considering that the maximum possible exposure in the sample is 10 years, it is reasonable to state that this specification suggests that the program had positive effects on the outcome for almost the entire range of years of exposure.

The estimates of the first stage of the Instrumental Variable method are reported in Table 14. Considering that only the individuals whose family was registered until 2006 are in the sample, the coefficients are negative as expected. In other words, the higher the municipality registration of other families the lower the expected exposure of the already registered individuals of this municipality.

Table 14 - BFP Exposure effects on Formal Labor Market Participation First Stage Coefficients

\begin{tabular}{lcc}
\hline & \multicolumn{2}{c}{ Endogenous Variable } \\
\cline { 2 - 3 } Instrument & BFP Years of Exposure & Sq. Years of Exposure \\
\hline SR Coverage 2006 & $-1.2269^{* * *}$ & $-9.0980^{* * *}$ \\
& $(0.0412)$ & $(0.4400)$ \\
Squared SR Coverage 2006 & $0.3960^{* * *}$ & $6.7398^{* * *}$ \\
& $(0.0383)$ & $(0.4090)$ \\
\hline
\end{tabular}

Statistical Significance: ${ }^{*} \mathrm{p}<0.1 ;{ }^{* *} \mathrm{p}<0.05 ;{ }^{* * *} \mathrm{p}<0.01$ 
Table 14 - BFP Exposure effects on Formal Labor Market Participation First Stage Coefficients

\section{Endogenous Variable}

Instrument BFP Years of Exposure Sq. Years of Exposure

Note: This table presents the coefficients of the endogenous variables of BFP Exposure and its squared term, and their instruments, the logarithm of the observed SR Coverage in 2006 in the municipality, and its squared term. Source: Author's calculation with data from IBGE, INEP, MDS, and MTE.

In the last robustness test, regression (3), only individuals of families registered in 2004 are considered. Although an important part of the variation in the program exposure measure is lost, this guarantees that all the families reached or were reached by the BFP manager of the municipality in the same year. This means that, given individual and family characteristics, the exposure varies from one municipality to the other. From those municipalities with the same poverty level, in the ones that more families were registered, the chance of each family to be granted with the BFP is lower. This logic makes sense considering the program's rule of balancing the BFP coverage between municipalities. This is done by prioritizing the municipalities with lower benefit coverage at the moment of releasing decision.

Note that, for the FLM participation and Earnings outcomes, there is not much sense in making the last robustness test ${ }^{57}$ that was done for Schooling. Formal Labor Market Participation and Earnings are not self-reported information, and do not suffer from the possibility of being outdated, as is the case for the SR information. These outcomes are usually reported by the human resources department of each company.

As was the case for schooling, the positive long-term effects of the program exposure during individuals' childhood on their Formal Labor Market Participation probability were shown robust to different specifications. The effects were also shown to be stronger for boys, individuals from smaller cities, and families with never formally-employed parents.

$\overline{57}$ The test of Regression (3) of Table 10 that considers the sample with only individuals that are still BFP beneficiaries. 


\subsubsection{Earnings in the Formal Labor Market}

Now I turn to the last long-term outcome of interest of this work, the Earnings that these young adults get in their formal jobs. I measure the Earnings as the yearly average of their nominal wage per hour. In all specifications, I consider the wages on the logarithmic scale, as usual in the literature.

Table 15 - BFP exposure effects on Earnings

\begin{tabular}{|c|c|c|c|}
\hline & \multicolumn{3}{|c|}{ Regressions } \\
\hline & (1) & (2) & (3) \\
\hline BFP Exp. 1 & $\begin{array}{c}-0.018^{* * *} \\
(0.004)\end{array}$ & $\begin{array}{c}-0.016^{* * *} \\
(0.004)\end{array}$ & $\begin{array}{c}-0.013^{* * *} \\
(0.004)\end{array}$ \\
\hline BFP Exp. 2 & $\begin{array}{c}-0.022^{* * *} \\
(0.003)\end{array}$ & $\begin{array}{c}-0.019^{* * *} \\
(0.003)\end{array}$ & $\begin{array}{c}-0.013^{* * *} \\
(0.004)\end{array}$ \\
\hline BFP Exp. 3 & $\begin{array}{c}-0.040^{* * *} \\
(0.003)\end{array}$ & $\begin{array}{c}-0.028^{* * *} \\
(0.003)\end{array}$ & $\begin{array}{c}-0.012^{* * *} \\
(0.004)\end{array}$ \\
\hline BFP Exp. 4 & $\begin{array}{c}-0.085^{* * *} \\
(0.006)\end{array}$ & $\begin{array}{c}-0.032^{* * *} \\
(0.006)\end{array}$ & $\begin{array}{c}-0.015^{* *} \\
(0.006)\end{array}$ \\
\hline Cohort 1997 & & $\begin{array}{c}-0.034^{* * *} \\
(0.002)\end{array}$ & $\begin{array}{c}-0.039^{* * *} \\
(0.002)\end{array}$ \\
\hline Cohort 1998 & & $\begin{array}{c}-0.069^{* * *} \\
(0.002)\end{array}$ & $\begin{array}{c}-0.079^{* * *} \\
(0.002)\end{array}$ \\
\hline Female & & $\begin{array}{c}-0.021^{* * *} \\
(0.002)\end{array}$ & $\begin{array}{c}-0.025^{* * *} \\
(0.002)\end{array}$ \\
\hline White & & $\begin{array}{c}0.054^{* * *} \\
(0.002)\end{array}$ & $\begin{array}{c}0.025^{* * *} \\
(0.002)\end{array}$ \\
\hline Migrant & & $\begin{array}{c}0.012^{* * *} \\
(0.002)\end{array}$ & $\begin{array}{c}0.016^{* * *} \\
(0.002)\end{array}$ \\
\hline Co-Head & & & $\begin{array}{c}0.012^{* * *} \\
(0.003)\end{array}$ \\
\hline Formal Co-Head & & & $\begin{array}{c}-0.119^{* * *} \\
(0.007)\end{array}$ \\
\hline Formal Head & & & $\begin{array}{c}-0.097^{* * *} \\
(0.007)\end{array}$ \\
\hline Avg Wage Head & & & $\begin{array}{c}0.054^{* * *} \\
(0.004)\end{array}$ \\
\hline Avg Wage Co-Head & & & $\begin{array}{c}0.056^{* * *} \\
(0.004)\end{array}$ \\
\hline Head Schooling & & & 0.001 \\
\hline
\end{tabular}


Table 15 - BFP exposure effects on Earnings

\begin{tabular}{|c|c|c|c|}
\hline & \multicolumn{3}{|c|}{ Regressions } \\
\hline & $(1)$ & $(2)$ & $(3)$ \\
\hline & & & $(0.001)$ \\
\hline Co-head Schooling & & & $\begin{array}{c}-0.003^{* * *} \\
(0.001)\end{array}$ \\
\hline Fam. Size & & & $\begin{array}{l}-0.003 \\
(0.003)\end{array}$ \\
\hline Sq. Fam. Size & & & $\begin{array}{c}0.0002 \\
(0.0002)\end{array}$ \\
\hline Mun. Density 2000 & & & $\begin{array}{l}0.001^{* *} \\
(0.001)\end{array}$ \\
\hline Mun. Pop 2000 & & & $\begin{array}{c}-0.011^{* * *} \\
(0.001)\end{array}$ \\
\hline Mun. \% Poor Fam. & & & $-0.111^{* * *}$ \\
\hline 2000 & & & $(0.003)$ \\
\hline Mun. Educ. Quality & & & -0.006 \\
\hline 2007 & & & $(0.007)$ \\
\hline Intercept & $\begin{array}{c}1.493^{* * *} \\
(0.007)\end{array}$ & $\begin{array}{c}1.466^{* * *} \\
(0.007)\end{array}$ & $\begin{array}{c}1.467^{* * *} \\
(0.014)\end{array}$ \\
\hline Observations & 116,685 & 116,604 & 113,162 \\
\hline Adjusted $\mathrm{R}^{2}$ & 0.219 & 0.233 & 0.251 \\
\hline $\begin{array}{l}\text { Statistical Significance: } \\
\text { Note: This table repor } \\
\text { coefficients of the log-e } \\
\text { dummy variables and } \\
\text { is the reference catege } \\
\text { covariates of the indivi } \\
\text { Column (2) to Column } \\
\text { family background, and } \\
\text { of the time of the individ } \\
\text { with data from IBGE, }\end{array}$ & $\begin{array}{l}\text { 'p }<0.1{ }^{* *} \\
\text { the estin } \\
\text { rnings reg } \\
\text { pvariates. } \\
\text { y. From } \\
\text { uals' char } \\
\text { (3) I add c } \\
\text { characteris } \\
\text { tal's childh } \\
\text { NEP, MDs }\end{array}$ & $\begin{array}{l}0.05 ;{ }^{* * *} \mathrm{p} \\
\text { tes of Ord } \\
\text { ssions on } \\
\text { te BFP le } \\
\text { lumn (1) } \\
\text { teristics a } \\
\text { ariates w } \\
\text { s of the r } \\
\text { d. Source } \\
\text { and MTE }\end{array}$ & $\begin{array}{l}\text { Least Squares } \\
\text { Exposure level } \\
\text { exposure zero } \\
\text { olumn (2) the } \\
\text { roduced. From } \\
\text { aracteristics of } \\
\text { ce municipality } \\
\text { or's calculation }\end{array}$ \\
\hline
\end{tabular}

In Table 15 each column presents coefficients estimates that consider a different set of covariates, which are incorporated in the model by groups. The first column reports the regression estimates with no control variables. In the second column, regression (2), the individual's control variables are added. In the last column, regression (3), the control 
variables of family background and municipality characteristics are introduced.

It is interesting to note that the magnitudes of the BFP Exposure negative coefficients reduce substantially as I introduce more covariates. This is the same direction of change observed in the coefficients of the outcome of the previous section. Although the baseline regression (3) still presents negative effects of the program on the Earnings, the robustness tests presented ahead do not confirm it.

Supposing that these negative effects were robust to different specifications, a potential phenomenon underlying the observed estimates could be the schooling versus experience trade-off faced by these young. In the short term, maybe it compensates to drop out of school and go to the labor market and get some experience. However, in the medium and long-term probably not. Unfortunately, only some years from now we will be able to get a better grasp on this aspect.

Table 16 presents the results of the investigation on some heterogeneous effects. In each column, there is a different sample, selected based on the individual's demographics or the characteristics of its municipality.

Table 16 - BFP Exposure effects on Earnings - Heterogeneous Effects

\begin{tabular}{lccccc}
\hline & \multicolumn{5}{c}{ Regressions } \\
\cline { 2 - 6 } & $(1)$ & $(2)$ & $(3)$ & $(4)$ & $(5)$ \\
\hline BFP Exp. 1 & $-0.017^{* * *}$ & $-0.010^{*}$ & $-0.014^{*}$ & $-0.014^{* * *}$ & $-0.026^{* * *}$ \\
BFP Exp. 2 & $(0.005)$ & $(0.005)$ & $(0.008)$ & $(0.005)$ & $(0.009)$ \\
& $-0.019^{* * *}$ & $-0.008^{*}$ & -0.012 & $-0.017^{* * *}$ & -0.005 \\
BFP Exp. 3 & $(0.005)$ & $(0.005)$ & $(0.008)$ & $(0.005)$ & $(0.008)$ \\
& $-0.017^{* * *}$ & $-0.008^{*}$ & -0.010 & $-0.015^{* * *}$ & -0.007 \\
BFP Exp. 4 & $(0.005)$ & $(0.005)$ & $(0.008)$ & $(0.005)$ & $(0.008)$ \\
& $-0.022^{* *}$ & -0.009 & $-0.042^{* * *}$ & $-0.014^{*}$ & -0.012 \\
\hline Observations & $(0.009)$ & $(0.008)$ & $(0.015)$ & $(0.008)$ & $(0.014)$ \\
Adjusted R ${ }^{2}$ & 48,548 & 64,614 & 17,061 & 64,879 & 23,363 \\
\hline Statistical Significance: ${ }^{*} \mathrm{p}<0.1 ;{ }^{* *} \mathrm{p}<0.05 ;{ }^{* * *} \mathrm{p}<0.01$ & 0.246 & 0.242 \\
\hline
\end{tabular}


Table 16 - BFP Exposure effects on Earnings - Heterogeneous Effects

\begin{tabular}{l}
$\qquad(1) \quad(2) \quad(3)$ \\
\cline { 2 - 3 } \\
Note: This table presents the coefficients of the BFP Exposure levels for ordinary \\
least square regressions of log-earnings, with the full set of control variables, selecting \\
sub-samples. Regression (1) considers only the girls, Regression (2) only the boys. \\
Regression (3) selects only the children of parents with at least one formal employment \\
during individuals childhood. Regression (4) considers individuals from small cities \\
(<50,000 families in 2000), while Regression (5) considers individuals from large \\
cities ( $>200,000$ families in 2000). Source: Author's calculation with data from IBGE, \\
INEP, MDS, and MTE.
\end{tabular}

The first column of coefficients represents the results for the sample restricted to Females. On the other hand, regression (2) concerns the sample restricted to Males. As commented in the other outcomes, this distinction is important if it is considered that fertility decisions may affect more the Females. It is observed that although with a small magnitude, the negative effects for Females are stronger and significant for all exposure levels. As the dependent variable is in the logarithmic scale, the interpretation is that a female exposed to the BFP during her childhood is expected to earn $2.2 \%$ less than a female in the control group.

Regression (3) considers only individuals from families in which both the Head and Co-head appear in the Formal Labor Market at least once during the individual childhood. This test shows us differences in the effects when I consider individuals from families with a better background. Moreover, with this sample, I control much better for the program income selection problem.

Regressions (4) and (5) consider potential heterogeneities between different municipality's population sizes. This investigation is motivated by the results from traditional Regional and Urban Economics literature, which states the existence of agglomeration economies. The dynamics and quality of schools, and opportunities in the labor market, may vary considerably with the urban population size.

The last set of results of the section comprises the robustness checks on the previous specifications. In Table 17 I present the results obtained when I change the BFP Exposure measure and the identification strategy to the Instrumental Variable approach. 
Table 17 - BFP Exposure effects on Earnings - Robustness Tests

\begin{tabular}{|c|c|c|c|}
\hline & \multicolumn{3}{|c|}{ Regressions } \\
\hline & (1) & (2) & $(3)$ \\
\hline Years of BFP & $\begin{array}{c}-0.002^{*} \\
(0.001)\end{array}$ & $\begin{array}{c}0.002 \\
(0.018)\end{array}$ & \\
\hline Squared Years of BFP & $\begin{array}{c}0.0002 \\
(0.0001)\end{array}$ & $\begin{array}{c}0.0003 \\
(0.0019)\end{array}$ & \\
\hline BFP Exp. 1 & & & $\begin{array}{c}0.001 \\
(0.006)\end{array}$ \\
\hline BFP Exp. 2 & & & $\begin{array}{l}-0.001 \\
(0.006)\end{array}$ \\
\hline BFP Exp. 3 & & & $\begin{array}{c}0.005 \\
(0.006)\end{array}$ \\
\hline BFP Exp. 4 & & & $\begin{array}{c}0.008 \\
(0.008)\end{array}$ \\
\hline $\begin{array}{l}\text { Observations } \\
\text { Adjusted } \mathrm{R}^{2}\end{array}$ & $\begin{array}{c}113,162 \\
0.251\end{array}$ & $\begin{array}{c}113,162 \\
0.249\end{array}$ & $\begin{array}{l}43,278 \\
0.255\end{array}$ \\
\hline
\end{tabular}

Note: This table presents the coefficients of robustness tests, always considering the full set of control variables. Column (1) reports the coefficients of Ordinary Least Squares of log-earnings, considering the Years of Exposure and its squared term as the interest variables. Column (2) presents the Two-Stage Least Squares estimates considering both interest variables as endogenous and instrumenting them by the logarithm of municipality SR Coverage in 2006, and its respective squared term. Column (3) presents the coefficients estimated considering the sample of individuals from families registered in the SR in 2004. Source: Author's calculation with data from IBGE, INEP, MDS, and MTE.

In regression (1) I assume different measures of Exposure. The time of BFP Exposure (in years) and the respective squared term.

In regression (2) I apply an Instrumental Variable approach, considering the municipality effort to register vulnerable families in the SR (in logarithmic scale), and the respective squared term. The squared term is justified by all the results of other specifications, which suggest non-linear effects of the BFP duration of exposure.

For the Instrumental Variable approach, I had to use the years of exposure because of the existence of only two instruments. The municipality effort to include families in 
the Single Register is represented by the SR Coverage observed in 2006, i.e., the number of families registered in 2006 divided by the number of poor families in the municipality, estimated with the 2000 Demographic Census data.

The first stage coefficients are reported in Table 18.

\begin{tabular}{lcc}
\multicolumn{3}{c}{ Table 18 - Wages - First Stage Coefficients } \\
\cline { 2 - 3 } Instrument & \multicolumn{2}{c}{ Endogenous Variable } \\
\hline SR Coverage 2006 & $-1.3516^{* * *}$ & $-10.21^{* * *}$ \\
& $(0.052)$ & $(0.46)$ \\
Squared SR Coverage 2006 & $0.3464^{* * *}$ & $5.59^{* * *}$ \\
& $(0.0442)$ & $(0.4157)$ \\
\hline
\end{tabular}

Statistical Significance: ${ }^{*} \mathrm{p}<0.1 ;{ }^{* *} \mathrm{p}<0.05 ;{ }^{* * *} \mathrm{p}<0.01$

Note: This table presents the first stage coefficients of the Two-Stage Least Squares method applied to the Earnings equation, whose coefficients are reported in Table 17. Source: Author's calculation with data from IBGE, INEP, MDS, and MTE.

The results of the first stage are in line with the expected. For each family, the more its municipality registers other families the lower its chance to be benefited, since the sample is composed only by registered families.

Regression (3) of Table 17 comprises only individuals of families registered in 2004. A lot of variation is lost, but this guarantees that each family was reached by the municipality in the same year. The release of benefits will vary from one municipality to the other. From those municipalities with the same poverty level, in the ones that more families were registered, the chance of each family to be granted with the BFP is lower due to the program rule of prioritizing the municipalities with lower current benefit coverage.

As argued previously, when the baseline, heterogeneous, and robustness results are analyzed together, it is hard to state any clear direction of the effects of the BFP Exposure during childhood on the Earnings obtained in the first years of formal employment of these young adults. Considering the potential interaction of experience with schooling decisions for these vulnerable populations, the data of the years to come will be crucial to go deeper into this question and get a better answer if the additional schooling induced by the program generated pecuniary gains in the Labor Market. 



\section{Final Remarks}

This dissertation presented the first long-term effects estimates of the largest Conditional Cash Transfer program in the world, the Bolsa Família Program (BFP). I focused on the effects of BFP exposure during individuals' childhood and adolescence on the Schooling level attained in early adulthood, the probability to participate in the Formal Labor Market (FLM), and the Earnings (Wages) obtained on these formal employments.

To enable these estimates I linked identified data from the Single Registry for Social Programs (SR), with the BFP payment registers, and the administrative records of the FLM, which resulted in a dataset with more than one-quarter of the Brazilian families, and practically the entire poor population of the country. Because of the work purposes and the timing of the program, I focused the analysis on the individuals born between 1996 to 1998 , which represents 7.6 million people.

The program implementation was not a randomized trial, so I had to elaborate a strategy to select the proper sample and construct a Natural Experiment. The selected individuals were children during the first program payment year in which the data is available (2004). In addition, they are likely under the legal liability of a family head in the first year of the Single Registry data, i.e., they are less than 18 years old in 2012. To avoid families that were benefited in previous years in the sample, I focused on families registered in the SR from 2004 to 2006. This was a period of strong expansion when roughly one-quarter of the families observed were identified, which likely brings an important and partially random variation in the order of inclusion of the families in the SR.

Summarizing the main identification strategy, I rely on the inclusion of many observable characteristics of the individual and its family as control variables, and on the rules of release of the benefits that assign priority to families from municipalities with lower current BFP coverage. This means that the same family in another municipality could be selected for the program just because the other municipality covered fewer families in the SR at a given year. Moreover, the yearly budget reserved for the program can also leave a family that was incorporated later in the SR in a waiting list. 
In an alternative identification strategy, I assumed exogeneity, from the family perspective, of the municipality effort to get vulnerable families into the Single Registry, which is a necessary condition to have the benefit released. Of course both strategies are not perfect. Since the data applied did not come from a randomized experiment, residual biases of selection on family and municipality unobservable characteristics may be affecting my estimates. However, the descriptive statistics suggests that the socio-economic background of the more exposed families are worse. Therefore, to consider the results as over-estimates, it is necessary for the selection on unobservables to be strong and to occur the other way around than the selection on observables. It does not seem to be very likely.

The three outcomes of interest are variables of different mathematical natures and therefore demanded different econometric models. The Schooling measure was constructed from primary data in the SR, and divided into six different and increasing levels. The econometric approach for this outcome is the Ordered Logit. The Formal Labor Market (FLM) participation has a binary nature, and for that reason, I applied one of the most traditional probabilistic models, the Logit. Both Schooling and FLM participation equations were estimated through traditional Maximum Likelihood methods. For the last outcome, Earnings, I estimated a log-linear model through Ordinary Least Squares. Concerning the alternative identification strategy, I applied the Instrumental Variable Probit for the FLM participation and the method of Two-Stage Least Squares for the Wages.

The descriptive statistics showed that the program had a strong focus on the most vulnerable families and the poorest municipalities. These numbers reinforced the need to add these variables in the estimates of the baseline econometric specifications.

The major results can be summarized as follows: the higher the time of exposure to the BFP during childhood and adolescence, the higher the level of Schooling the individual present when it is 18 years old, and the higher the probability of participating in the Formal Labor Market. Results for wages vary from slightly negative to non-significant when I include more control variables or change the identification strategy to the instrumental variable approach. 
Selecting the sample groups to test for heterogeneous effects showed that the stronger schooling and formal labor market participation effects occurred for males, for children of never formally employed parents, and for smaller cities. This last result is consistent with the theories of Urban Economics since bigger urban centers may have strong economic dynamics and the relative importance of the CCTs may be much smaller. A similar argument can be constructed for children of formally employed parents. These children potentially have a much better family background, and their parents would invest in them regardless of the BFP conditionalities and benefits.

In the robustness tests, the instrumental variable approach showed the same positive effects for the probability of Formal Labor Market participation, while presented not statistically significant results for the wage equation.

I shall explicitly present now some limitations of this work, which comprises important topics related to it. Concerning Schooling, since the measure is the highest level attained, I leave out a very relevant discussion, the quality of the education provided for these low-income children in the schools across the country.

Considering the Labor Market outcomes, I need to recognize that the informal sector tends to be, as is the case for Brazil, very representative for developing countries. Unfortunately, because of the lack of identified data, it is very hard to consider this sector in the analyses. However, evidence for Brazil has shown that the formal sector concentrates higher productivity jobs, and the regulation it embeds does not cause unemployment. More than that, it increases the output and welfare through improving the allocation of workers and increasing competition in the Labor Market (Meghir et al., 2015). Therefore, by investigating if more exposed individuals during their childhood are more prone to participate in the FLM some years later, I believe that I have provided a valuable piece of knowledge of the long-term relation of the CCTs and the Labor Market.

The BFP is a large program and was implemented without randomization. Hence, the estimates of differential effects of the BFP between groups with different exposure durations may be embedded with spillovers and general equilibrium responses. For instance, 
a municipality with a rapid release of benefits may have incorporated many new students on its existing schools, and this may have spillovers on the children that were already studying there. Concerning the labor market, if the poor individuals more exposed to the program are getting more education, or postponing their participation in the labor market, this may have consequences in the equilibrium wages of each activity, through changes in labor offer and supply. This discussion is important, but is out of the scope of this work.

In general, the results showed that the BFP may have had also the desired long-term role of improving the second generation future in Brazil. Although I did not find positive effects for Earnings, it is remarkable that the more exposed individuals from poor families reached higher schooling level and are more prone to get a formal job, which is related to better quality and higher productivity activities.

The linked data built in this dissertation allows to observe an important set of variables of individuals and their families over time. This motivates to seek for answers of other important research questions. To keep it short, I indicate two immediate extensions of this work. First, it would be interesting to check how the parents' schooling and labor outcomes responded just after the release of the benefits, and also in the long-run. The second group of interesting questions is related to the local aggregate effects of the program. For instance, to investigate how the measures of aggregate economic activity of each municipality, or zip code, responded to the amount of benefit released in a given period. 


\section{Bibliography}

Angelucci, M., O. Attanasio, and V. Di Maro (2012). The impact of oportunidades on consumption, savings and transfers. Fiscal Studies 33(3), 305-334. 18

Angelucci, M. and G. De Giorgi (2009). Indirect effects of an aid program: how do cash transfers affect ineligibles' consumption? The American Economic Review 99(1), 486-508. 18

Attanasio, O. and A. Mesnard (2006). The impact of a conditional cash transfer programme on consumption in colombia. Fiscal studies 27(4), 421-442. 18

Azzoni, C. R., J. J. Guilhoto, E. A. Haddad, G. J. Hewings, M. A. Laes, and G. R. Moreira (2009). Social policies, personal and regional income inequality in brazil: an io analysis. In Brazil under Lula, pp. 243-261. Springer. 8

Baird, S., D. McKenzie, and B. Özler (2018). The effects of cash transfers on adult labor market outcomes. IZA Journal of Development and Migration 8(1), 22. 16

Banerjee, A. V., A. Banerjee, and E. Duflo (2011). Poor economics: A radical rethinking of the way to fight global poverty. Public Affairs. 18

Barbosa, A. L. N. d. H. and C. H. L. Corseuil (2014). Conditional cash transfer and informality in brazil. IZA Journal of Labor \& Development $\underline{3}(1), 37.17$

Bardasi, E. and G. Garcia (2014). Social safety nets and gender: learning from impact evaluations and world bank projects. Technical report, The Word Bank. 19

Barham, T., K. Macours, and J. A. Maluccio (2013). Boys' cognitive skill formation and physical growth: Long-term experimental evidence on critical ages for early childhood interventions. American Economic Review: Papers and Proceedings 103(3), 467-71. 22, 32

Barham, T., K. Macours, and J. A. Maluccio (2017). Are conditional cash transfers fulfilling their promise? schooling, learning, and earnings after 10 years. CEPR Discussion Paper No. DP11937. 22 
Barham, T., K. Macours, and J. A. Maluccio (2018). Experimental evidence of exposure to a conditional cash transfer during early teenage years: Young women's fertility and labor market outcomes. CEPR Discussion Paper No. DP13165. 22

Barrera-Osorio, F., L. L. Linden, and J. E. Saavedra (2019). Medium-and long-term educational consequences of alternative conditional cash transfer designs: Experimental evidence from colombia. American Economic Journal: Applied Economics 11(3), 54-91. $19,22,23$

Bastagli, F., J. Hagen-Zanker, L. Harman, V. Barca, G. Sturge, T. Schmidt, and L. Pellerano (2016). Cash transfers: what does the evidence say. A rigorous review of programme impact and the role of design and implementation features. London: ODI. 16, 19

Becker, G. S. (1960). Underinvestment in college education? The American Economic $\underline{\text { Review }} \underline{50}(2), 346-354.33$

Becker, G. S. (1962). Investment in human capital: A theoretical analysis. Journal of political economy $\underline{70}(5$, Part 2), 9-49. 9, 30, 31

Becker, G. S. (1964). Human capital: A theoretical and empirical analysis, with special reference to education. 31

Behrman, J. R., S. W. Parker, and P. E. Todd (2011). Do conditional cash transfers for schooling generate lasting benefits? a five-year followup of progresa/oportunidades. $\underline{\text { Journal of Human Resources }}$ 46(1), 93-122. 22

Brollo, F., K. Maria Kaufmann, and E. La Ferrara (2020). Learning spillovers in conditional welfare programmes: Evidence from brazil. The Economic Journal 130(628), 853-879. 19

Camargo, P. C. and E. T. Pazello (2014). Uma análise do efeito do programa bolsa família sobre o desempenho médio das escolas brasileiras. Economia Aplicada 18(4), 623-640. 
Cameron, A. C. and P. K. Trivedi (2009). Microeconometrics using stata, Volume 5. Stata press College Station, TX. 42

Carvalho, I. M. M. d. (2004). Algumas lições do programa de erradicação do trabalho infantil. São Paulo em Perspectiva 18(4), 50-61. 27

Chein, F. and C. Pinto (2018). Credit constraint and human capital investment: an empirical analysis using brazilian household budget survey. Applied Economics 50(21), 2369-2385. 33

Chitolina, L., M. N. Foguel, and N. A. Menezes-Filho (2016). The impact of the expansion of the bolsa familia program on the time allocation of youths and their parents. Revista Brasileira de Economia 70(2), 183-202. 17, 19

Costa, L. V., M. J. Braga, and E. C. Teixeira (2017). Impactos do programa bolsa família sobre o consumo de nutrientes das famílias beneficiárias. Ensaios Fee 37(4), 947-974. 18

Covarrubias, K., B. Davis, and P. Winters (2012). From protection to production: productive impacts of the malawi social cash transfer scheme. Journal of Development $\underline{\text { Effectiveness }} \underline{4}(1), 50-77.16$

Cunha, F. and J. Heckman (2007). The technology of skill formation. American Economic $\underline{\text { Review }} \underline{97}(2), 31-47.9,31$

Daidone, S., B. Davis, J. Dewbre, and K. Covarrubias (2015). Lesothos child grant programme. 16, 21

De Brauw, A., D. O. Gilligan, J. Hoddinott, and S. Roy (2015a). Bolsa família and household labor supply. Economic Development and Cultural Change 63(3), 423-457. 17

De Brauw, A., D. O. Gilligan, J. Hoddinott, and S. Roy (2015b). The impact of bolsa familia on schooling. World Development 70, 303-316. 19 
De Oliveira, G. L. and A. L. S. Chagas (2020). Effects of a cash transfer programme on origin-destination migration flows. Regional Science Policy \& Practice 12(1), 83-104. 8,21

Del Rey, E. and F. Estevan (2013). Conditional cash transfers and education quality in the presence of credit constraints. Economics of Education Review 34, 76-84. 20

Denes, G., B. K. Komatsu, and N. Menezes-Filho (2016). Uma avaliação dos impactos macroeconômicos e sociais de programas de transferência de renda nos municípios brasileiros. INSPER Police Paper (21). 21

Estevan, F. (2013). The impact of conditional cash transfers on public education expenditures: A political economy approach. European Journal of Political Economy $\underline{32}$, 268-284. 20

Foguel, M. N. and R. P. d. Barros (2010). The effects of conditional cash transfer programmes on adult labour supply: an empirical analysis using a time-series-cross-

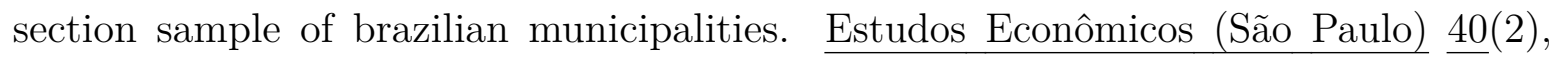
259-293. 17

Heckman, J. J., J. E. Humphries, and G. Veramendi (2018). Returns to education: The causal effects of education on earnings, health, and smoking. Journal of Political Economy $126(\mathrm{~S} 1), \mathrm{S} 197-\mathrm{S} 246.31$

Heckman, J. J., L. J. Lochner, and P. E. Todd (2006). Earnings functions, rates of return and treatment effects: The mincer equation and beyond. Handbook of the Economics of Education 1, 307-458. 31, 42

IBGE (2020). Instituto brasileiro de geografia e estatística. available at $<$ http://www. ibge. gov. bra >, Retrieved on March 11, 2020. 15

Keane, M. P. and K. I. Wolpin (2001). The effect of parental transfers and borrowing constraints on educational attainment. International Economic Review 42(4), 1051-1103. 33 
Lavinas, L. (1998). Programas de garantia de renda mínima: perspectivas brasileiras. 27

MC. Ministry of citizenship. available at $<$ http://www. mds. gov. br/bolsafamilia $>$, Retrieved on March 11, 2020. 24

McCullagh, P. (1980). Regression models for ordinal data. Journal of the Royal Statistical Society: Series B (Methodological) 42(2), 109-127. 37

Meghir, C., R. Narita, and J.-M. Robin (2015). Wages and informality in developing countries. American Economic Review 105(4), 1509-46. 89

Menezes-Filho, N., R. Moita, and E. de Carvalho Andrade (2014). Running away from the poor: Bolsa-familia and entry in school markets. CEP 4546, 042. 20

Millán, T. M., T. Barham, K. Macours, J. A. Maluccio, and M. Stampini (2019). Long-term impacts of conditional cash transfers: Review of the evidence. The World Bank Research Observer $\underline{34}(1), 119-159.12,21$

Millán, T. M., K. Macours, J. A. Maluccio, and L. Tejerina (2020). Experimental long-term effects of early-childhood and school-age exposure to a conditional cash transfer program. $\underline{\text { Journal of Development Economics }} \underline{143}$, 102385. 23

Mincer, J. (1974). Schooling, experience, and earnings. human behavior \& social institutions no. 2. 30,31

Neri, M. C., F. M. Vaz, and P. H. G. F. d. Souza (2013). Efeitos macroeconômicos do programa bolsa família: uma análise comparativa das transferências sociais. Programa Bolsa Família: uma década de inclusão e cidadania. Brasília: Ipea 1, 193-206. 21

OECD (2017). Education at a glance 2017: OECD indicators. OECD Publishing, Paris. 33,34

Oliveira, A. M. H. C. (2009). An evaluation of the bolsa familia program in brazil: Expenditures, education and labor outcomes. Unpublished Report available at https://paa2009.princeton.edu/papers/90741. 17, 18 
Parker, S. and E. Skoufias (2000). The impact of progresa on work, leisure and time allocation. Washington, DC: International Food Policy Research Institute. 16

Parker, S. W. and T. Vogl (2018). Do conditional cash transfers improve economic outcomes in the next generation? evidence from mexico. NBER Working Paper No. w24303. 23

Reis, M. C. (2020). Os ensinos público e privado no brasil e a incidência de sobre-educação no mercado de trabalho. IPEA, Texto para Discussão No. 2558. 33

Ribas, R. P. (2019). Liquidity constraints, spillovers, and entrepreneurship: evidence from a cash transfer program. Small Business Economics, 1-28. 17

Santos, D. B., A. R. Leichsenring, N. Menezes Filho, and W. Mendes-Da-Silva (2017). Os efeitos do programa bolsa família sobre a duração do emprego formal dos indivíduos de baixa renda. Revista de Administração Pública-RAP 51(5), 708-733. 17

Schultz, T. W. (1961). Investment in human capital. The American economic review, 1-17. 9, 30, 31

Senarc - Ministry of Citizenship (2008). Portaria n. 341 from october 7, 2008. 24

Silveira Neto, R. D. M. and C. R. Azzoni (2011). Non-spatial government policies and regional income inequality in brazil. Regional Studies $\underline{45}$ (4), 453-461. 21

Silveira-Neto, R. d. M. and G. B. Duarte (2010). Impacto do programa bolsa família sobre a frequência escolar: o caso da agricultura familiar no nordeste do brasil. Revista de $\underline{\text { Economia e Sociologia Rural }}$ 48(3), 635-657. 8

Skoufias, E. and V. Di Maro (2006). Conditional cash transfers, adult work incentives, and poverty. The World Bank. 16

Soares, S., P. H. G. F. De Souza, R. G. Osório, and F. G. Silveira (2010). Os impactos do benefício do programa bolsa família sobre a desigualdade e pobreza. Bolsa Família 2003-2010: Avanços e Desafios, 27-52. 8 
Soares, S., R. Guerreiro Osorio, F. Veras Soares, M. Medeiros, and E. Zepeda (2009). Conditional cash transfers in brazil, chile and mexico: impacts upon inequality. Estudios económicos. 8, 20

Soares, S. and N. Sátyro (2010). O programa bolsa família: desenho institucional e possibilidades futuras. Bolsa Família 2003-2010: avanços e desafios, chapter 1, 27. 26, 27

Spence, A. M. (1974). Market signaling: Informational transfer in hiring and related screening processes, Volume 143. Harvard Univ Pr. 32

Todd, P. E. and W. Zhang (2020). A dynamic model of personality, schooling, and occupational choice. Quantitative Economics 11(1), 231-275. 32

Transparência (2020). Portal da transparência. available at $<$ http://www. portaltransparencia. gov. br>, Retrieved on March 11, 2020. 15

Wooldridge, J. M. (2010). Econometric analysis of cross section and panel data. MIT press. 38,40 



\section{Appendix}

Tables with Descriptive Statistics for Cohorts 1997 and 1998.

Table 19 - Descriptive statistics across BFP Exposure - Cohort 1997

\begin{tabular}{|c|c|c|c|c|c|}
\hline \multirow[b]{2}{*}{ Variable } & \multirow[b]{2}{*}{ Measure } & \multicolumn{4}{|c|}{ BFP Exposure Level } \\
\hline & & 0 & 1 & 2 & 3 \\
\hline Individuals & $\mathrm{N}$ & 2,242 & 7,155 & 13,016 & 28,073 \\
\hline \multirow{4}{*}{$\begin{array}{l}\text { Schooling } \\
\text { attained at } 18 \text { y.o. }\end{array}$} & Mean & 2.30 & 2.47 & 2.52 & 2.58 \\
\hline & Std. Dev. & 0.95 & 0.77 & 0.75 & 0.72 \\
\hline & Min & 0.00 & 0.00 & 0.00 & 0.00 \\
\hline & Max & 5.00 & 5.00 & 5.00 & 5.00 \\
\hline \multirow[t]{4}{*}{ Formal Employed } & Mean & 0.35 & 0.38 & 0.36 & 0.31 \\
\hline & Std. Dev. & 0.48 & 0.49 & 0.48 & 0.46 \\
\hline & Min & 0.00 & 0.00 & 0.00 & 0.00 \\
\hline & Max & 1.00 & 1.00 & 1.00 & 1.00 \\
\hline \multirow[t]{4}{*}{ Avg. Real hourly Wage } & Mean & 7.44 & 7.27 & 7.25 & 7.17 \\
\hline & Std. Dev. & 2.41 & 2.23 & 2.17 & 2.31 \\
\hline & Min & 2.79 & 2.01 & 1.76 & 2.04 \\
\hline & Max & 31.24 & 42.16 & 50.05 & 55.07 \\
\hline Years of BFP & Mean & 0.00 & 2.28 & 4.94 & 7.85 \\
\hline \multirow[t]{3}{*}{ Exposure } & Std. Dev. & 0.00 & 0.72 & 0.86 & 0.87 \\
\hline & Min & 0.00 & 1.00 & 4.00 & 7.00 \\
\hline & Max & 0.00 & 3.00 & 6.00 & 9.00 \\
\hline Age at First & Mean & 18.07 & 18.16 & 18.13 & 18.38 \\
\hline \multirow{3}{*}{ Employment } & Std. Dev. & 1.31 & 1.34 & 1.33 & 1.27 \\
\hline & Min & 16.00 & 16.00 & 16.00 & 16.00 \\
\hline & Max & 20.00 & 20.00 & 20.00 & 20.00 \\
\hline \multirow[t]{4}{*}{ Female } & Mean & 0.50 & 0.49 & 0.48 & 0.47 \\
\hline & Std. Dev. & 0.50 & 0.50 & 0.50 & 0.50 \\
\hline & Min & 0.00 & 0.00 & 0.00 & 0.00 \\
\hline & Max & 1.00 & 1.00 & 1.00 & 1.00 \\
\hline \multirow[t]{4}{*}{ White } & Mean & 0.42 & 0.39 & 0.35 & 0.26 \\
\hline & Std. Dev. & 0.49 & 0.49 & 0.48 & 0.44 \\
\hline & Min & 0.00 & 0.00 & 0.00 & 0.00 \\
\hline & Max & 1.00 & 1.00 & 1.00 & 1.00 \\
\hline \multirow[t]{4}{*}{ Migrant } & Mean & 0.45 & 0.41 & 0.40 & 0.38 \\
\hline & Std. Dev. & 0.50 & 0.49 & 0.49 & 0.48 \\
\hline & Min & 0.00 & 0.00 & 0.00 & 0.00 \\
\hline & Max & 1.00 & 1.00 & 1.00 & 1.00 \\
\hline \multirow[t]{4}{*}{ Formal Head } & Mean & 0.44 & 0.46 & 0.42 & 0.27 \\
\hline & Std. Dev. & 0.50 & 0.50 & 0.49 & 0.44 \\
\hline & Min & 0.00 & 0.00 & 0.00 & 0.00 \\
\hline & Max & 1.00 & 1.00 & 1.00 & 1.00 \\
\hline \multirow[t]{4}{*}{ Co-head } & Mean & 0.61 & 0.56 & 0.53 & 0.54 \\
\hline & Std. Dev. & 0.49 & 0.50 & 0.50 & 0.50 \\
\hline & Min & 0.00 & 0.00 & 0.00 & 0.00 \\
\hline & Max & 1.00 & 1.00 & 1.00 & 1.00 \\
\hline \multirow[t]{4}{*}{ Formal Co-head } & Mean & 0.37 & 0.34 & 0.30 & 0.25 \\
\hline & Std. Dev. & 0.48 & 0.47 & 0.46 & 0.43 \\
\hline & Min & 0.00 & 0.00 & 0.00 & 0.00 \\
\hline & Max & 1.00 & 1.00 & 1.00 & 1.00 \\
\hline
\end{tabular}


Table 19 - Descriptive statistics across BFP Exposure - Cohort 1997

\begin{tabular}{|c|c|c|c|c|c|}
\hline \multirow[b]{2}{*}{ Variable } & \multirow[b]{2}{*}{ Measure } & \multicolumn{4}{|c|}{ BFP Exposure Level } \\
\hline & & 0 & 1 & 2 & 3 \\
\hline \multirow{4}{*}{$\begin{array}{l}\text { Co-head Avg } \\
\text { Real Hourly Wage }\end{array}$} & Mean & 8.91 & 8.30 & 7.73 & 7.07 \\
\hline & Std. Dev. & 4.92 & 4.40 & 4.00 & 3.83 \\
\hline & Min & 2.74 & 1.56 & 2.02 & 1.57 \\
\hline & Max & 46.05 & 54.15 & 55.74 & 55.07 \\
\hline Head Avg Real & Mean & 6.60 & 6.35 & 6.23 & 5.85 \\
\hline \multirow[t]{3}{*}{ Hourly Wage } & Std. Dev. & 3.47 & 3.39 & 3.21 & 2.59 \\
\hline & Min & 2.25 & 1.47 & 1.51 & 1.49 \\
\hline & Max & 43.75 & 52.53 & 49.33 & 43.84 \\
\hline \multirow[t]{4}{*}{ Head Schooling } & Mean & 2.28 & 2.16 & 2.07 & 1.87 \\
\hline & Std. Dev. & 1.17 & 1.14 & 1.12 & 1.10 \\
\hline & Min & 0.00 & 0.00 & 0.00 & 0.00 \\
\hline & Max & 5.00 & 5.00 & 5.00 & 5.00 \\
\hline \multirow[t]{4}{*}{ Co-head Schooling } & Mean & 1.99 & 1.94 & 1.82 & 1.56 \\
\hline & Std. Dev. & 1.17 & 1.13 & 1.11 & 1.09 \\
\hline & Min & 0.00 & 0.00 & 0.00 & 0.00 \\
\hline & $\operatorname{Max}$ & 5.00 & 5.00 & 5.00 & 5.00 \\
\hline \multirow[t]{4}{*}{ Family Size } & Mean & 3.80 & 4.07 & 4.21 & 4.54 \\
\hline & Std. Dev. & 1.25 & 1.39 & 1.48 & 1.60 \\
\hline & Min & 1.00 & 1.00 & 1.00 & 1.00 \\
\hline & Max & 10.00 & 14.00 & 16.00 & 14.00 \\
\hline Munic. & Mean & 840.86 & 888.12 & $1,155.01$ & $1,029.14$ \\
\hline \multirow[t]{3}{*}{ Density 2000} & Std. Dev. & $1,880.25$ & $1,894.83$ & $2,215.74$ & $2,093.90$ \\
\hline & Min & 0.28 & 0.13 & 0.13 & 0.13 \\
\hline & Max & $11,924.99$ & $11,924.99$ & $11,924.99$ & $11,924.99$ \\
\hline Munic. & Mean & 184.45 & 204.04 & 218.45 & 197.33 \\
\hline \multirow{3}{*}{ Families 2000} & Std. Dev. & 575.01 & 518.42 & 613.40 & 564.02 \\
\hline & Min & 0.37 & 0.34 & 0.33 & 0.26 \\
\hline & Max & $3,173.50$ & $3,173.50$ & $3,173.50$ & $3,173.50$ \\
\hline Munic. Poor & Mean & 0.46 & 0.45 & 0.47 & 0.55 \\
\hline \multirow[t]{3}{*}{ Families 2000} & Std. Dev. & 0.19 & 0.20 & 0.20 & 0.21 \\
\hline & Min & 0.10 & 0.11 & 0.07 & 0.10 \\
\hline & Max & 0.92 & 0.96 & 0.94 & 0.96 \\
\hline Munic. Education & Mean & 4.16 & 4.20 & 4.06 & 3.78 \\
\hline \multirow[t]{3}{*}{ Quality 2007} & Std. Dev. & 0.75 & 0.76 & 0.76 & 0.76 \\
\hline & Min & 2.20 & 1.80 & 1.80 & 0.90 \\
\hline & Max & 7.70 & 7.50 & 7.70 & 7.60 \\
\hline Munic. SR & Mean & 0.82 & 0.77 & 0.72 & 0.72 \\
\hline \multirow[t]{3}{*}{ Coverage 2006} & Std. Dev. & 0.26 & 0.23 & 0.23 & 0.23 \\
\hline & Min & 0.22 & 0.13 & 0.19 & 0.10 \\
\hline & Max & 3.50 & 3.50 & 3.50 & 3.50 \\
\hline
\end{tabular}

Note: This table reports descriptive statistics for each variable of the linked data for the individuals that were born in 1997, whose family was registered in the SR between 2004 and 2006. The mean of the dummy variables (Female, Migrant, Formal Head, Co-Head, and Formal Co-Head) must be interpreted as the proportion of that category in the data. The number of municipality resident families are measured in thousands. Source: Author's calculation with data from IBGE, INEP, MDS, and MTE. 
Table 20 - Descriptive statistics across BFP Exposure - Cohort 1998

\begin{tabular}{|c|c|c|c|c|c|c|}
\hline \multirow[b]{2}{*}{ Variable } & \multirow[b]{2}{*}{ Measure } & \multicolumn{5}{|c|}{ BFP Exposure Level } \\
\hline & & 0 & 1 & 2 & 3 & 4 \\
\hline Individuals & $\mathrm{N}$ & 1,890 & 5,829 & 11,218 & 22,924 & 8,193 \\
\hline \multirow{4}{*}{$\begin{array}{l}\text { Schooling } \\
\text { attained at } 18 \text { y.o. }\end{array}$} & Mean & 2.33 & 2.59 & 2.62 & 2.62 & 2.60 \\
\hline & Std. Dev. & 1.02 & 0.72 & 0.71 & 0.70 & 0.71 \\
\hline & Min & 0.00 & 0.00 & 0.00 & 0.00 & 0.00 \\
\hline & Max & 5.00 & 5.00 & 5.00 & 5.00 & 5.00 \\
\hline \multirow[t]{4}{*}{ Formal Employed } & Mean & 0.27 & 0.27 & 0.27 & 0.20 & 0.21 \\
\hline & Std. Dev. & 0.44 & 0.44 & 0.44 & 0.40 & 0.41 \\
\hline & Min & 0.00 & 0.00 & 0.00 & 0.00 & 0.00 \\
\hline & $\operatorname{Max}$ & 1.00 & 1.00 & 1.00 & 1.00 & 1.00 \\
\hline \multirow{4}{*}{$\begin{array}{l}\text { Avg. Real } \\
\text { Hourly Wage }\end{array}$} & Mean & 7.38 & 7.10 & 7.21 & 7.14 & 7.05 \\
\hline & Std. Dev. & 2.42 & 2.10 & 2.33 & 2.50 & 2.14 \\
\hline & Min & 3.89 & 2.25 & 1.67 & 1.74 & 2.00 \\
\hline & $\operatorname{Max}$ & 37.08 & 42.15 & 47.16 & 55.10 & 34.61 \\
\hline \multirow{4}{*}{$\begin{array}{l}\text { Years of BFP } \\
\text { Exposure }\end{array}$} & Mean & 0.00 & 2.41 & 4.98 & 8.08 & 10.00 \\
\hline & Std. Dev. & 0.00 & 0.67 & 0.73 & 0.67 & 0.00 \\
\hline & Min & 0.00 & 1.00 & 4.00 & 7.00 & 10.00 \\
\hline & Max & 0.00 & 3.00 & 6.00 & 9.00 & 10.00 \\
\hline \multirow{4}{*}{$\begin{array}{l}\text { Age at First } \\
\text { Employment }\end{array}$} & Mean & 17.71 & 17.70 & 17.81 & 17.92 & 17.90 \\
\hline & Std. Dev. & 1.14 & 1.16 & 1.14 & 1.10 & 1.11 \\
\hline & Min & 16.00 & 16.00 & 16.00 & 16.00 & 16.00 \\
\hline & Max & 19.00 & 19.00 & 19.00 & 19.00 & 19.00 \\
\hline \multirow[t]{4}{*}{ Female } & Mean & 0.49 & 0.48 & 0.48 & 0.47 & 0.47 \\
\hline & Std. Dev. & 0.50 & 0.50 & 0.50 & 0.50 & 0.50 \\
\hline & Min & 0.00 & 1.00 & 0.00 & 0.00 & 0.00 \\
\hline & Max & 1.00 & 1.00 & 1.00 & 1.00 & 1.00 \\
\hline \multirow[t]{4}{*}{ White } & Mean & 0.46 & 0.40 & 0.37 & 0.25 & 0.26 \\
\hline & Std. Dev. & 0.50 & 0.49 & 0.48 & 0.44 & 0.44 \\
\hline & Min & 0.00 & 0.00 & 0.00 & 0.00 & 0.00 \\
\hline & Max & 1.00 & 1.00 & 1.00 & 1.00 & 1.00 \\
\hline \multirow[t]{4}{*}{ Migrant } & Mean & 0.42 & 0.39 & 0.39 & 0.38 & 0.36 \\
\hline & Std. Dev. & 0.49 & 0.49 & 0.49 & 0.48 & 0.48 \\
\hline & Min & 0.00 & 0.00 & 0.00 & 0.00 & 0.00 \\
\hline & Max & 1.00 & 1.00 & 1.00 & 1.00 & 1.00 \\
\hline \multirow[t]{4}{*}{ Formal Head } & Mean & 0.52 & 0.50 & 0.46 & 0.31 & 0.30 \\
\hline & Std. Dev. & 0.50 & 0.50 & 0.50 & 0.46 & 0.46 \\
\hline & Min & 0.00 & 0.00 & 0.00 & 0.00 & 0.00 \\
\hline & Max & 1.00 & 1.00 & 1.00 & 1.00 & 1.00 \\
\hline \multirow[t]{4}{*}{ Co-head } & Mean & 0.59 & 0.56 & 0.52 & 0.55 & 0.53 \\
\hline & Std. Dev. & 0.49 & 0.50 & 0.50 & 0.50 & 0.50 \\
\hline & Min & 0.00 & 0.00 & 0.00 & 0.00 & 0.00 \\
\hline & Max & 1.00 & 1.00 & 1.00 & 1.00 & 1.00 \\
\hline \multirow[t]{4}{*}{ Formal Co-head } & Mean & 0.40 & 0.37 & 0.33 & 0.27 & 0.26 \\
\hline & Std. Dev. & 0.49 & 0.48 & 0.47 & 0.44 & 0.44 \\
\hline & Min & 0.00 & 0.00 & 0.00 & 0.00 & 0.00 \\
\hline & Max & 1.00 & 1.00 & 1.00 & 1.00 & 1.00 \\
\hline \multirow{4}{*}{$\begin{array}{l}\text { Co-head Avg } \\
\text { Real Hourly Wage }\end{array}$} & Mean & 9.04 & 8.65 & 8.23 & 7.47 & 7.15 \\
\hline & Std. Dev. & 4.96 & 4.54 & 4.29 & 4.12 & 3.64 \\
\hline & Min & 2.99 & 2.08 & 2.02 & 1.46 & 1.76 \\
\hline & Max & 49.72 & 53.69 & 56.07 & 54.71 & 49.84 \\
\hline Head Avg Real & Mean & 6.97 & 6.61 & 6.37 & 6.21 & 6.01 \\
\hline
\end{tabular}


Table 20 - Descriptive statistics across BFP Exposure - Cohort 1998

\begin{tabular}{|c|c|c|c|c|c|c|}
\hline \multirow[b]{2}{*}{ Variable } & \multirow[b]{2}{*}{ Measure } & \multicolumn{5}{|c|}{ BFP Exposure Level } \\
\hline & & 0 & 1 & 2 & 3 & 4 \\
\hline \multirow[t]{3}{*}{ Hourly Wage } & Std. Dev. & 3.81 & 3.11 & 2.94 & 3.15 & 2.54 \\
\hline & Min & 1.82 & 1.75 & 1.43 & 1.52 & 1.44 \\
\hline & Max & 47.67 & 46.31 & 55.10 & 52.53 & 39.36 \\
\hline \multirow[t]{4}{*}{ Head Schooling } & Mean & 2.46 & 2.22 & 2.15 & 1.91 & 1.87 \\
\hline & Std. Dev. & 1.18 & 1.13 & 1.12 & 1.11 & 1.06 \\
\hline & Min & 0.00 & 0.00 & 0.00 & 0.00 & 0.00 \\
\hline & Max & 5.00 & 5.00 & 5.00 & 5.00 & 5.00 \\
\hline \multirow{4}{*}{ Co-head Schooling } & Mean & 2.18 & 2.00 & 1.87 & 1.58 & 1.57 \\
\hline & Std. Dev. & 1.13 & 1.12 & 1.10 & 1.08 & 1.08 \\
\hline & Min & 0.00 & 0.00 & 0.00 & 0.00 & 0.00 \\
\hline & Max & 5.00 & 5.00 & 5.00 & 5.00 & 5.00 \\
\hline \multirow{4}{*}{ Family Size } & Mean & 3.66 & 4.09 & 4.15 & 4.51 & 4.58 \\
\hline & Std. Dev. & 1.20 & 1.41 & 1.44 & 1.60 & 1.59 \\
\hline & Min & 1.00 & 1.00 & 1.00 & 1.00 & 2.00 \\
\hline & Max & 12.00 & 17.00 & 14.00 & 15.00 & 16.00 \\
\hline Munic. & Mean & 977.04 & 852.17 & $1,077.25$ & 879.72 & $1,193.52$ \\
\hline \multirow{3}{*}{ Density 2000} & Std. Dev. & $2,144.63$ & $1,855.81$ & $2,122.21$ & $1,983.41$ & $2,135.14$ \\
\hline & Min & 0.23 & 0.16 & 0.13 & 0.13 & 0.23 \\
\hline & $\operatorname{Max}$ & $11,924.99$ & $11,924.99$ & $11,924.99$ & $11,924.99$ & $11,924.99$ \\
\hline Munic. & Mean & 213.13 & 208.82 & 217.98 & 156.33 & 242.30 \\
\hline \multirow[t]{3}{*}{ Families 2000} & Std. Dev. & 639.98 & 516.14 & 620.29 & 498.60 & 601.53 \\
\hline & Min & 0.53 & 0.48 & 0.27 & 0.26 & 0.44 \\
\hline & Max & $3,173.50$ & $3,173.50$ & $3,173.50$ & $3,173.50$ & $3,173.50$ \\
\hline Munic. Poor & Mean & 0.44 & 0.44 & 0.46 & 0.56 & 0.53 \\
\hline \multirow[t]{3}{*}{ Families 2000} & Std. Dev. & 0.19 & 0.19 & 0.19 & 0.21 & 0.20 \\
\hline & Min & 0.12 & 0.10 & 0.11 & 0.11 & 0.10 \\
\hline & Max & 0.91 & 0.93 & 0.96 & 0.96 & 0.96 \\
\hline Munic. Education & Mean & 4.22 & 4.23 & 4.10 & 3.76 & 3.81 \\
\hline \multirow[t]{3}{*}{ Quality 2007} & Std. Dev. & 0.71 & 0.74 & 0.77 & 0.78 & 0.72 \\
\hline & Min & 1.90 & 1.80 & 1.80 & 0.90 & 1.60 \\
\hline & Max & 6.20 & 6.90 & 7.70 & 7.60 & 7.50 \\
\hline Munic. SR & Mean & 0.81 & 0.76 & 0.74 & 0.73 & 0.71 \\
\hline \multirow[t]{3}{*}{ Coverage 2006} & Std. Dev. & 0.23 & 0.22 & 0.23 & 0.23 & 0.24 \\
\hline & Min & 0.27 & 0.21 & 0.21 & 0.10 & 0.17 \\
\hline & Max & 1.88 & 3.50 & 3.50 & 3.50 & 2.00 \\
\hline
\end{tabular}

Note: This table reports descriptive statistics for each variable of the linked data for the individuals that were born in 1998, whose family was registered in the SR between 2004 and 2006. The mean of the dummy variables (Female, Migrant, Formal Head, Co-Head, and Formal Co-Head) must be interpreted as the proportion of that category in the data. The number of municipality resident families are measured in thousands. Source: Author's calculation with data from IBGE, INEP, MDS, and MTE. 
Heterogeneous Effects of BFP Exposure on Schooling and FLM Participation

Table 21 - Schooling Level Predicted Probability - Females

\begin{tabular}{|c|c|c|c|c|}
\hline $\begin{array}{l}\text { BFP Exp. } \\
\text { Level }\end{array}$ & $\begin{array}{c}\text { Schooling } \\
\text { Level }\end{array}$ & $\begin{array}{c}\text { Prob. within } \\
\operatorname{BFP}(\%)\end{array}$ & $\begin{array}{c}\text { Lower } 95 \% \\
\text { C.I. }\end{array}$ & $\begin{array}{c}\text { Upper } 95 \% \\
\text { C.I. }\end{array}$ \\
\hline 0 & 0 & 0.98 & 0.82 & 1.14 \\
\hline 0 & 1 & 11.80 & 10.48 & 13.12 \\
\hline 0 & 2 & 42.21 & 40.44 & 43.97 \\
\hline 0 & 3 & 40.49 & 37.90 & 43.09 \\
\hline 0 & 4 & 4.46 & 3.90 & 5.01 \\
\hline 0 & 5 & 0.06 & 0.05 & 0.08 \\
\hline 1 & 0 & 0.54 & 0.47 & 0.61 \\
\hline 1 & 1 & 6.94 & 6.42 & 7.46 \\
\hline 1 & 2 & 32.80 & 31.46 & 34.13 \\
\hline 1 & 3 & 51.82 & 50.50 & 53.14 \\
\hline 1 & 4 & 7.78 & 7.21 & 8.36 \\
\hline 1 & 5 & 0.11 & 0.08 & 0.14 \\
\hline 2 & 0 & 0.43 & 0.38 & 0.49 \\
\hline 2 & 1 & 5.61 & 5.23 & 6.00 \\
\hline 2 & 2 & 28.86 & 27.67 & 30.05 \\
\hline 2 & 3 & 55.36 & 54.34 & 56.38 \\
\hline 2 & 4 & 9.59 & 8.97 & 10.21 \\
\hline 2 & 5 & 0.14 & 0.11 & 0.18 \\
\hline 3 & 0 & 0.37 & 0.33 & 0.42 \\
\hline 3 & 1 & 4.89 & 4.57 & 5.21 \\
\hline 3 & 2 & 26.39 & 25.31 & 27.48 \\
\hline 3 & 3 & 57.25 & 56.40 & 58.10 \\
\hline 3 & 4 & 10.93 & 10.28 & 11.59 \\
\hline 3 & 5 & 0.16 & 0.12 & 0.20 \\
\hline 4 & 0 & 0.39 & 0.34 & 0.44 \\
\hline 4 & 1 & 5.05 & 4.64 & 5.46 \\
\hline 4 & 2 & 26.96 & 25.57 & 28.35 \\
\hline 4 & 3 & 56.84 & 55.76 & 57.92 \\
\hline 4 & 4 & 10.61 & 9.81 & 11.41 \\
\hline 4 & 5 & 0.16 & 0.12 & 0.20 \\
\hline
\end{tabular}

Note: The table presents results considering only the females of the sample. It reports the predicted probability of attaining each Schooling level for each BFP Exposure level, conditional on the control variables assuming the values reported on Table 7 . For the covariates considered in logarithm scale in the models (parents' wages and municipality characteristics), I applied the log transformation on the values reported on Table 7. The 95\% Lower and Upper Confidence Intervals estimated through Delta Method are also reported. Source: Author's calculations with the data from MDS, MTE, IBGE, and INEP. 
Table 22 - Schooling Level Predicted Probability - Males

\begin{tabular}{|c|c|c|c|c|}
\hline $\begin{array}{l}\text { BFP Exp. } \\
\text { Level }\end{array}$ & $\begin{array}{c}\text { Schooling } \\
\text { Level }\end{array}$ & $\begin{array}{l}\text { Prob. within } \\
\operatorname{BFP}(\%)\end{array}$ & $\begin{array}{c}\text { Lower } 95 \% \\
\text { C.I. }\end{array}$ & $\begin{array}{c}\text { Upper } 95 \% \\
\text { C.I. }\end{array}$ \\
\hline 0 & 0 & 1.29 & 1.10 & 1.49 \\
\hline 0 & 1 & 16.20 & 14.57 & 17.84 \\
\hline 0 & 2 & 53.49 & 52.60 & 54.38 \\
\hline 0 & 3 & 26.89 & 24.59 & 29.18 \\
\hline 0 & 4 & 2.09 & 1.83 & 2.35 \\
\hline 0 & 5 & 0.03 & 0.02 & 0.04 \\
\hline 1 & 0 & 0.59 & 0.52 & 0.66 \\
\hline 1 & 1 & 8.15 & 7.58 & 8.72 \\
\hline 1 & 2 & 43.76 & 42.48 & 45.04 \\
\hline 1 & 3 & 42.91 & 41.38 & 44.45 \\
\hline 1 & 4 & 4.51 & 4.17 & 4.86 \\
\hline 1 & 5 & 0.07 & 0.05 & 0.09 \\
\hline 2 & 0 & 0.48 & 0.43 & 0.54 \\
\hline 2 & 1 & 6.79 & 6.35 & 7.23 \\
\hline 2 & 2 & 40.23 & 39.00 & 41.45 \\
\hline 2 & 3 & 46.95 & 45.63 & 48.28 \\
\hline 2 & 4 & 5.46 & 5.08 & 5.83 \\
\hline 2 & 5 & 0.09 & 0.06 & 0.12 \\
\hline 3 & 0 & 0.40 & 0.36 & 0.45 \\
\hline 3 & 1 & 5.75 & 5.40 & 6.10 \\
\hline 3 & 2 & 36.92 & 35.74 & 38.09 \\
\hline 3 & 3 & 50.37 & 49.19 & 51.54 \\
\hline 3 & 4 & 6.45 & 6.04 & 6.87 \\
\hline 3 & 5 & 0.11 & 0.08 & 0.14 \\
\hline 4 & 0 & 0.45 & 0.40 & 0.51 \\
\hline 4 & 1 & 6.41 & 5.93 & 6.89 \\
\hline 4 & 2 & 39.10 & 37.65 & 40.55 \\
\hline 4 & 3 & 48.16 & 46.63 & 49.68 \\
\hline 4 & 4 & 5.78 & 5.33 & 6.24 \\
\hline 4 & 5 & 0.10 & 0.07 & 0.12 \\
\hline
\end{tabular}

Note: The table presents results considering only the males of the sample. It reports the predicted probability of attaining each Schooling level for each BFP Exposure level, conditional on the control variables assuming the values reported on Table 7 . For the covariates considered in logarithm scale in the models (parents' wages and municipality characteristics), I applied the log transformation on the values reported on Table 7. The 95\% Lower and Upper Confidence Intervals estimated through Delta Method are also reported. Source: Author's calculations with the data from MDS, MTE, IBGE, and INEP. 
Table 23 - Schooling Level Predicted Probability - Parents Not Formal

\begin{tabular}{|c|c|c|c|c|}
\hline $\begin{array}{l}\text { BFP Exp. } \\
\text { Level }\end{array}$ & $\begin{array}{c}\text { Schooling } \\
\text { Level }\end{array}$ & $\begin{array}{l}\text { Prob. within } \\
\operatorname{BFP}(\%)\end{array}$ & $\begin{array}{c}\text { Lower } 95 \% \\
\text { C.I. }\end{array}$ & $\begin{array}{c}\text { Upper } 95 \% \\
\text { C.I. }\end{array}$ \\
\hline 0 & 0 & 1.47 & 1.23 & 1.71 \\
\hline 0 & 1 & 15.87 & 14.08 & 17.67 \\
\hline 0 & 2 & 51.43 & 50.33 & 52.53 \\
\hline 0 & 3 & 28.79 & 26.14 & 31.43 \\
\hline 0 & 4 & 2.40 & 2.07 & 2.73 \\
\hline 0 & 5 & 0.04 & 0.03 & 0.05 \\
\hline 1 & 0 & 0.61 & 0.54 & 0.69 \\
\hline 1 & 1 & 7.38 & 6.85 & 7.91 \\
\hline 1 & 2 & 39.70 & 38.36 & 41.04 \\
\hline 1 & 3 & 46.61 & 45.13 & 48.10 \\
\hline 1 & 4 & 5.60 & 5.18 & 6.03 \\
\hline 1 & 5 & 0.09 & 0.06 & 0.11 \\
\hline 2 & 0 & 0.54 & 0.48 & 0.60 \\
\hline 2 & 1 & 6.50 & 6.10 & 6.91 \\
\hline 2 & 2 & 37.25 & 36.08 & 38.41 \\
\hline 2 & 3 & 49.24 & 48.04 & 50.45 \\
\hline 2 & 4 & 6.37 & 5.97 & 6.78 \\
\hline 2 & 5 & 0.10 & 0.07 & 0.12 \\
\hline 3 & 0 & 0.45 & 0.40 & 0.50 \\
\hline 3 & 1 & 5.56 & 5.25 & 5.87 \\
\hline 3 & 2 & 34.16 & 33.12 & 35.20 \\
\hline 3 & 3 & 52.25 & 51.26 & 53.25 \\
\hline 3 & 4 & 7.46 & 7.03 & 7.88 \\
\hline 3 & 5 & 0.12 & 0.09 & 0.15 \\
\hline 4 & 0 & 0.48 & 0.42 & 0.54 \\
\hline 4 & 1 & 5.86 & 5.45 & 6.28 \\
\hline 4 & 2 & 35.20 & 33.86 & 36.54 \\
\hline 4 & 3 & 51.27 & 49.97 & 52.58 \\
\hline 4 & 4 & 7.07 & 6.57 & 7.58 \\
\hline 4 & 5 & 0.11 & 0.08 & 0.14 \\
\hline
\end{tabular}

Note: The table presents results considering the sample with only individuals whose parents were never formally employed. It reports the predicted probability of attaining each Schooling level for each BFP Exposure level, conditional on the control variables assuming the values reported on Table 7 . For the covariates considered in logarithm scale in the models (municipality characteristics), I applied the log transformation on the values reported on Table 7 . The 95\% Lower and Upper Confidence Intervals estimated through Delta Method are also reported. Source: Author's calculations with the data from MDS, MTE, IBGE, and INEP. 
Table 24 - Schooling Level Predicted Probability - Formal Parents

\begin{tabular}{|c|c|c|c|c|}
\hline $\begin{array}{l}\text { BFP Exp. } \\
\text { Level }\end{array}$ & $\begin{array}{c}\text { Schooling } \\
\text { Level }\end{array}$ & $\begin{array}{l}\text { Prob. within } \\
\operatorname{BFP}(\%)\end{array}$ & $\begin{array}{l}\text { Lower } 95 \% \\
\text { C.I. }\end{array}$ & $\begin{array}{c}\text { Upper } 95 \% \\
\text { C.I. }\end{array}$ \\
\hline 0 & 0 & 0.78 & 0.51 & 1.06 \\
\hline 0 & 1 & 13.76 & 11.12 & 16.39 \\
\hline 0 & 2 & 45.47 & 42.73 & 48.20 \\
\hline 0 & 3 & 36.33 & 31.78 & 40.88 \\
\hline 0 & 4 & 3.61 & 2.80 & 4.41 \\
\hline 0 & 5 & 0.05 & 0.02 & 0.09 \\
\hline 1 & 0 & 0.46 & 0.32 & 0.59 \\
\hline 1 & 1 & 8.53 & 7.37 & 9.69 \\
\hline 1 & 2 & 37.57 & 35.10 & 40.03 \\
\hline 1 & 3 & 47.30 & 44.52 & 50.08 \\
\hline 1 & 4 & 6.05 & 5.18 & 6.93 \\
\hline 1 & 5 & 0.09 & 0.04 & 0.15 \\
\hline 2 & 0 & 0.40 & 0.28 & 0.51 \\
\hline 2 & 1 & 7.50 & 6.55 & 8.45 \\
\hline 2 & 2 & 35.17 & 32.86 & 37.49 \\
\hline 2 & 3 & 49.91 & 47.48 & 52.35 \\
\hline 2 & 4 & 6.90 & 6.00 & 7.81 \\
\hline 2 & 5 & 0.11 & 0.05 & 0.17 \\
\hline 3 & 0 & 0.32 & 0.23 & 0.42 \\
\hline 3 & 1 & 6.20 & 5.48 & 6.93 \\
\hline 3 & 2 & 31.60 & 29.47 & 33.72 \\
\hline 3 & 3 & 53.40 & 51.36 & 55.43 \\
\hline 3 & 4 & 8.34 & 7.36 & 9.33 \\
\hline 3 & 5 & 0.13 & 0.06 & 0.21 \\
\hline 4 & 0 & 0.39 & 0.27 & 0.52 \\
\hline 4 & 1 & 7.47 & 6.27 & 8.67 \\
\hline 4 & 2 & 35.09 & 32.10 & 38.08 \\
\hline 4 & 3 & 50.00 & 46.89 & 53.11 \\
\hline 4 & 4 & 6.93 & 5.78 & 8.09 \\
\hline 4 & 5 & 0.11 & 0.04 & 0.17 \\
\hline
\end{tabular}

Note: The table presents results considering the sample with only individuals whose parents were at least once formally employed. It reports the predicted probability of attaining each Schooling level for each BFP Exposure level, conditional on the control variables assuming the values reported on Table 7 . For the covariates considered in logarithm scale in the models (parents' wages and municipality characteristics), I applied the log transformation on the values reported on Table 7. The 95\% Lower and Upper Confidence Intervals estimated through Delta Method are also reported. Source: Author's calculations with the data from MDS, MTE, IBGE, and INEP. 
Table 25 - Schooling Level Predicted Probability - Small Cities

\begin{tabular}{|c|c|c|c|c|}
\hline $\begin{array}{l}\text { BFP Exp. } \\
\text { Level }\end{array}$ & $\begin{array}{l}\text { Schooling } \\
\text { Level }\end{array}$ & $\begin{array}{l}\text { Prob. within } \\
\operatorname{BFP}(\%)\end{array}$ & $\begin{array}{c}\text { Lower } 95 \% \\
\text { C.I. }\end{array}$ & $\begin{array}{l}\text { Upper } 95 \% \\
\text { C.I. }\end{array}$ \\
\hline 0 & 0 & 1.50 & 1.31 & 1.69 \\
\hline 0 & 1 & 18.99 & 17.47 & 20.52 \\
\hline 0 & 2 & 51.81 & 51.26 & 52.36 \\
\hline 0 & 3 & 25.56 & 23.73 & 27.39 \\
\hline 0 & 4 & 2.11 & 1.89 & 2.33 \\
\hline 0 & 5 & 0.03 & 0.02 & 0.04 \\
\hline 1 & 0 & 0.69 & 0.62 & 0.76 \\
\hline 1 & 1 & 9.79 & 9.21 & 10.37 \\
\hline 1 & 2 & 43.76 & 42.73 & 44.78 \\
\hline 1 & 3 & 41.17 & 39.86 & 42.49 \\
\hline 1 & 4 & 4.53 & 4.24 & 4.82 \\
\hline 1 & 5 & 0.06 & 0.05 & 0.08 \\
\hline 2 & 0 & 0.55 & 0.49 & 0.60 \\
\hline 2 & 1 & 7.97 & 7.54 & 8.41 \\
\hline 2 & 2 & 40.02 & 39.00 & 41.03 \\
\hline 2 & 3 & 45.76 & 44.62 & 46.89 \\
\hline 2 & 4 & 5.63 & 5.30 & 5.95 \\
\hline 2 & 5 & 0.08 & 0.06 & 0.10 \\
\hline 3 & 0 & 0.47 & 0.43 & 0.52 \\
\hline 3 & 1 & 6.97 & 6.60 & 7.33 \\
\hline 3 & 2 & 37.43 & 36.44 & 38.43 \\
\hline 3 & 3 & 48.58 & 47.54 & 49.61 \\
\hline 3 & 4 & 6.46 & 6.11 & 6.81 \\
\hline 3 & 5 & 0.09 & 0.08 & 0.11 \\
\hline 4 & 0 & 0.50 & 0.44 & 0.55 \\
\hline 4 & 1 & 7.28 & 6.82 & 7.75 \\
\hline 4 & 2 & 38.29 & 37.07 & 39.51 \\
\hline 4 & 3 & 47.67 & 46.36 & 48.97 \\
\hline 4 & 4 & 6.17 & 5.76 & 6.58 \\
\hline 4 & 5 & 0.09 & 0.07 & 0.11 \\
\hline
\end{tabular}

Note: The table presents results considering the sample with only individuals from municipalities that had less than 50,000 resident families in 2000. It reports the predicted probability of attaining each Schooling level for each BFP Exposure level, conditional on the control variables assuming the values reported on Table 7 . For the covariates considered in logarithm scale in the models (parents' wages and municipality characteristics), I applied the log transformation on the values reported on Table 7. The 95\% Lower and Upper Confidence Intervals estimated through Delta Method are also reported. Source: Author's calculations with the data from MDS, MTE, IBGE, and INEP. 
Table 26 - Schooling Level Predicted Probability - Big Cities

\begin{tabular}{|c|c|c|c|c|}
\hline $\begin{array}{l}\text { BFP Exp. } \\
\text { Level }\end{array}$ & $\begin{array}{l}\text { Schooling } \\
\text { Level }\end{array}$ & $\begin{array}{l}\text { Prob. within } \\
\operatorname{BFP}(\%)\end{array}$ & $\begin{array}{c}\text { Lower } 95 \% \\
\text { C.I. }\end{array}$ & $\begin{array}{c}\text { Upper } 95 \% \\
\text { C.I. }\end{array}$ \\
\hline 0 & 0 & 1.21 & 0.92 & 1.50 \\
\hline 0 & 1 & 11.58 & 9.58 & 13.58 \\
\hline 0 & 2 & 47.04 & 44.40 & 49.69 \\
\hline 0 & 3 & 37.09 & 32.90 & 41.28 \\
\hline 0 & 4 & 3.02 & 2.41 & 3.62 \\
\hline 0 & 5 & 0.05 & 0.03 & 0.08 \\
\hline 1 & 0 & 0.91 & 0.74 & 1.08 \\
\hline 1 & 1 & 9.00 & 7.93 & 10.06 \\
\hline 1 & 2 & 42.85 & 40.70 & 45.00 \\
\hline 1 & 3 & 43.19 & 40.45 & 45.92 \\
\hline 1 & 4 & 3.98 & 3.44 & 4.53 \\
\hline 1 & 5 & 0.07 & 0.04 & 0.11 \\
\hline 2 & 0 & 0.75 & 0.62 & 0.89 \\
\hline 2 & 1 & 7.57 & 6.69 & 8.46 \\
\hline 2 & 2 & 39.65 & 37.45 & 41.86 \\
\hline 2 & 3 & 47.15 & 44.61 & 49.70 \\
\hline 2 & 4 & 4.78 & 4.16 & 5.40 \\
\hline 2 & 5 & 0.09 & 0.05 & 0.13 \\
\hline 3 & 0 & 0.59 & 0.48 & 0.69 \\
\hline 3 & 1 & 5.99 & 5.31 & 6.67 \\
\hline 3 & 2 & 35.11 & 32.96 & 37.26 \\
\hline 3 & 3 & 52.12 & 49.91 & 54.33 \\
\hline 3 & 4 & 6.08 & 5.35 & 6.81 \\
\hline 3 & 5 & 0.11 & 0.06 & 0.17 \\
\hline 4 & 0 & 0.72 & 0.58 & 0.86 \\
\hline 4 & 1 & 7.24 & 6.33 & 8.16 \\
\hline 4 & 2 & 38.81 & 36.40 & 41.21 \\
\hline 4 & 3 & 48.13 & 45.41 & 50.86 \\
\hline 4 & 4 & 5.01 & 4.32 & 5.69 \\
\hline 4 & 5 & 0.09 & 0.05 & 0.14 \\
\hline
\end{tabular}

Note: The table presents results considering the sample with only individuals from municipalities that had more than 200,000 resident families in 2000. It reports the predicted probability of attaining each Schooling level for each BFP Exposure level, conditional on the control variables assuming the values reported on Table 7 . For the covariates considered in logarithm scale in the models (parents' wages and municipality characteristics), I applied the log transformation on the values reported on Table 7. The 95\% Lower and Upper Confidence Intervals estimated through Delta Method are also reported. Source: Author's calculations with the data from MDS, MTE, IBGE, and INEP. 
Table 27 - FLM Participation Predicted Probability - Heterogeneous Effects

\begin{tabular}{|c|c|c|c|c|}
\hline Sample & $\begin{array}{c}\text { BFP Exposure } \\
\text { Level }\end{array}$ & $\begin{array}{l}\text { Prob. within } \\
\text { BFP }(\%)\end{array}$ & $\begin{array}{c}\text { Lower } 95 \% \\
\text { C.I. }\end{array}$ & $\begin{array}{c}\text { Upper } 95 \% \\
\text { C.I. }\end{array}$ \\
\hline \multirow{5}{*}{ Complete } & 0 & 25.00 & 23.71 & 26.29 \\
\hline & 1 & 26.49 & 25.45 & 27.53 \\
\hline & 2 & 27.72 & 26.73 & 28.70 \\
\hline & 3 & 28.43 & 27.47 & 29.39 \\
\hline & 4 & 28.58 & 27.21 & 29.95 \\
\hline \multirow{5}{*}{ Females } & 0 & 20.30 & 18.68 & 21.92 \\
\hline & 1 & 20.82 & 19.53 & 22.12 \\
\hline & 2 & 21.62 & 20.40 & 22.84 \\
\hline & 3 & 22.24 & 21.05 & 23.43 \\
\hline & 4 & 22.34 & 20.60 & 24.08 \\
\hline \multirow{5}{*}{ Males } & 0 & 23.58 & 21.91 & 25.25 \\
\hline & 1 & 25.87 & 24.52 & 27.22 \\
\hline & 2 & 27.36 & 26.07 & 28.65 \\
\hline & 3 & 28.02 & 26.78 & 29.27 \\
\hline & 4 & 28.22 & 26.43 & 30.00 \\
\hline \multirow{5}{*}{$\begin{array}{c}\text { Parents Never } \\
\text { Formally Employed }\end{array}$} & 0 & 14.69 & 13.28 & 16.10 \\
\hline & 1 & 15.65 & 14.55 & 16.74 \\
\hline & 2 & 16.69 & 15.67 & 17.70 \\
\hline & 3 & 17.07 & 16.13 & 18.00 \\
\hline & 4 & 17.83 & 16.41 & 19.25 \\
\hline \multirow{5}{*}{$\begin{array}{c}\text { Parents } \\
\text { Formally Employed }\end{array}$} & 0 & 27.54 & 24.32 & 30.77 \\
\hline & 1 & 27.20 & 24.69 & 29.70 \\
\hline & 2 & 29.06 & 26.66 & 31.45 \\
\hline & 3 & 28.55 & 26.27 & 30.83 \\
\hline & 4 & 27.90 & 24.12 & 31.69 \\
\hline \multirow{5}{*}{$\begin{array}{l}\text { Small } \\
\text { Cities }\end{array}$} & 0 & 27.81 & 26.21 & 29.40 \\
\hline & 1 & 30.04 & 28.71 & 31.37 \\
\hline & 2 & 30.99 & 29.73 & 32.24 \\
\hline & 3 & 32.17 & 30.93 & 33.41 \\
\hline & 4 & 32.81 & 31.05 & 34.58 \\
\hline \multirow{5}{*}{$\begin{array}{l}\text { Big } \\
\text { Cities }\end{array}$} & 0 & 22.26 & 19.39 & 25.14 \\
\hline & 1 & 21.18 & 19.11 & 23.25 \\
\hline & 2 & 22.89 & 20.80 & 24.98 \\
\hline & 3 & 22.26 & 20.25 & 24.26 \\
\hline & 4 & 21.73 & 19.22 & 24.24 \\
\hline
\end{tabular}

Note: The table presents the predicted probability of participating in the Formal Labor Market over the BFP Exposure level conditional on the control variables assuming the values reported on Table 7 . For the covariates considered in logarithm scale in the models (parents' wages and municipality characteristics), I applied the log transformation on the values reported on table. For each indicated sample the model is estimated again, and then the prediction is performed with the respective set of coefficients. The 95\% Lower and Upper Confidence Intervals are estimated through the Delta Method. Source: Author's calculations with the data from MDS, MTE, IBGE, and INEP. 